Linköping Studies in Science and Technology

Dissertation No. 2152

\title{
Life Cycle Costing
}

SUPPORTING COMPANIES TOWARDS A CIRCULAR ECONOMY

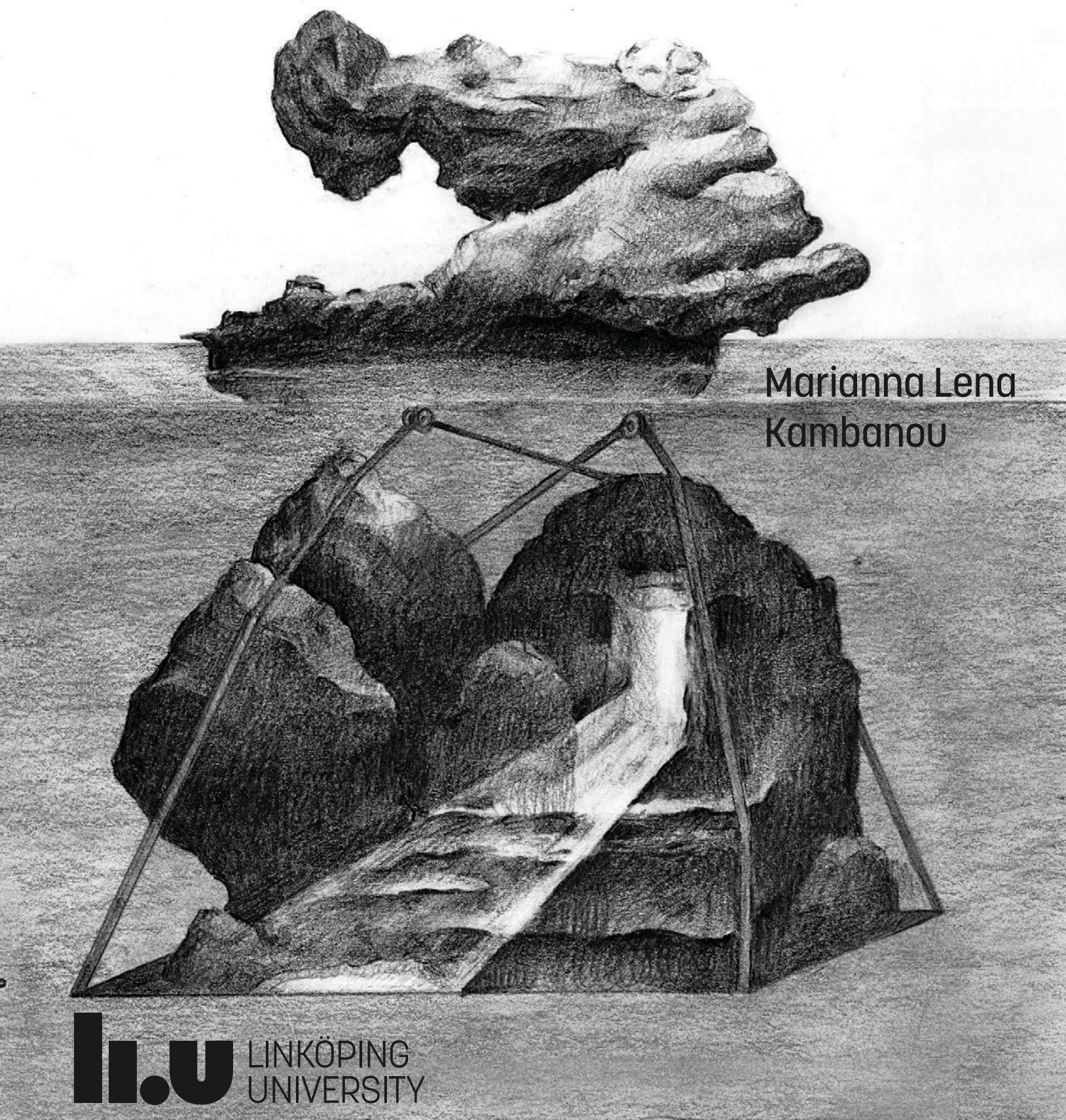



Linköping Studies in Science and Technology. Dissertations No. 2152.

\section{Life Cycle Costing}

Supporting companies towards a circular economy

Marianna Lena Kambanou

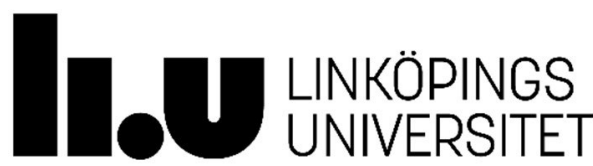


The cover, exclusive of the words and University logo, was made by the artist Angela Liosi.

Articles have been reprinted with permission of their respective copyright owners.

(C) Marianna Lena Kambanou, 2021, (unless otherwise noted)

"Life Cycle Costing - Supporting companies towards a circular economy"

The cover essay is published under the:

Attribution - Non-Commercial - No Derivatives 4.0 International

(CC BY-NC-ND 4.0)

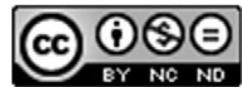

(c) EY-NC This work is licensed under a Creative Commons AttributionNonCommercial 4.0 International License.

https://creativecommons.org/licenses/by-nc/4.0/

Linköping Studies in Science and Technology

Dissertation No. 2152

ISSN: 0345-7524

ISBN: 978-91-7929-622-3

Printed in Sweden by LiU Tryck, 2021

Distributed by:

Linköping University

Department of Management and Engineering

SE-581 83 Linköping, Sweden 


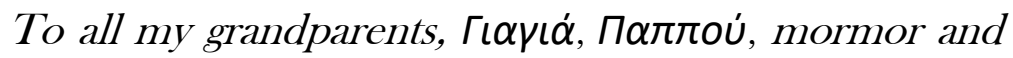
Joe, who all exceeded expectations in terms of education and told the best stories. 



\section{ABSTRACT}

Increased consumption has resulted in the depletion of non-renewable resources and an explosion in waste. A circular economy proposes to sustain economic growth but decouple it from resource consumption by keeping products and materials in the economy. Established companies have an important role to play because they can implement maintenance, repair, remanufacture, recycling and other circular measures for their offerings, thus facilitating their retention in the economy. When applying circular measures for existing products, their costs and revenues change across the lifecycle, sometimes significantly, thereby calling into question the financial viability of the more circular offering. Life cycle costing (LCC), an existing method for calculating the costs of a product or service across the lifecycle, can help companies take stock of these changes. LCC can also be used in conjunction with life cycle assessment (LCA), a method for assessing the environmental impacts of a product or service across the lifecycle.

The aim of this research, therefore, is to explore how LCC can be used to support established companies in selecting and implementing circular measures for their offerings. The research is conducted through case studies involving four companies, and data is collected through literature reviews, document and cost data sets analysis, interviews and focus groups. The findings are based on six publications.

The identified uses for LCC go beyond the ones that lead to its selection and are commonly discussed in the literature. Firstly, the difference in material cost between the alternatives being compared can be calculated from the LCC results. This can be used as an indicator of the alternatives' comparative circularity performance. LCC can also provide input to designers on which parts of the offering to prioritize applying a circular measure, as well as cost exchangeability. One of the most significant uses is that LCC can help create awareness, build up an understanding and provide a forum for discussing the challenges associated with implementing circular measures, such as the changing financial incentive structure, uncertainty, improvement areas for information systems and mismatches in stakeholders' financial incentives. This use is critical in helping individuals and companies overcome mind-set and cultural barriers to a circular economy. Finally, LCC can spread the lifecycle idea and evidence the need for life cycle management (LCM), but may lead to a narrower understanding of the term life cycle and put the focus exclusively on resources rather than environmental impacts.

Another finding is that companies, despite the many uses, may not use LCC because it contests elements of their extant practices, such as collective knowledge, mind-set of individuals and symbolic and material objects. It is the outcome of this contestation that will play a significant role in determining if LCC is used.

The research also identifies methodological considerations, either generally applicable or specifically relating to the identified uses. For example, data displays and disseminating results are key when using LCC to understand challenges. An important methodological consideration when using LCC to compare alternatives from a 
financial perspective is whether the alternatives are of equal functionality and value for the customer. If not, the customer's willingness to pay will change, and revenue will need to be calculated. Apart from companies, this is an important consideration for researchers using LCC to build up a body of knowledge on the economic benefits of more circular offerings compared to business-as-usual. Another issue concerns boundary setting and what to include in the life cycle, which should be decided in a multidisciplinary team. The same is recommended for the majority of methodological choices.

Concerning future LCC method development, the variety of uses should be acknowledged and explicitly addressed. The reasons for not adopting LCC should also be addressed, and method development should consider how to support establishing LCC as a practice over time so that it improves and becomes routinized. This also means that companies should approach LCC in the same way. In line with this, more effort needs to be put into understanding why LCC is not adopted and developing the methodology to overcome the reasons. Finally, this research demonstrates that LCC can have more uses than at first apparent. Maybe this can inspire researchers to re-examine methods and tools and, in the spirit of a circular economy, try "to do more with less". 


\section{SAMMANFATTNING}

Ökad konsumtion har lett till en uttömning av icke-förnybara resurser och en explosion av avfall. Som motpol till detta föreslår cirkulär ekonomi en bibehållen ekonomisk tillväxt som är frånkopplad resursförbrukning genom att hålla kvar produkter och material i ekonomin. Etablerade företag har här en viktig roll att spela eftersom de kan implementera cirkulära åtgärder för deras existerande produkter, så som underhåll, lagning, återtillverkning eller återvinning, och därigenom möjliggöra att de finns kvar i ekonomin. När cirkulära åtgärder används för existerande produkter så ändras deras kostnads- och inkomstflöden över livscykeln, vilket kan leda företag till att ifrågasätta den cirkulära åtgärdens finansiella prestanda och genomförbarhet. Livscykelkostnadsanalys (LCC, eng. life cycle costing), en existerande metod som används för att beräkna en produkts eller tjänsts kostnad under dess livscykel, kan hjälpa företag att beräkna och beskriva dessa eventuella ändringar i kostnads- och inkomstflöden. LCC kan även användas i samband med livscykelanalys (LCA, eng. life cycle assessment), en metod för att bedöma en produkts eller tjänsts påverkan på miljön under dess livscykel.

Mot denna bakgrund syftar denna forskning till att undersöka hur LCC kan användas för att stötta etablerade företag i deras arbeta med att välja och implementera cirkulära åtgärder för deras existerande produkter och tjänster. Forskningen bygger på fallstudier med fyra företag där data har samlats in genom litteraturstudier, dokumentanalys, analys av kostnadsdata, intervjuer och fokusgruppssessioner. Resultaten är baserade på sex stycken publikationer.

Fler användningsområden för LCC identifieras utöver de användningsområden som ofta leder till att LCC väljs och som återfinns i litteraturen. För det första så kan skillnaden i materialkostnader mellan studerade alternativ beräknas i en LCC, vilket sedan kan användas som en indikator för att jämföra alternativens cirkularitet. LCC kan även ge värdefull information till designers om vilken del av en produkt eller tjänst som bör prioriteras utifrån ett cirkularitetsperspektiv, samt för den cirkulära åtgärdens kostnadsutbytbarhet. Ett av de mest betydelsefulla användningsområdena är att LCC kan skapa medvetenhet kring, och bygga upp en förståelse för cirkulära åtgärder, samt skapa ett forum för att diskutera utmaningar kopplade till deras implementering. Dessa utmaningar kan till exempel vara förändringar $i$ den finansiella incitamentsstrukturen, osäkerheter, förbättringsområden av informationssystem och brister i intressenternas ekonomiska incitament. Användningen av LCC som verktyg för diskussion är avgörande för att individer och företag ska kunna ändra attityder kring, och övervinna företagskulturella barriärer till, en cirkulär ekonomi. Till sist kan LCC även sprida livscykeltänk och visa på behovet av livscykelperspektiv i beslutsprocesser och förvaltning, men kan därigenom också leda till en smalare förståelse av begreppet livscykel där fokus endast sätts på resursfrågor istället för på miljöpåverkan.

Utöver detta visar resultatet även på att företag är ovilliga att använda LCC på grund av att den utmanar redan existerande företagselement så som kollektiv kunskap, individers attityder, samt objekts symboliska och materiella betydelse. Resultatet av 
detta utmanande spelar en betydelsefull roll för om LCC kommer att användas eller inte.

Forskningsresultatet pekar även ut beaktanden som är viktiga för LCC metodik. Exempelvis att hur data och resultat visas och dissemineras är en nyckelfaktor för att förstå utmaningar kopplade till implementering av cirkulära åtgärder. Dessutom är det viktigt att undersöka om olika alternativ är funktionellt likvärdiga och av samma värde för kunden. Om värdet förändras behöver även inkomstflöden beräknas och tillföras analysen. I resultatet framkommer även ett viktigt beaktande för forskare som använder LCC, nämligen att det krävs att en kunskapsbas byggs upp kring de ekonomiska vinster som cirkulära produkter och tjänster innebär i jämförelse med konventionella produkter och tjänster. Ett annat identifierat problem gäller hur systemgränserna bör sättas och vilka delar av livscykeln som bör innefattas i LCC studier, detta bör göras av en multidisciplinär grupp. Denna rekommendation gäller även för en majoritet av metodikbesluten i en LCC.

Framtida forskning om LCC metodik bör beakta och explicit betänka den breda variationen av användningsområden som identifierats i denna forskning. Utöver detta behövs studier som fokuserar på bristen på användning av LCC och som skapar en förståelse för varför denna brist finns. Dessutom behövs metodutveckling för att stötta införandet av rutiner kring användandet av LCC. Avslutningsvis visar denna forskning på att LCC kan ha fler användningsområden och nyttor för företag än vad som är uppenbart, och kanske kan detta inspirera forskare att ompröva existerande metoder och verktyg för att i cirkulär ekonomi-anda försöka "göra mer med mindre”. 


\section{¿YNOUH}

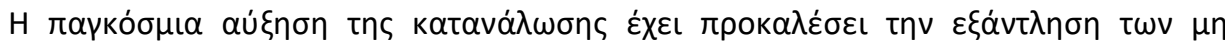

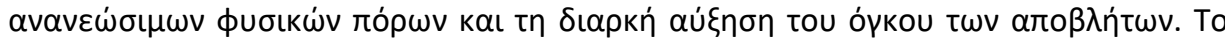

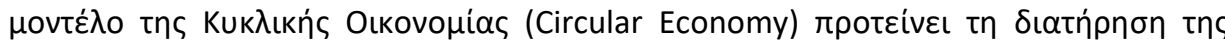

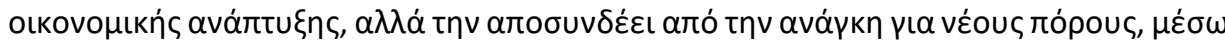

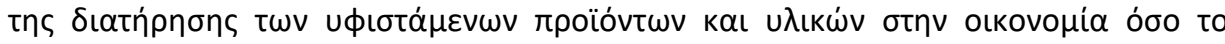

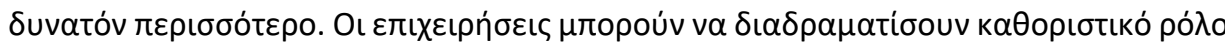

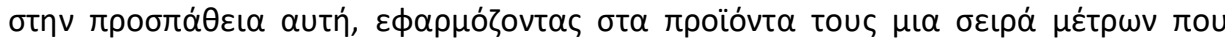

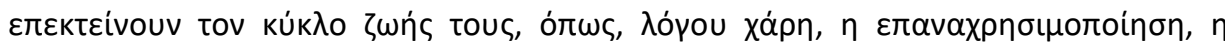

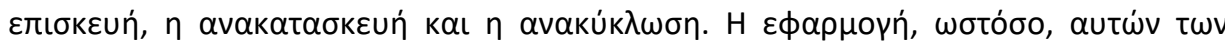

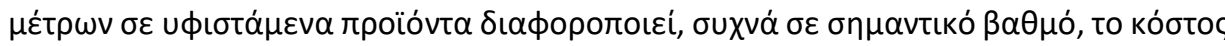

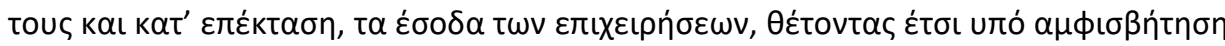

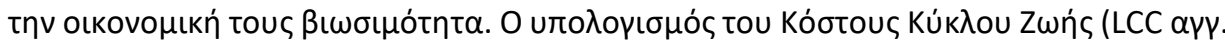

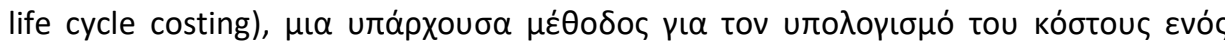

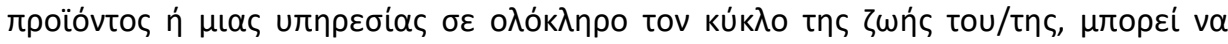

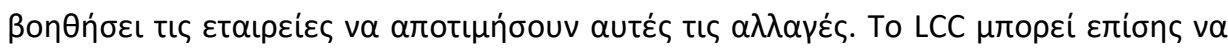

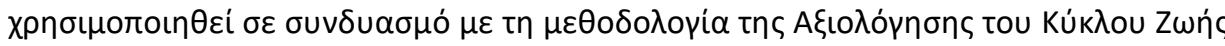

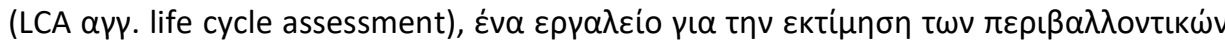

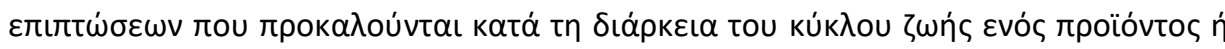

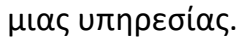

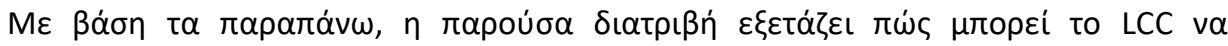

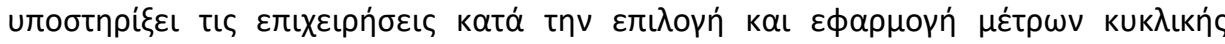

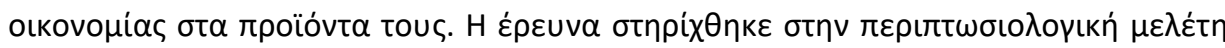

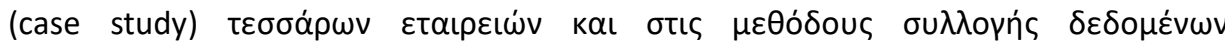

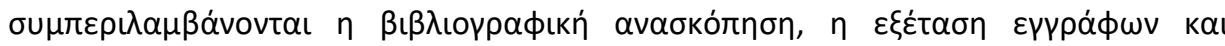

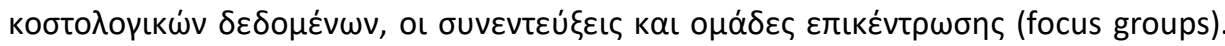

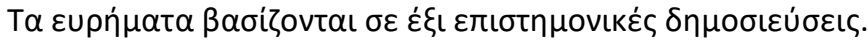

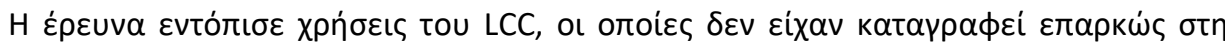

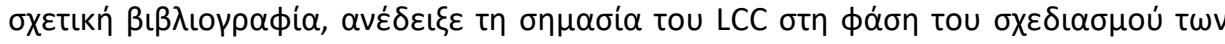

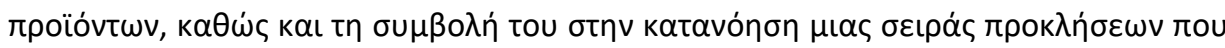

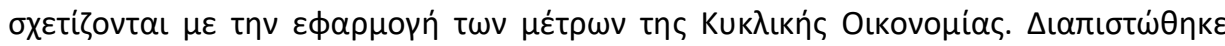

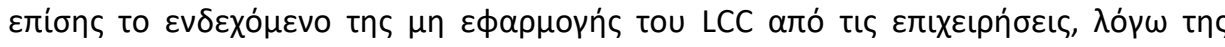

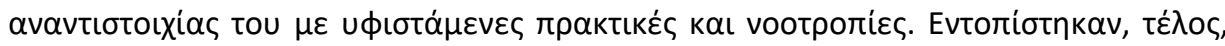

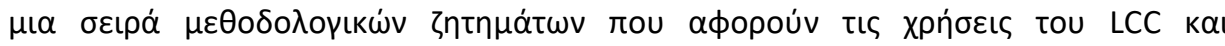

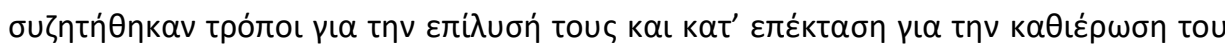

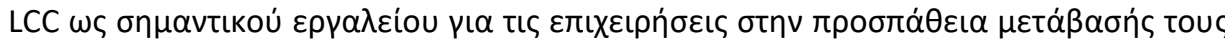

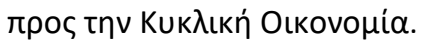




\section{ACKNOWLEDGEMENTS}

I am faced with the same challenge as a practitioner about to conduct LCC: the objective is clear, but where to draw the boundaries of acknowledgement are not. The abilities and knowledge that I needed to do this were seeded long before the 1 st of June, 2015, the date this journey officially started, and during these years, many people have supported me.

The people who should receive the first recognition are my parents for investing heavily in those early years and cultivating analytical thought, reading and writing skills. Although the educational system does a lot, the importance of parents in supplementing it is, or at least was when I was growing up, paramount. Moreover, even today, my mother will often proofread and help me at the drop of a hat.

I will have to skip the intervening years and all the educators who played their part, making just a brief stop to acknowledge the IIIEE and especially Oksana Mont for sending me the job posting for this PhD position and Carl Dalhammer for advice on policy over a coffee.

Moving to my PHD studies, a debt of gratitude goes out to the funders, including Company X, Vinnova and Mistra REES, as well as the people who partook in research from the companies. Four people stand out especially: Carl-Olov Naeslund for being a constant support and seeing the lifecycle, Boris Ahnberg for seeing the future (and telling me about it), Anders Lyckstedt for hunting with me in the haystack of costs and Eva-Karin Mattsson for clearly explaining so many things, which only a practitioner knows.

One quick stop should also be made at Chalmers to thank Pernilla Gluch for the constructive feedback at my $90 \%$ seminar and Anne-Marie Tillman, with whom I have enjoyed some great academic discussions. Both of you helped me grow.

Moving on to Linköping University and my colleagues at the division of Industriell Miljöteknik: what a wonderful collection of people and diverse personalities!! I have shared moments of fun and in-depth discussion with all of you, and I want to thank each of you and aim to do so when I distribute the kappa. The place of honour goes to my supervisors. Mattias Lindahl your energy, positivity and willingness to find solutions to any challenge known to man is inspirational, and your stubbornness is only matched by my own. Thank you for taking this journey with me! Tomohiko Sakao, thank you for approaching things with structure and method and teaching me so much about research. I have enjoyed our academic discussions, chats and constructive confrontations, but most of all, our teamwork. Some further shoutouts from Envtech have to be made to:

... the people who read and commented on the thesis: Stefan Anderberg, Sergio Brambila, Roozbeh Feiz, Wisdom Kanda, Joakim Krook and Sara Gustafsson

... Sofia Dahlgren, Carina Sundberg, Linda Hagman and Maria Eriksson for being a lovely group of people to have lunch with and always making space to squeeze one more person around the table 
... all the PhDs, and especially JL and Tharaka, for our little chats and, although not a PhD, Alyssa Blumenthal for the fun we had during the first year

... Annelie Carlson, for making it evidently clear that you were there if needed

... Murat Mirata, for being a good neighbour in many ways

... Sara Gustafsson, for being a great female role model and course leader

... Axel Lindfors, for our joint little projects, i.e., PhD education days, FUR, writing workshops and so many discussions, "stycke is a great word, right?"

... Olof Hjelm, for leadership and trying to keep us all on some kind of common trajectory, may the odds be ever in your favour

... Wisdom Kanda, for being truly wise and a person to turn to for advice

... Venus Krantz, my last officemate as a PhD, for the fun you brought both in and out of the office and for improving my Swedish vocabulary

... Sergio Brambila, for being my friend and helping me put things into perspective; it is not always easy to find you, but always definitely worth the effort

... Johannes Matschewsky, we have analysed everything under the stars, and had we bothered to write it down, the world's problems would now be solved; you have been the best officemate ever... and since then we just moved our office online.

The final stop includes the people who support me from near and far. Thank you:

...Axel, Klara, Anna-Karin and Rikard, for helping out in small and big ways here in Linköping

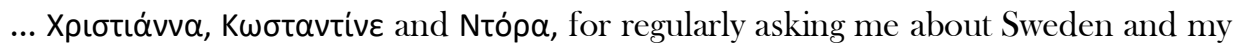
studies and building a bridge throughout these years

... Corey, for tea, friendship, tea, humour, tea, advice and tea with hot water

... Dashenka: who would have known when we first met all those years ago in a queue in China that our friendship would still be going strong?

... Aunty Wendy, for being my pen pal since learning to write or maybe even before, I guess you have some drawings...

... Laurence and Daniel, for doing exactly what brothers should do, teasing and making jokes...without... ever... stopping...

... my family in Sweden: James, Suzanne, Amelia, Oskar and Elysia for our holidays, barbeques, walks, meals, birthdays, ice-skating and so much more

... did I mention Mummy and Daddy?

... my little Thalia and Zoe, the fun and joy you bring is the best reason to stop writing this book and go to the park, just a few more words and I'm finished

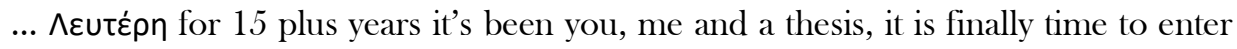
the next stage. The extent of your contribution is beyond measure. 


\section{Prologue}

Due to the mix of traditions and approaches to the final PhD deliverable, I feel compelled to inform the reader in advance of what to expect and how I approach this thesis.

Firstly, this is a "compilation thesis". This means that it is based on a series of papers, usually five. When selecting which publications to include, my aim has not been to display all the work done during my PhD studies. Instead, I choose articles that could build upon each other to provide a perspective complementary to the individual articles. This means that no new results are provided, but the synthesis uses elements of the articles and reflects on them further in relation to each other and other academic literature. For example, from Paper IV, the guideline is not reiterated, but the methodological discussion of LCC's strengths and limitations is heavily used. I make this point to pre-empt any expectations on the reader's part that the thesis builds directly on all the findings of the articles.

Why did I choose this route? There are a number of reasons: firstly, the synthesis of the findings has the potential to deliver new insights. Secondly, spending five months, which is the time it takes to write a thesis, to simply reiterate already published material without trying to derive something more is not a constructive or productive activity from anyone's standpoint. Thirdly, as I am working within a particular field, I feel compelled to gather and organize my methodological findings as requested by my supervisors at the beginning of my studies. Finally, having co-authored a number of articles, I try, in the thesis, to focus on the findings where I made my primary contribution.

A separate point I would like to address concerns the initial framing. This research is funded through projects that I was not involved in setting up, and therefore, many contextual choices are not my own. I reason these choices in a similar way to which the people responsible explained their reasoning to me. For example, the choice of LCC was made for me in the projects. This is not uncommon for funded PhD studies that require a project to have been accepted before a candidate is employed. However, from then on, the direction the research took was very much up to me, so there are many choices, which are my own especially, concerning theoretical framing and building up narratives from the data.

One final point is that although the backbone of this thesis derives from the use of LCC in the companies, the LCC results from Company $\mathrm{X}$ are not published due to confidentiality reasons. What I have published refers to the process of LCC rather than the results and findings thereof. This is lamentable with respect to knowledge development, but I have done my best to include as many insights gained as possible, not only in the publications but also in the thesis. Thus, the reader is forewarned about the previously mentioned omissions.

With these introductory points covered, I trust the reader is now better disposed towards the content of this thesis. 


\section{List OF APPENDEd PUblications}

Paper I Kambanou, M.L., \& Lindahl, M. (2016). A Literature Review of Life Cycle Costing in the Product-Service System Context. Procedia CIRP, 47, 186-191.

Paper II Matschewsky, J., Kambanou, M.L, \& Sakao, T. (2018). Designing and providing integrated product-service systems - challenges, opportunities and solutions resulting from prescriptive approaches in two industrial companies. International Journal of Production Research, 56, 2150-2168.

Paper III Kaddoura, M., Kambanou, M.L., Tillman, A.M., \& Sakao, T. (2019). Is Prolonging the Lifetime of Passive Durable Products a LowHanging Fruit of a Circular Economy? A Multiple Case Study. Sustainability, 11, 4819.

Paper IV Kambanou, M.L., \& Sakao, T. (2020). Using life cycle costing (LCC) to select circular measures: A discussion and practical approach. Resources, Conservation and Recycling, 155, 104650.

Paper V Kambanou, M.L. (2020). Life Cycle Costing: Understanding How It Is Practised and Its Relationship to Life Cycle Management - A Case Study. Sustainability, 12, 3252.

Paper VI Kambanou, M.L. (2020). Additional uses for life cycle costing in life cycle management. Procedia CIRP, 90, 718-723. 


\section{Other PUBlications}

\section{Journal publications}

Alamerew, Y.A., Kambanou, M.L., Sakao, T., Brissaud, D. (2020). A Multi-Criteria Evaluation Method of Product-Level Circularity Strategies. Sustainability, 12, 5129.

Ingemarsdotter, E., Kambanou, M.L., Jamsin, E., Sakao, T., \& Balkenende, R. (2021). Challenges and solutions in condition-based maintenance implementation A multiple case study. Journal of Cleaner Production, 296, 126420

\section{Conference abstracts and posters}

Kambanou, M.L. (May, 2019). Selling integrated products \& services: The role \& financial perspective of the sales organization. Poster presented at The Spring Servitization Conference, Linköping, Sweden

Kambanou, M.L., Mirata, M. (October, 2017). Economic quantification of industrial symbiosis from the perspective of the organization. Presented at $18^{h}$ European Roundtable for Sustainable Consumption and Production, Skiathos, GR

Kambanou, M.L. (April, 2016). The challenge of finding data to support the transition to sustainability: the case of PSS. Presented at Reimagining Planetary Boundaries Humanities, Arts \& Sciences - Early-Career Sustainability Symposium, Copenhagen, DK

\section{Reports}

Kambanou, M.L. (2020). En guide för mer cirkulära produkter och ţänster baserat på ekonomiska kriterier. Produktion 2030. LIU-IEI-R, R--20/00336-SE. 


\section{TABLE OF CONTENTS}

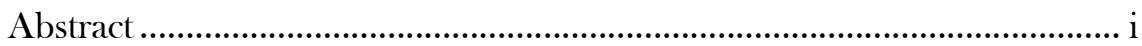

Sammanfattning ...................................................................................

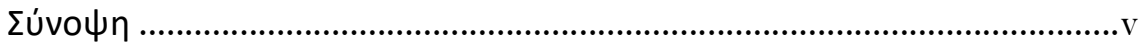

Acknowledgements....................................................................................

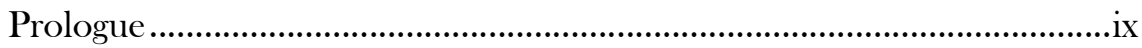

List of Appended Publications.........................................................................

Other Publications...................................................................................ii

Figures and Tables.....................................................................................

Glossary and Abbreviations....................................................................

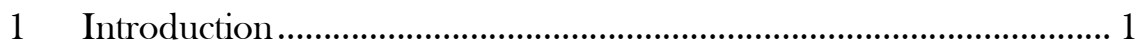

1.1 The circular economy context..................................................... 1

1.2 Research motivation ....................................................................... 2

1.3 Research aim and questions ........................................................... 4

1.4 Scope and delimitations............................................................. 5

1.5 Research process and papers ........................................................ 6

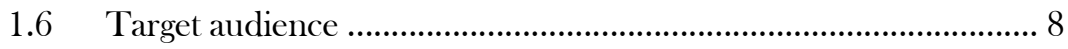

1.7 Thesis outline............................................................................. 8

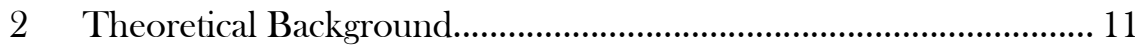

2.1 Circular measures .................................................................... 11

2.2 Product-service systems ............................................................. 12

2.3 Life cycle management ................................................................ 13

2.4 Life cycle costing..................................................................... 14

2.5 Environmental considerations....................................................... 19

2.6 Connecting the concepts .............................................................. 20

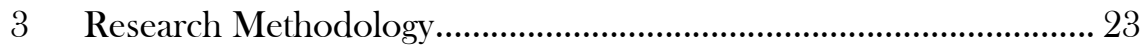

3.1 Theoretical underpinnings ......................................................... 23

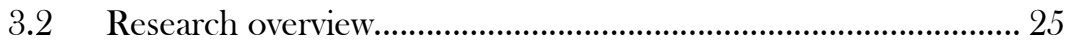

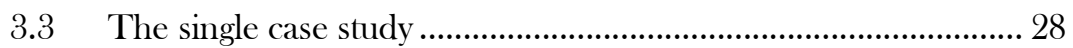

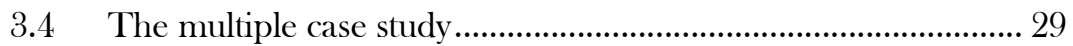

3.5 The complementarity of the two case studies................................... 31

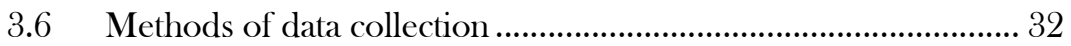

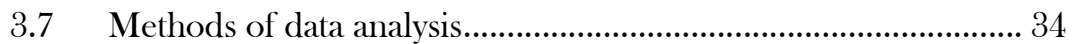

$3.8 \quad$ Validity and reliability ……………………………........................ 35

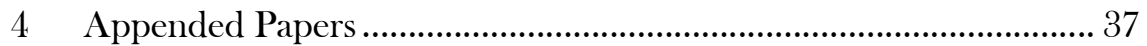

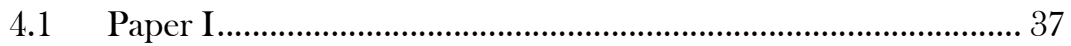

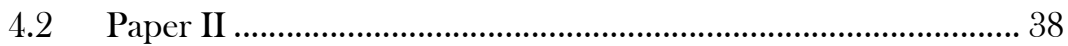




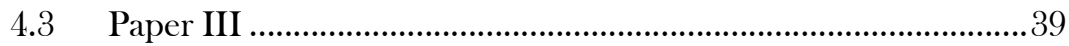

4.4 Paper IV ......................................................................... 4.

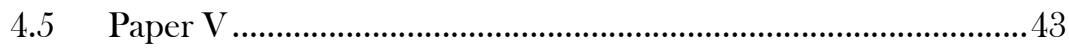

4.6 Paper VI.............................................................................. 45

5 Discussion: Identified Uses of LCC.................................................... 47

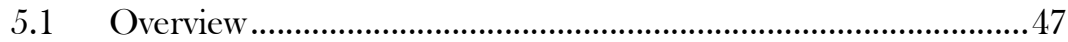

5.2 Comparing alternatives................................................................ 48

5.3 Providing input to design ............................................................51

5.4 Understanding and overcoming challenges...................................54

5.5 Propelling an emergent life cycle management...............................56

6 Discussion: Reasons for Not Using LCC..............................................59

7 Discussion: Methodological Considerations of LCC ………………..... 61

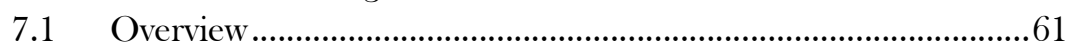

7.2 Alternatives and functional unit ....................................................64

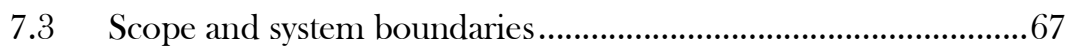

7.4 LCC model development and calculation.........................................68

7.5 Interpretation and review ............................................................

7.6 Dissemination.............................................................................

7.7 Implications on future methodological LCC development...........72

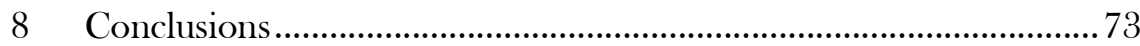

8.1 Implications of the conclusions .....................................................

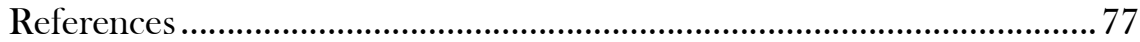




\section{FigURES AND TABLES}

\section{List of tables}

Table 1 Appended publications and author's contribution .........................................6

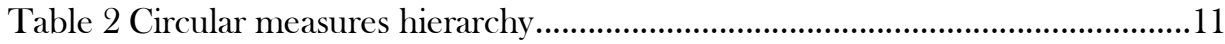

Table 3 LCC cost estimation methods ................................................................... 17

Table 4 Connecting case studies, papers, research questions, data collection

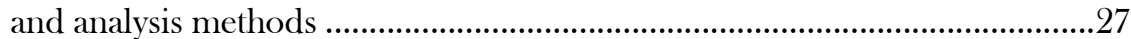

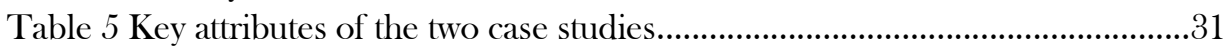

Table 6 Reduction of LCA and LCC of circular offerings compared to business-as-usual ..................................................................................40

Table 7 Strengths and limitations of using LCC to select and implement

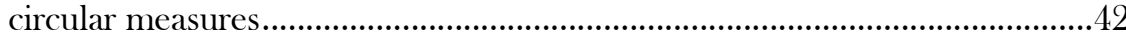

Table 8 Implications of conceptualizing LCC as a practice on future methodological development......................................................................44

Table 9 The LCC uses identified in this research ..............................................47

Table 10 Methodological considerations for using LCC to support companies in selecting and implementing circular measures..........................................62

Table 11 Functional equivalence and customer value of the compared alternatives at the multiple case study ........................................................65

Table 12 List of activities included in each lifecycle stage for LCC and LCA...........69

\section{List of figures}

Figure 1 Connections between research questions and papers .................................7

Figure 2 Visualization of the thesis background...................................................20

Figure 3 Results for LCC of beach flag and event tent before and after implementing the circular measure (Company A) ..........................................51

Figure 4 Results for LCC of recycling bin and lockers before and after implementing the circular measure (Company B) .......................................52

Figure 5 Results for LCC of the inlet before and after redesign (Company C) .........53 


\section{Glossary AND AbBREVIATIONS}

active product

a product that consumes energy or materials during its operational phase

business-as-usual (BAU) the way a company conducts business before a circular measure is implemented

circular measures .any kind of measure applied to a product with the aim of reducing the material resources needed across the lifecycle

circular offering .an offering for which a circular measure has been implemented

environmental LCC (eLCC) a specific type of LCC including all internal costs covered by all actors connected to a specific functional unit and externalities that are expected to be internalized (Lichtenvort et al., 2008)

Life Cycle Assessment (LCA).......... method for calculating the environmental impacts over the whole lifecycle of an offering

Life Cycle Costing (LCC) a method for calculating the costs over the whole lifecycle of an offering or the part of its lifecycle that a specific actor is responsible for

Life Cycle Management (LCM) ......the business activity of managing a product or service across its lifecycle with the aim of minimizing its environmental impacts

method a way of working, in a predefined and systematic way, which facilitates the user's work towards a desired outcome

methodological consideration. a part or aspect of a methodology that needs to be thought about in a certain light in a specific context

metric a defined measurement method and measurement scale

offering. products or services offered by a company

passive product a product that does not consume energy or materials during its operational phase

practice "a routinized type of behaviour which consists of several elements, interconnected to one other: forms of bodily activities, forms of mental activities, 'things' and their use, a background 
knowledge in the form of understanding, knowhow, states of emotion and motivational knowledge" (Reckwitz, 2002, p. 249)

Product-Service System (PSS) ......... an integrated offering of tangible products and intangible services

SME small to medium-size enterprise

tool ................................................ a means that, in a predefined and systematic way, facilitates the user's work towards a desired outcome

use(noun) a purpose for which something is used 
xviii 


\section{INTRODUCTION}

\subsection{The circular economy context}

The social and economic advancement, brought on by the industrial revolution(s) and enjoyed by an ever-increasing percentage of the global population', came at a cost to the environment (WCED, 1987). More than two billion tonnes of waste are generated globally per annum (Kaza, Yao, Bhada-Tata, \& Van Woerden, 2018), natural resource depletion occurs at a faster rate than nature's ability to restore and emissions from human-related activities are stressing the earth's climate. The accumulative effects are leading to the deterioration of ecosystems and posing a threat to the livelihood of many (IRP, 2017).

In acknowledgement of these and other pressing environmental and social equity challenges, a global mandate in the form of 17 Sustainable Development Goals has been adopted by the United Nations (UN General Assembly, 2015). Intrinsically in these goals, there is an understanding that strategies towards a more sustainable future should also support economic growth, with the United Nations advocating for "triple win" or "win-win-win" solutions that aim to reconcile the conflict between environmental preservation, economic prosperity and social welfare (ibid.). In this context, economic growth is portrayed as the underlying cause of many environmental impacts while also being the prerequisite of both economic prosperity and social welfare. Therefore, the normative aim is to decouple environmental impacts from economic growth (UNEP, 2011).

A circular economy is a proposed economic system that could facilitate decoupling economic growth from resource use and, consequently, environmental impacts (Korhonen, Honkasalo, \& Seppälä, 2018). The circular economy concept has emerged over the last decades and is currently receiving a lot of attention from governments, business communities and academics (Blomsma \& Brennan, 2017). Its aim is to robustly preserve the value of products, their components and materials in the economy by extending or intensifying their operational life (Ellen MacArthur Foundation, 2013). It relies on the premise that closing and prolonging technical and biological cycles through, for example, maintenance, reuse, remanufacturing, recycling or cascading will reduce non-renewable resource consumption, make resource use more efficient and minimize waste generation while not impeding growth and the opening up of new business opportunities (Kirchherr, Reike, \& Hekkert, 2017). Thus, a space is created for building up environmental and social capital. Although closing biological and technical cycles are equally important, they differ greatly in how they are implemented. Therefore, one of the two has to be chosen. In this thesis, the focus is on technical cycles.

Although this approach has shown promising results, there are concerns about whether the combined visions of decoupling resource consumption, reducing

${ }^{1}$ The effects of the corona-pandemic on these trends are currently unknown. 
connected environmental impacts and sustained economic growth can be realized at the speed and rate needed to avoid the destruction of life-sustaining ecosystems (Parrique et al., 2019). Critics also point out that ample room is left in a circular economy to ignore environmental impacts that do not derive directly from resource consumption and waste generation as well as challenges pertaining to social equity and distribution of wealth (Korhonen et al., 2018; Murray, Skene, \& Haynes, 2017). There is also concern about potential rebound effects (Zink \& Geyer, 2017). It is clear that, although a promising solution, the UN Sustainable Development Goals cannot be met solely by implementing a circular economy (Geissdoerfer, Savaget, Bocken, \& Hultink, 2017). Other approaches addressing, for example, specific social challenges, consumption reduction, growth stagnation and redistribution of resources within and between populations have been put forward. Due to concerns for climate change, the implementation of all solutions and approaches, including circular economy, is currently surrounded by a sense of urgency and a need to scale up (UN General Assembly, 2015).

A number of countries have introduced policies to foster a circular economy (McDowall et al., 2017), and policies and governmental support are crucial to implementing such an economy. But a government's capacity to lead the change has limits due to complex and globalised production and consumption systems and neoliberalism (Howieson, Burnes, \& Summers, 2019). Therefore, if change is to come, it needs to be driven both top-down from governments and bottom-up from other actors (Ghisellini, Cialani, \& Ulgiati, 2016; Lieder \& Rashid, 2016). Companies are a focal part of the bottom-up drive (Lewandowski, 2016). Existing companies with established products and process will need to adapt their strategy and operations, and essentially many of their activities so that they preserve the value of products and resources in the economy for as long as possible (Bocken, de Pauw, Bakker, \& van der Grinten, 2016).

\subsection{Research motivation}

Although companies are envisioned as agents of change, the bottom-up-drive has yet to really gain momentum. An ever-growing body of literature, for example, (Mont, Plepys, Whalen, \& Nußholz, 2017)and Rizos et al. (2016), stands as testimony to the multifaceted challenges both incumbents and new entrants, face in implementing a change that supports a circular economy, here named a circular measure. These barriers are cultural, regulatory, market and technological (Kirchherr et al., 2018). The market barriers can also be considered financial, resulting from, for example, the low cost of non-renewable materials, high upfront investment costs, high costs of labour and return logistics, as well as liquidity issues (Mont et al., 2017). A key reason that the circular economy narrative, which promises to deliver both economic and environmental prosperity, is falling short is that companies cannot turn it into financially viable business cases.

Companies, apart from some rare exceptions, will not drive responsible business unless it is profitable (Laasch \& Conaway, 2016) or provides them with a competitive advantage, for example, control of branding on the second hand market (Allwood, 
Ashby, Gutowski, \& Worrell, 2011). Therefore, getting to grips with the financial implications of implementing circular measures as well as calculating and estimating costs and their uncertainty is of paramount importance to the companies, regardless of whether they approach a circular measure driven by business incentives or a sense of responsibility towards the environment and society.

Life cycle costing (LCC) is a method that is identified to be useful in supporting companies' in structuring a detailed economic account of their offerings ${ }^{2}$. LCC is a method for calculating costs of an offering over the lifecycle and providing a way to structure costs and revenue as a negative cost (Hoogmartens, Van Passel, Van Acker, \& Dubois, 2014; Hunkeler, Lichtenvort, \& Rebitzer, 2008). There are a number of reasons for opting for LCC. Firstly, LCC focuses on the offering so it can evaluate the financial impact of a circular measure on the offering and provide a basis to compare it with business-as-usual (Kerdlap \& Cornago, 2021). Secondly, it has a lifecycle perspective, thus capturing many of the financial implications, which occur beyond the traditional costing boundaries for a company (Bradley, Jawahir, Badurdeen, \& Rouch, 2018). This is important because many circular measures, such as that of offering products-as-a-service, that is, product-service systems (PSS), result in companies taking over costs from their customers. Finally, LCC can be used as a complement to life cycle assessment (LCA), which is a method for assessing the environmental impacts of an offering across the lifecycle (Baumann \& Tillman, 2004; Finnveden \& Moberg, 2005) and has been named as the method of choice for assessing the environmental performance of circular products or measures (Sassanelli, Rosa, Rocca, \& Terzi, 2019; Walker, Coleman, Hodgson, Collins, \& Brimacombe, 2018). They both have the offering as the unit of analysis, and when used together, the LCC informs decisionmakers of the financial perspective and the LCA of the environmental perspective (Hoogmartens et al., 2014).

In this research, the ambition is to support companies, and more specifically, established companies, in selecting and implementing circular measures for their existing offerings using LCC. Three research gaps are identified related to this.

The first gap concerns the potential uses of LCC. Two key uses are already mentioned: the provision of detailed financial information across the lifecycle, often with the objective of comparing alternatives, and its use as a complement to LCA, these being the reasons for selecting LCC. However, there are other challenges or barriers associated with selecting and implementing circular measures, and companies need tools that will help them ideate, design and improve as well as evaluate (Bocken, Strupeit, Whalen, \& Nußholz, 2019). There is also the potential to connect LCC with the management of offering across the lifecycle, namely, life cycle management (LCM)(Bey, 2018). This opens an area of enquiry on other uses associated with LCC that go beyond simply delivering a detailed financial account to decision-makers.

The second gap concerns the reasons that companies do not use LCC. There is no shortage of LCC methods. Both national and international standards exist for specific industries, such as ISO 15663 for the petroleum, petrochemical and natural gas

${ }^{2}$ Offering means products and/or services brought to the market by a company 
industries and IEC 60300-3-3 and ISO 15686 for buildings and construction. A number of other LCC methods developed by researchers exist, which also tend to be case or industry-specific (Gluch, Gustafsson, Baumann, \& Lindahl, 2018; Korpi \& AlaRisku, 2008). Despite this abundance of methods and a fairly long history, LCC is not widely adopted by industry, and when it is, the prescriptive methods are only loosely followed (Hochschorner \& Noring, 2011). Few researchers have explored the reasons for this (D'Incognito, Costantino, \& Migliaccio, 2015).

The third gap involves the methodological considerations. In some cases, calculating LCC will just require changing some digits in the existing economic assessments. Still, the implementation of some circular measures, for example, remanufacturing, and offering PSS, presents companies with the challenge of what to cost, to what extent and how to perform the computations (Bradley et al., 2018; Settanni, Newnes, Thenent, Parry, \& Goh, 2014). The reasons for this are multiple and not all obvious. However, some indications exist in the literature, such as when implementing circular measures, companies often take on activities that they do not traditionally perform, or they execute them in a very different way (Ghisellini et al., 2016; Lindahl, Sundin, \& Sakao, 2014; Tukker, 2015). There is a lot of uncertainty because by extending the products' lifetime, the time horizon expands and thereby, unpredictability (Erkoyuncu et al., 2019). Moreover, offerings can be used by multiple customers or remanufactured, which makes it unclear where to set the boundaries (Bradley et al., 2018). Additionally, as mentioned earlier, using LCC and LCA together is not straightforward and, therefore, a methodological issue (Bierer, Götze, Meynerts, \& Sygulla, 2015; Settanni, 2008). Finally, LCC may have other uses in this context, not extensively discussed in the literature, which require specific methodological considerations, or there could be reasons that LCC is not used that can be addressed by methodology.

\subsection{Research aim and questions}

The aim is to explore how LCC can support companies, and more specifically, existing companies, in selecting and implementing circular measures for their offerings. The aim is operationalized through three research questions:

RQ1: How can LCC be used to support companies in selecting and implementing circular measures for their offerings?

Some uses of LCC are well documented in the literature such as providing detailed financial information across the lifecycle, often with the objective of comparing alternatives or being used as a complement to LCA. The focus here is to identify other ways that LCC can support companies with selecting and implementing circular measures, for example, what challenges connected to implementing circular measures can LCC help identify and overcome. The argumentation for doing this is not only to fill "two needs with one deed" but also to document the more subtle effects LCC might have. 
RQ2: Why do companies not use LCC?

The second question, to complement the first research question, tries to identify why companies do not use LCC. Despite LCC being a method with a long history, its adoption is still not widespread, and if it is used, it is often not at the level of sophistication described in LCC methodologies (Gluch et al., 2018). Therefore, the second question seeks to determine reasons that LCC is not used by companies or not used as prescribed.

RQ3: What are the core methodological considerations of LCC when used to support companies in the selection and implementation of circular measures for their offerings?

Finally, the third research question concerns the methodological considerations that will make the uses identified in Research Question 1 possible and that help overcome the reasons for not using LCC identified in the second research question. Further to this, the implications of these findings on future methodological LCC development is reflected upon.

\subsection{Scope and delimitations}

In this section, the scope and boundaries of this thesis are detailed. This thesis places itself in the context of a circular economy. However, the circular economy builds upon concepts that have been around for a long time, such as material or resource efficiency (Allwood et al., 2011), performance economy (Stahel, 2010) and industrial ecology (Frosch, 1992). This means that the circular economy acts as an umbrella concept for approaches addressed in other research streams, such as product-service systems (PSS), eco-design, lifecycle thinking, remanufacturing, recycling (Blomsma \& Brennan, 2017). This research liberally makes use of the knowledge built up in these streams of research and the terminology therein because to do otherwise would be to try to "reinvent the wheel".

This thesis does not focus on the circular economy as a general concept but on its operationalisation in companies and, more specifically, on supporting existing companies in successfully selecting and implementing circular measures for their existing products. Of the three levels of analysis that have been put forward for a circular economy, namely, micro (company or consumer or product level), meso (industrial cluster level) and macro (country, region and city level)(Ghisellini et al., 2016), the level used in this thesis is the micro level of the single company and its products. However, since the lifecycle is crucial to both a circular economy and LCC, the perspective of the customer and other actors in the supply chain in relation to the company and the company's offering is also included.

This thesis focuses on established companies; new entrants on the market whose offerings are developed from scratch with the aim of closing loops, for example, independent remanufactures, are not included in the scope. Again, this does not mean 
that the findings are not relevant to them but that that they have not been tested for them.

The primary data has mainly been collected in Sweden. However, two of the four collaborating companies operate internationally; therefore, the findings can also be relevant in international settings.

A key issue for many researchers dealing with sustainability assessments is "accounting for externalities" (Hunkeler et al., 2008). This is important if the aim is to place a monetary value on environmental or societal impacts (Neugebauer, Forin, \& Finkbeiner, 2016). However, this is not proposed in this thesis. Here, LCA is used to assess the environmental impacts and LCC the economic impacts. This thesis focuses on real cash flows of costs and revenue.

\subsection{Research process and papers}

This thesis is the outcome of PhD studies at Linköping University in sustainable systems and specializing in environmental management and engineering; its format is classified as a "compilation thesis", a collection of articles. Six publications form the backbone of this thesis. These are listed in Table 1, in chronological order of publication, where the thesis author's contributions are also described.

Table 1 Appended publications and author's contribution

\begin{tabular}{|c|c|c|}
\hline \multicolumn{2}{|c|}{ Publications } & \multirow{2}{*}{$\begin{array}{l}\text { Contribution by Kambanou } \\
\text { The idea, data collection, coding, theme } \\
\text { generation, writing and incorporation of } \\
\text { reviewer comments was my responsibility. } \\
\text { Lindahl provided comments and wrote } \\
\text { Section 3.4.3. }\end{array}$} \\
\hline $\begin{array}{l}\text { Paper } \\
\text { I }\end{array}$ & $\begin{array}{l}\text { Kambanou, M.L., \& Lindahl, M. } \\
\text { (2016). A Literature Review of } \\
\text { Life Cycle Costing in the } \\
\text { Product-Service System } \\
\text { Context. Procedia CIRP }\end{array}$ & \\
\hline $\begin{array}{l}\text { Paper } \\
\text { II }\end{array}$ & $\begin{array}{l}\text { Matschewsky, J., Kambanou, } \\
\text { M.L., \& Sakao, T. (2018). } \\
\text { Designing and providing } \\
\text { integrated product-service } \\
\text { systems - challenges, } \\
\text { opportunities and solutions } \\
\text { resulting from prescriptive } \\
\text { approaches in two industrial } \\
\text { companies. International } \\
\text { Journal of Production Research }\end{array}$ & $\begin{array}{l}\text { As second author, my main contribution } \\
\text { was in providing data for one of the case } \\
\text { studies and jointly creating themes for } \\
\text { challenges and solutions with } \\
\text { Matschewsky. I co-wrote Sections } 4.1 .1 \text {, } \\
4.13,4.1 .4 \text { and } 4.2 .2 \text { and provided feedback } \\
\text { regularly on the rest of the document and } \\
\text { edited. Matschewsky had the idea, wrote } \\
\text { the original and the revised manuscript. } \\
\text { Sakao provided regular feedback and } \\
\text { guidance. }\end{array}$ \\
\hline $\begin{array}{l}\text { Paper } \\
\text { III }\end{array}$ & $\begin{array}{l}\text { Kaddoura, M., Kambanou, M.L., } \\
\text { Tillman, A.M., \& Sakao, T. } \\
\text { (2019). Is Prolonging the } \\
\text { Lifetime of Passive Durable } \\
\text { Products a Low-Hanging Fruit } \\
\text { of a Circular Economy? A } \\
\text { Multiple Case Study. } \\
\text { Sustainability }\end{array}$ & $\begin{array}{l}\text { As second author, I was responsible for } \\
\text { supervising LCC data collection, } \\
\text { conducting the LCC analysis and placing } \\
\text { the work in the context of circular economy } \\
\text { and PSS. I wrote the majority of Sections } 1 \\
\text { and } 2 \text { as well as all of } 5.2 \text {. and } 5.3 \text { and } \\
\text { proofread. Parallel analysis of LCA and LCC } \\
\text { was done together with Kaddoura, who }\end{array}$ \\
\hline
\end{tabular}




\begin{tabular}{|c|c|c|}
\hline \multicolumn{2}{|c|}{ Publications } & \multirow{2}{*}{$\begin{array}{l}\text { Contribution by Kambanou } \\
\text { was responsible for the LCA, all sensitivity } \\
\text { analyses, visualization and remaining } \\
\text { writing. The idea originated from Tillman } \\
\text { and Sakao, who provided regular feedback } \\
\text { and guidance. }\end{array}$} \\
\hline & & \\
\hline $\begin{array}{l}\text { Paper } \\
\text { IV }\end{array}$ & $\begin{array}{l}\text { Kambanou, M.L., \& Sakao, T. } \\
\text { (2020). Using life cycle costing } \\
\text { (LCC) to select circular } \\
\text { measures: A discussion and } \\
\text { practical approach. Resources, } \\
\text { Conservation and Recycling }\end{array}$ & $\begin{array}{l}\text { I wrote the original draft and the } \\
\text { subsequent reviewed versions, collected } \\
\text { the data, developed the methodology and } \\
\text { conceptualized the discussion. The idea of } \\
\text { creating a guideline was Sakao's, who } \\
\text { contributed to its development and } \\
\text { provided regular feedback. }\end{array}$ \\
\hline $\begin{array}{l}\text { Paper } \\
\text { V }\end{array}$ & $\begin{array}{l}\text { Kambanou, M.L. (2020). Life } \\
\text { Cycle Costing: Understanding } \\
\text { How It Is Practised and Its } \\
\text { Relationship to Life Cycle } \\
\text { Management-A Case Study. } \\
\text { Sustainability }\end{array}$ & $\begin{array}{l}\text { As sole author, I was responsible for } \\
\text { conceptualization, data collection, } \\
\text { development of analysis framework, } \\
\text { analysis and writing all versions. }\end{array}$ \\
\hline $\begin{array}{l}\text { Paper } \\
\text { VI }\end{array}$ & $\begin{array}{l}\text { Kambanou, M.L. (2020). } \\
\text { Additional uses for life cycle } \\
\text { costing in life cycle } \\
\text { management. Procedia CIRP }\end{array}$ & $\begin{array}{l}\text { As sole author, I was responsible for } \\
\text { conceptualization, data collection, theme } \\
\text { generation and writing all versions. }\end{array}$ \\
\hline
\end{tabular}

Figure 1 represents how each of the papers contributes to answering the research questions.

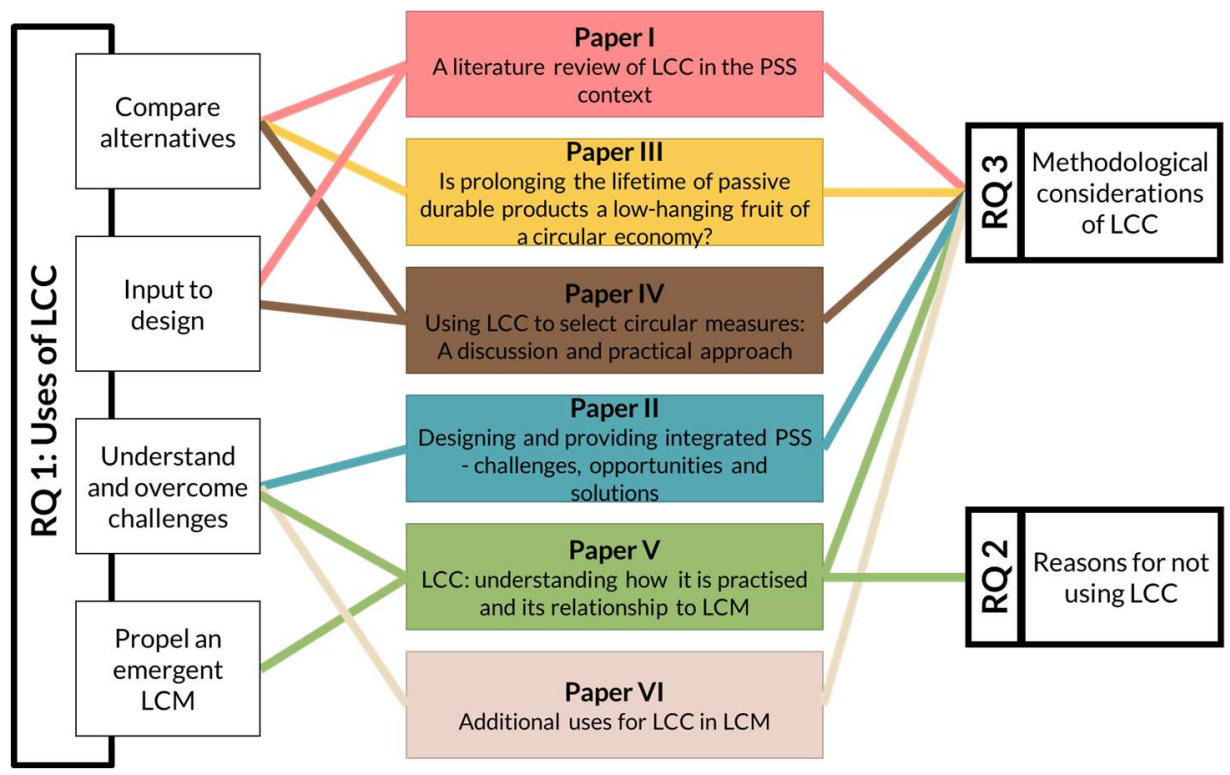

Figure 1 Connections between research questions and papers (some titles have been shortened and words abbreviated) 
The papers are re-ordered to simplify the visualisation. Papers IV, V and VI place the focus on LCC and how it is used, whereas in Papers II and III the focus is on the outcome of studies using LCC. Paper I is a literature review that focuses on how other authors have used LCC in the context of product-service systems (PSS). PSS is one of the concepts used in this thesis because it is a way to operationalize the circular measures that this thesis focuses on. It is further discussed, in the following chapter, "Theoretical background". Another key concept in the papers, which is also elaborated on in the "Theoretical background" and only briefly touched upon in the introduction, is that of life cycle management (LCM).

\subsection{Target audience}

The target readers of this thesis can be divided into five main groups. The term "readers" is used in this section to include both practitioners and researchers.

The first group is readers at companies thinking of implementing circular measures, PSS, LCM, and so on. They can learn how LCC can support them in order to decide whether to use the method or not.

The second consists of readers wanting to use LCC, regardless of field or discipline or context or whether or not it is accompanied by LCA. This work can inform them of the various uses and the methodological considerations that need to be taken into account.

The third group is readers wanting to develop LCC methods. LCC methods are infrequently developed, and an examination of the methodological considerations described may enhance their uptake, minimize their tailoring and make them more effective.

The fourth group is comprised of readers wanting to evaluate the financial implications of changes at the micro level to products or services.

Finally, readers developing methods in general make up the fifth group. A part of this research uses practice theory to investigate why LCC is tailored and how it can be used to propel LCM. Viewing methods as affecting people and practices other than the explicitly intended ones can be a useful approach for other researchers to use in order to understand how the methods they suggest perform other activities.

\subsection{Thesis outline}

This thesis comprises eight chapters and six appended articles. Chapter 1 introduces the circular economy context, where companies are envisioned as agents of change but are, in fact, struggling and in need of support. LCC is argued to be a method that has the potential to support them, and the research questions are set up to explore that potential. Next, the contributions of the appended papers in answering these research questions are presented. In Chapter 2, the four key concepts of the thesis: circular measures, PSS, LCM and LCC, are discussed and how they interrelate elaborated on. Various other concepts, which are essential to understanding the 
findings, are also presented, such as LCA and practice theory. Chapter 3 then describes the research methodology. In Chapter 4, a brief summary of the main findings from each of the appended papers is provided. Chapters 5, 6 and 7 respectively answer the first, second and third research questions. Chapter 5 describes the four identified uses of LCC as well as sub-uses. Next, Chapter 6 discusses why LCC is not adopted. In Chapter 7, the methodological considerations deriving from using LCC are presented, as well as the implications of such considerations on the future development of LCC methods. Finally, Chapter 8 comprises a concluding summary of the research findings. 


\section{THEORETICAL BACKGROUND}

Apart from LCC, there are three key concepts that this thesis builds upon: circular measures, product-service systems (PSS) and life cycle management (LCM). These, and how they relate to each other, are presented at the start, followed by LCC and environmental considerations. The chapter closes by reflecting on the concepts in relation to the research aim. The concepts are discussed from the micro level of analysis, that is, offerings and companies.

\subsection{Circular measures}

One of the common ways to explain the circular economy in the company context is through the strategies or "how to" measures it comprises (Table 2).

Table 2 Circular measures hierarchy

Based on Potting, Hekkert, Worrell, and Hanemaaijer (2017)

\begin{tabular}{lll}
\hline Measures & Definitions \\
\hline \multirow{2}{*}{$\begin{array}{l}\text { Smarter } \\
\text { product } \\
\text { consumption } \\
\text { and } \\
\text { production }\end{array}$} & Refuse & $\begin{array}{l}\text { Make product redundant by abandoning its } \\
\text { function or by offering the same function with a } \\
\text { radically different product }\end{array}$ \\
\cline { 2 - 3 } & Rethink & Make product use more intensive e.g., sharing \\
\cline { 2 - 3 } & Reduce & $\begin{array}{l}\text { Increase efficiency in product manufacture or use } \\
\text { e.g., use fewer virgin raw materials }\end{array}$ \\
\cline { 2 - 3 } & Reuse & $\begin{array}{l}\text { Use the discarded product with its original } \\
\text { function, by another consumer, without any } \\
\text { intervention to the product }\end{array}$ \\
\cline { 2 - 3 } $\begin{array}{l}\text { Extend } \\
\text { lifespan of } \\
\text { products and } \\
\text { their parts }\end{array}$ & Repair & $\begin{array}{l}\text { Use the product with its original function, by the } \\
\text { same or another consumer, after its repair and } \\
\text { maintenance }\end{array}$ \\
\cline { 2 - 3 } & Refurbish & $\begin{array}{l}\text { Use the product with its original function after its } \\
\text { restoration }\end{array}$ \\
\cline { 2 - 3 } $\begin{array}{ll}\text { lifespan of } \\
\text { materials }\end{array}$ & Remanufacture & $\begin{array}{l}\text { Use parts of the product in a new product with the } \\
\text { same function as the original product }\end{array}$ \\
\cline { 2 - 3 } & Recover & $\begin{array}{l}\text { Use the product or its parts in a new product with a } \\
\text { different function to that of the original product }\end{array}$ \\
\cline { 2 - 3 } & Repurpose & $\begin{array}{l}\text { Recover materials from discarded products } \\
\text { Recover energy from materials by incineration }\end{array}$ \\
\hline
\end{tabular}

These strongly relate to the Waste Framework Directive's "4Rs" for waste management: reduce, reuse, recycle and recover (Directive 2008/98/EC). There is an underlying hierarchy to the "how to" measures, where the preferable ones are those 
expected to deliver the best overall environmental outcome as perceived through the glasses of least possible resource consumption or material efficiency (Kirchherr et al., 2017). In the " $4 \mathrm{R}$ " framework, this translates to first reducing, then reusing, followed by recycling and finally recovering energy (Directive 2008/98/EC). Table 2 presents a more nuanced version of the " $4 \mathrm{R}$ " framework, the " $9 \mathrm{Rs}$ " developed by Potting et al. (2017).

Various terms are used to refer to the "how to" measures, for example, circular strategies (Blomsma \& Tennant, 2020) or material efficiency strategies (Walker et al., 2018) or resource efficiency measures (Böckin, Willskytt, André, Tillman, \& Ljunggren Söderman, 2020). In the context of this research, the term circular measures is used because the focus is on making changes to offerings towards a circular economy. On the other hand, a strategy in a company context is a plan of action for the whole organization (Chaffee, 1985). The lifecycle perspective is relevant in the circular economy context because circular measures are interventions across products' lifecycles with the aim of extending and managing them differently (Blomsma \& Tennant, 2020).

For companies to implement circular measures, they need to find ways of deriving value from products over extended periods and valorising the residual value of discarded products (Geissdoerfer et al., 2017). To do this, they need to rethink the way they capture, create and deliver value (Lewandowski, 2016). The term circular business models has emerged to describe many different ways companies can comprehensively change how they do business to make circular measures profitable (Pieroni, McAloone, \& Pigosso, 2019). As discussed later, offering products as a service -as a PSS-is one of the most promising ways (Kjaer, Pigosso, Niero, Bech, \& McAloone, 2018). Redesigning the business model goes hand in hand with redesign of the offering, comprising product and service components (den Hollander, Bakker, \& Hultink, 2017; Lindahl, 2018).

\subsection{Product-service systems}

PSS is defined here as an integrated offering of products and services which aim at jointly fulfilling customer utility and value (Boehm \& Thomas, 2013). In the simplest form of PSS, the product is sold accompanied by on-demand after-sales services (product-oriented PSS). However, when used in academic literature, PSS usually refers to the more complex forms of offering products-as-a-service, where the customer pays for being able to use it (use- or availability-oriented) or for the outcome it provides (result-oriented)(Meier, Roy, \& Seliger, 2010; Tukker, 2004). Here, the producers retain ownership of the product and extend their responsibility for portions of the products' operational phase and even take over some of the customers' activities. The process of an organization transitioning from sales to PSS is also known as servitization (Raddats, Kowalkowski, Benedettini, Burton, \& Gebauer, 2019), which is an adjacent field of research.

This extension of responsibility for the product over other parts of its lifecycle has many repercussions. Firstly, it organically creates a need for managing the lifecycle 
either through product lifecycle management (PLM) or through LCM. Secondly, it increases costs as they are shifted to the producer from the customer, for example, maintenance costs. At the same time, the revenue is earned from smaller instalments paid at regular intervals for the duration of the operational life. Therefore, LCC is considered key to understanding the financial perspective of a PSS (Pagoropoulos, 2017). Finally, it creates incentives for the producer to postpone product obsolescence so that it can have a long operational life over which to earn more money and minimize operational costs (Mont, 2002). This final point is how PSS contribute to, at least theoretically, reducing resource consumption; it is also where the connection with the circular economy is. PSS are viewed as a way to operationalize the circular economy both in PSS and in the circular economy literature (Tukker, 2015). Confusingly, PSS oare sometimes conceptualized as a business model and sometimes as the offerings around which a business model is built. Regardless, bringing PSS to the market requires that companies change the way they do business (Reim, Parida, \& Örtqvist, 2015) as well as how they integrate the design of the service and product component (Cavalieri \& Pezzotta, 2012).

For some authors, for instance, Mont (2002), environmental benefits are a defining attribute of a PSS. This was especially true during PSS's formative years. Since then, the output of PSS literature has shifted from the environmental perspective to the business perspective (Tukker, 2015; Velamuri, Neyer, \& Möslein, 2011). There is an ongoing effort in the academic community to understand under which conditions PSS actually can bring about environmental and economic win-win situations and support a circular economy (Kjaer et al., 2018).

\subsection{Life cycle management}

LCM in the environmental engineering field is the business activity of managing a product and service across its lifecycle with the aim of minimizing its environmental impacts (Remmen, Jensen, \& Frydendal, 2007; Westkämper, Alting, \& Arndt, 2000). It makes use of a variety of tools and methods knotted together by lifecycle thinking, such as life cycle assessment (LCA), eco-design and LCC. The results from these methods and tools are integrated with data and knowledge from other information systems (Bey, 2018). Here, LCC is a method that contributes to the economic perspective and provides quantitative monetary information (Rebitzer \& Hunkeler, 2003; Remmen et al., 2007).

The definition just presented it slightly different from how LCM is used in other disciplines or, as Bey (2018) put it: "LCM can, with full legitimacy and good reasoning be practiced without a focus on environment and sustainability". In both cases, LCM highlights the importance of data, information and knowledge management across the lifecycle and its integration into decision-making (Terzi, Bouras, Dutta, Garetti, \& Kiritsis, 2010) as well as the importance of managing activities at the company level. Thus, it influences multiple products, prospectively integrating different companies and even extending the scope to include multiple lifecycles (Hauschild, Herrmann, \& Kara, 2017). The difference lies in the explicit environmental aims (Bey, 2018). 
As a term, LCM is seldom explicitly connected to circular measures and PSS; the importance of lifecycle approaches and data and knowledge management is almost self-evident. It materializes in the use of methods and tools from the LCM "toolkit" in the circular economy and PSS research. For example, Lindahl et al. (2014) used both LCA and LCC and Walker et al. (2018) concluded that LCA is the best method of assessing the environmental dimension of circular measures. It also materializes in the research on how digitalization and lifecycle information can support the implementation of circular measures and PSS (see, e.g., Antikainen, Uusitalo, and Kivikytö-Reponen (2018)).

\subsection{Life cycle costing}

LCC aims at calculating the costs of products, assets or services over their lifecycle (Sherif \& Kolarik, 1981; Woodward, 1997). Depending on the interpretation placed on the word "lifecycle", LCC covers all phases in a lifecycle (Asiedu \& Gu, 1998) or multiple lifecycles (Bradley et al., 2018) or even just the part of a lifecycle that an actor is responsible for (Hoogmartens et al., 2014). As a method, it precedes the emergence of environmentally oriented lifecycle thinking and is often used without the intention of environmental progress (Lichtenvort et al., 2008). Its development and uptake lie in the realization that when assessing an investment, too much importance is placed upon the start-up costs or market price that may form only a fraction of the total costs. In many cases, operation, maintenance and end-of-life will contribute the largest proportion of costs. Because LCC covers long-term costs, identifying all the costs and estimating them as well as the uncertainty surrounding them is challenging (Blanchard \& Fabrycky, 2006). Moreover, the results need to be interpreted in correlation with other sources of information in order to make a decision.

LCC is often used as a method for studying a phenomenon. However, research where LCC is the object of analysis is not as abundant and these studies overwhelmingly focus on the development of LCC methods (Gluch et al., 2018). Representative topics are: what cost elements to include and how to perform the computation (Bradley et al., 2018; Settanni et al., 2014), how to estimate cost and uncertainty (Rodríguez, Pezzotta, Pinto, \& Romero, 2019) and how to integrate it with LCA (Bi, De Kleine, \& Keoleian, 2017; Bierer et al., 2015). Actual LCC case studies were found to be lacking by Korpi and Ala-Risku (2008). Although more case studies have been published in recent years, for example, Iraldo, Facheris, and Nucci (2017), there is still a lack of case studies, especially in the context of PSS (Annarelli, Battistella, \& Nonino, 2016; Lindahl et al., 2014).

A common methodological framework for conducting LCC does not exist. There are sector-specific standards like ISO 15686 or IEC 60300-3-3 and a "smorgasbord" of researcher-developed LCC methods (Gluch et al., 2018), for example, lifecycle cost approaches for water sanitation and hygiene systems (Fonseca et al., 2011). This is indicative of a common theme throughout LCC's history- approaches are sector, case or question specific. This was observed by Sherif and Kolarik (1981), who after reviewing the state of the art concluded that LCC had been developed based on applications and not hypothetical models. Over twenty-five years later, both 
(Lichtenvort et al., 2008) and Korpi and Ala-Risku (2008) observed that this situation remained mostly unchanged. Despite the variety of sector-specific LCC methodologies, Hochschorner and Noring (2011) and Gluch et al. (2018) found that LCC was either not used or used according to company-developed methods or simplified versions of available LCC methodologies. Some researchers put this down to a lack of appropriate methodology (Opoku, 2013), however, Korpi and Ala-Risku (2008) raised the question of whether the problem is a lack of available methodologies or that methodologies cannot be followed because costing is so context specific that it has to be developed for each case.

Other reasons for a lack of adoption or tailoring are a lack of expertise and data or the effort involved as well as a lack of demand by the customers (Higham, Fortune, \& James, 2015). Knauer and Möslang (2018) found that companies were more likely to adopt LCC if they had responsibility for downstream costs, for example, warranties, or could significantly influence downstream costs through product design. Gluch et al. (2018) suggested that the tailoring may happen because there is a conflict between the intended use of a methodology, that is, a detailed and fully accurate account, and the intended use in the company, which is to facilitate a conversation on long term effects or possibly even to legitimize a preferred choice. It is unclear why the adoption rate is low and whether further tailoring of LCC methods is an outcome of objective logical reasoning or if there are other underlying reasons, such as a lack of expertise or different intended use.

\section{Uses}

Use is a purpose for which something is used. It is almost synonymous with the word "objective" found in various LCC methods, but it is used here to include a slightly broader and less defined set of purposes, whereas objective is a clearly defined goal. The main use of LCC is to assist decision-makers in selecting between alternatives, such as investment alternatives or suppliers or maintenance schedules. A review of published LCC case studies up to 2008 by Korpi and Ala-Risku (2008) only identified comparative uses. LCC is often used in parallel to LCA, to understand the trade-offs between environmental benefits and costs for any given set of alternatives. It is this use that LCC often has when supporting LCM (Aurich, Fuchs, \& Wagenknecht, 2006). In the circular economy and PSS context, researchers evaluate by means of LCA and LCC the environmental and economic outcomes of a more circular offering, for example PSS, compared to its business-as-usual alternative (see, e.g., Lindahl et al. (2014)). The purpose is to build up a body of knowledge (Harris, Martin, \& Diener, 2021) to understand under what conditions the more circular offerings lead to positive economic and environmental outcomes. LCC and LCA's integration, however, is in itself a topic of ongoing research (Zhang, Guo, Gu, \& Gu, 2018).

A second use is to support decision-makers with general planning by using a standalone LCC to identify uncertainty and risk hot spots or cost drivers (IEC, 2017). This information can then be used in specific applications, such as budgeting or pricing performance contracts at the bidding stage (Erkoyuncu et al., 2013) or design. Usually, companies have good knowledge and control over the manufacturing and sales and distribution phases and can calculate these costs with fairly high accuracy. However, 
once products enter their operational phase, there are external unforeseeable parameters that start to affect the operational costs (Rodríguez et al., 2019). These parameters include, but are not limited to, the behaviour of the user, the environmental conditions in which they exist, the intensity of use and even the influence of the user deciding when and how and it will be disposed of. This uncertainty and subsequent risks are associated both with not knowing the source of the uncertainty and not knowing its magnitude (Marshall, Ojiako, Wang, Lin, \& Chipulu, 2019). Understanding and measuring cost uncertainty is a use of LCC and an ongoing research topic due to its complexity. The ultimate purpose is that uncertainty and risk can be managed and mitigated through LCM. Knauer and Möslang (2018) found that companies derive more cognitive benefits from LCC, including improving cost awareness and transparency, and especially, cost driver identification than beneficial results, for example, cost reduction or changed pricing.

LCC has been developed mainly for use by individual actors, normally companies, public bodies or consumers who estimate their own costs (Lichtenvort et al., 2008). To serve their objectives, LCC sometimes has to include some other actors' costs as well, for example, customer costs. When academics use LCC, the scope can include the costs borne by any actors in the value chain.

\section{Methodology}

Despite the lack of a strict established standard methodology for LCC, it is possible to identify a common procedure consisting of four steps: goal and scope definition, LCC model development, calculation, and interpretation and review. At every step of the way, decisions should be compatible with the objective (Rodríguez et al., 2019).

I. Goal and scope definition

This stage includes defining the context (Rodríguez et al., 2019), stating a reason for conducting the LCC, and the objective or goal (Woodward, 1997). Then, a number of methodological decisions are made, including setting the scope or system boundaries, for example, lifecycle stages, actors' perspectives, defining the cost object or alternatives to be studied as well as any scenarios, for instance, maintenance scenario (Asiedu \& Gu, 1998; Blanchard \& Fabrycky, 2006). At this stage, any limitations, assumptions, conditions or constraints also need to be identified, for example, information availability limitations (IEC, 2017). In particular, assumptions made in relation to the time value of money, including inflation and discount rate as well as taxation, have to be clarified (Kaufman, 1969).

II. LCC model development

A model is a simplified representation of the real world, and in the case of LCC, it is expressed as mathematical relationships between cost elements and estimation techniques for calculating them. For example:

$$
C_{M F C}=\left(C_{P P M}+C_{U}\right) \times N_{M S}
$$

where $\mathrm{C}_{\mathrm{MFC}}$ stands for maintenance facilities cost, $\mathrm{C}_{\mathrm{PPM}}$ for cost of maintenance facility support, $\mathrm{C}_{\mathrm{U}}$ for cost of utilities and $\mathrm{N}_{\mathrm{ss}}$ for number of maintenance sites. LCC model development is in itself a process, starting from an overarching level and then working 
in more details and cost breakdown structures. Development includes identifying cost elements and cost categories: different levels of aggregation or labels for cost elements derived from lifecycle stages, or fixed and variable costs or activities or categories of resources such as materials, energy and labour (IEC, 2017). The mathematical relationships between cost elements as well as how to estimate the costs elements included in the next step can be the result of various methods, such as statistical analysis, expert opinion and engineering principles (Asiedu \& Gu, 1998; Rodríguez et al., 2019). These methods will be determined at this stage in the model. Basic cost estimation methods are presented in Table 3.

Table 3 LCC cost estimation methods

\begin{tabular}{ll}
\hline Cost estimation methods & Description \\
\hline Analogous & $\begin{array}{l}\text { Cost estimates based on historical data from similar } \\
\text { systems }\end{array}$ \\
\hline Parametric & $\begin{array}{l}\text { Cost estimates based on rules of thumb, mathematical } \\
\text { algorithms and their explanatory variables and parameters }\end{array}$ \\
\hline Detailed or engineering & $\begin{array}{l}\text { Estimates of labour time, material, prices used to estimate } \\
\text { direct costs of components }\end{array}$ \\
\hline
\end{tabular}

III. Calculation

The final step is to collect the input data for the model and compute the results. Although described as a linear process, there is a lot of reiteration between the model development, the choice of estimation techniques and the actual data collection. Initial findings may lead to cost model refinement. This stage also includes conducting an uncertainty or sensitivity analysis using, for example, Monte Carlo simulation. In several cases the sensitivity analysis is, however, skipped, and the results are presented in a deterministic way (Korpi \& Ala-Risku, 2008).

IV. Interpretation and review

The results will always need some further interpretation to fulfil the objective, for example, identifying cost drivers or a more general interpretation in relation to the context, the assumptions, the data quality, and so on. The results and the outcome of the interpretation will need to be presented. This often involves categorizing outputs and results logically, for example, from a lifecycle perspective, developing a cost profile and summary or a Pareto diagram (Blanchard \& Fabrycky, 2006). In most methodologies, authors advocate conducting a review to critically assess whether the goal and objectives were met and that the whole process was done within the boundaries and at a level that provides useful and trustworthy results (IEC, 2017). Independent review of the model, data and assumptions could also potentially be a part of this process.

\section{A practice approach to LCC}

The uses detailed earlier in this chapter largely perceive LCC as a method that provides costing results used in various forms of decision-making. To further explore 
the uses of LCC in Paper V, the research draws on practice theory, for example (Reckwitz, 2002; Schatzki, 1996), and its use in the field of organizational studies to view companies as a collection of practices that produce, reproduce and transform the company (Feldman \& Orlikowski, 2011; Nicolini, 2013). LCC and LCM are conceptualized as practices, which are routinized sets of bodily and mental activities (Reckwitz, 2002). Although practices are often ongoing and recurrent (Feldman \& Orlikowski, 2011), they do not have perpetuity qualities; some will be used once, some will endure and some will fade or be transformed over long periods (Nicolini, 2013). New or innovative practices contest extant practices (Feldman \& Orlikowski, 2011; Nicolini, 2009; Palo, Åkesson, \& Löfberg, 2019).

When LCC (or any tools for that matter) is introduced in a company, it can be perceived as a practice that contests and conforms to extant practices. Here, LCC is a social process rather than just a method in the LCM toolkit. However, in this context, LCM is also perceived as another practice within the bundle that makes up the organization. LCC, and indeed, LCM too, is thus not a method implemented through careful planning and impeccable following of the methodology. Instead, they are emergent social processes. This perspective has been explored for LCM by NilssonLindén, Diedrich, and Baumann (2020); Schmidt (2013); Seidel-Sterzik, McLaren, and Garnevska (2018). For example, Nilsson-Lindén et al. (2020) took a social sciences-derived approach to LCM to study how lifecycle practices emerge and perform LCM. Their findings from a longitudinal case study are that LCM is situated in lifecycle practices, which emerge from local actors who gradually connect and form networks that work together towards LCM. Their research refers to all lifecycle practices, but LCC was not used at the case company.

\section{LCC and other lifecycle tools}

LCA is generally accepted as the major method to analyse the environmental and material aspect of products holistically, where environmental impacts from all the product's lifecycle stages, that is, from raw material extraction to disposal or recycling, are accounted for (Baumann \& Tillman, 2004; Hoogmartens et al., 2014). Unlike LCC, LCA is regulated by ISO 14040.

An issue that has been mentioned before but not yet explicitly addressed is the definition of the term lifecycle and what activities, costs and environmental impacts etc., it includes. Views of the lifecycle from other disciplines such as marketing, where lifecycle refers to the length of time from putting a product on the market until its eventual removal from the shelves (Anderson \& Zeithaml, 1984) are left aside. Here, the focus is on the lifecycle of a single offering as it goes through the process of production, consumption and disposal. In LCA, the offerings' lifetime is understood as everything that has an environmental impact and contributes to delivering one unit of function (Baumann \& Tillman, 2004). Although not entirely explicit regarding where to set the boundaries in LCA, the various frameworks and not least ISO 14040 provide ample support (Diener, 2017).

This is different from how LCC treats the concept of the lifecycle and what to cost. A functional unit is not necessary, and the boundaries can be set almost anywhere; it is 
up to the user to choose based on the objective (Rodríguez et al., 2019). Therefore, in the context of the circular economy, where obsolescence is avoided by products going through multiple loops (Bocken et al., 2016), Bradley et al. (2018) proposed an LCC model that takes into consideration all the "loops" or multiple lifecycles. The challenge with this concept is how the "product" is defined and how much it can change before it ceases being the same product, and where does each loop or the lifecycle end. For example, does the lifecycle stop at recycling or remanufacturing? This challenge of defining a product lifetime is a conceptual one in the circular economy (Diener, 2017) and by extension, in PSS and LCM.

In order to put the environmental perspective as accounted for in LCA together with the economic perspective, a specific type of LCC has been developed called environmental LCC, or eLCC, which is a standardized approach (Hunkeler et al., 2008; Moreau \& Weidema, 2015). A key difference between LCC and eLCC is which actors' costs are included (Hoogmartens et al., 2014). eLCC must be in balance with LCA and refer to the same functional unit and cover the costs of all actors in the supply chain including manufacturer, user, intermediaries and actors that take care of the final disposal, that is, have the same scope (Lichtenvort et al., 2008). Additionally, it must cover externalities, which are assumed to be internalized.

A discussion on the inclusion of societal costs and externalized environmental costs has also emerged in recent years. This has led to a third strand of LCC, namely, societal LCC. Societal LCC is in its infancy, and there is as yet no set format to it, but it should include the costs covered by all actors, including society and the environment (Neugebauer et al., 2016). There are many difficulties to societal LCC because the cost of environmental externalities, as well as accumulated impacts on society and health, are very difficult to establish and place a monetary value on (Hoogmartens et al., 2014; Klöpffer, 2008).

\subsection{Environmental considerations}

Although circular measures, PSS and LCM have been presented as ways of reducing either resource consumption or environmental impacts associated with products and services, such an outcome cannot be taken for granted.

The first reason is that circular measures and PSS come with trade-offs and are not equally suited to all types of products (Böckin et al., 2020; Cooper \& Gutowski, 2017). For example, "reduce" is high on the circular measure hierarchy (Table 2). However, reducing the material in the production stage may come with a trade-off, as durability may be sacrificed (Cooper \& Gutowski, 2017). Another example is that it can be better to replace active products when there is more to be gained by improved energy efficiency in the new models than reversing obsolesce (Böckin et al., 2020). This demonstrates that circular measures, as well as their inherent hierarchy presented in Table 2, are "a rule of thumb" based on the best expected environmental outcomes. Even the Directive 2008/98/EC, makes allowances for waste streams to depart from the hierarchy when environmental protection justifies it. Another consideration is that circular measures are not mutually exclusive, as more than one can be applied to an 
offering simultaneously, often leading to better results (Willskytt \& Tillman, 2019); this raises the question of which combinations to choose when more than one is possible. Ideally, a LCA would be used to see which measures achieve the best environmental outcome, and the choice would be case specific. The reason is that LCAs help avoid burden shifting between different lifecycle stages or between different types of environmental impact (Baumann \& Tillman, 2004). LCA is preferable to relying on the waste hierarchy or other circularity indicators or performance assessments (Sassanelli et al., 2019; Walker et al., 2018).

However, although an LCA result might secure a relative reduction of environmental impacts per offering or unit of function, research is also trying to determine under what conditions it will result in the reduction of environmental impacts in absolute terms (Kjaer et al., 2018). Relative reduction does not ensure absolute reduction or decoupling due to so-called rebound effects (Hertwich, 2005; Zink \& Geyer, 2017). The obtained benefits per unit may not be translated into benefits on the aggregate level because the more circular offerings do not displace primary production but open up new market segments, so overall demand increases or the circular measures lead to a price drop. This increases available income, which in turn is used to consume other products. Although the existence of rebound effects is known, their magnitude and ways of evaluating them need to be further researched.

\subsection{Connecting the concepts}

In this section, the author reflects upon the concepts presented in this chapter to explain how they jointly inform the research conducted. Figure 2 presents the author's own visualisation of how the concepts connect.

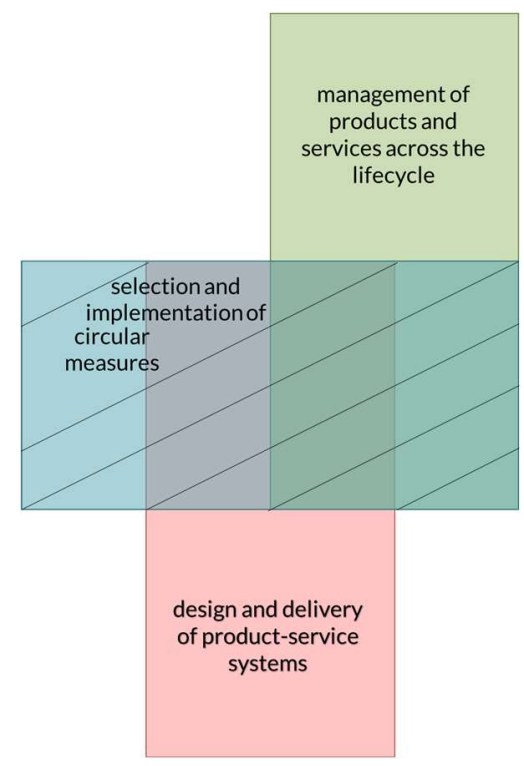

Figure 2 Visualization of the thesis background

The box with the diagonal lines indicates the research scope 
This thesis aims to explore how LCC can support companies and, more specifically, existing companies in selecting and implementing circular measures for their offerings. Apart from LCC, three other concepts are used and presented, namely, circular measures, PSS and LCM. The first common denominator of the three concepts is that they introduce solution spaces for reducing resource use or improving environmental performance. The second common denominator is that although they approach the issues from slightly different perspectives, they all focus on the microlevel of analysis. This means that changing products and the company's activities to manage the products are key ways of reducing resource use or improving environmental performance. From a company perspective, these changes include but are not limited to redesign of the product and its integration of services, finding new ways to fulfil the same "function", finding new business models, restructuring supporting processes such as distribution, production and reversing obsolescence. There are many overlaps between them some of which were discussed previously.

In this thesis, circular economy is the overarching solution space, with circular measures narrowing it down to specific interventions for products. The application of a circular measure will lead to a more circular offering compared to business-as-usual. One type of offering is a PSS. PSS are seen as a way to operationalize the circular economy and contribute with a large existing body of knowledge. However, not all PSS research is considered relevant because it is not all focused on leading to reduced resource consumption. Circular measures result in changes to products' lifecycles. Therefore, companies need to adjust their management activities and perspectives to focus on the lifecycle. Here, LCM contributes with company-wide processes, methods and tools to support lifecycle thinking, including both LCC and LCA. Therefore, in order to identify how LCC can support companies in selecting and implementing circular measures for their offerings, this thesis draws on the knowledge within these concepts. This is depicted in Figure 2, although there is no proportionality to the blocks. 


\section{Research Methodology}

The chapter starts by introducing pragmatism as the guiding paradigm. This is followed by an overview of the research approach, where the papers, research questions, case studies and methods of data collection and analysis are connected. These are subsequently presented in more detail. The chapter closes by discussing validity and reliability.

\subsection{Theoretical underpinnings}

\section{Pragmatism as the guiding paradigm of this research}

This research is based on two joint research projects involving Linköping University and partnering companies. The companies that got involved in these projects wanted to implement or improve circular measures and faced some challenges. They decided to collaborate with academia to jointly research ways to overcome these challenges. LCC was introduced in both projects as a prescriptive method, and this thesis documents the learnings from using LCC in this context. The companies were driven to implement circular measures by seeing business opportunities and the potential to have a positive impact on the environment. Therefore, the motivation for this research, apart from being supported by the literature (see introduction), is also supported by the reality of the four partnering companies (as perceived by them). The ambition of assisting companies in implementing circular measures is normative, driven by the overarching values of society, described through political intent, for example, the Circular Economy Action Plan, as well as the values of the researchers and companies involved.

This connection to companies and their reality, for example, their current challenges and needs, plays a large role in defining the research paradigm of this thesis, that is how the research problem is understood and addressed (Kuhn, 1970). The foundations for this research's approach can be found in the philosophical school known as pragmatism; see, for example, Brandom (2011), Putnam (1995) and Goodman (1995). The ontology, that is the philosophical assumptions and belief system about the form and nature of reality (Pearce, 2016) of pragmatism stands in contrast to prevailing positivist and anti-positivist views of reality. Whereas positivism emphasizes that reality exists independently for the individual, anti-positivism's thesis is that reality is ambiguous and that each individual uniquely interprets it (Guba \& Lincoln, 2005). Pragmatists, on the other hand, argue that reality is grounded in the environment and experience of each individual and can only be imperfectly understood. Therefore, a researcher chooses one version of reality over another lead by how well that choice results in anticipated or desired outcomes (Tashakkori \& Teddlie, 1998). Based on that and as further discussed in this section, this research liberally uses different theories; for example, it views the organization both as "mechanistic" in Paper IV and as "fluid and emergent" in Paper V. Such pluralism is condoned by pragmatism if it helps fulfil the aims. 
In its epistemological disposition, pragmatism is concerned with an instrumental view on knowledge, which means that knowledge is viewed as an instrument for solving problems and aiding human actions (Bush, 1993). Or as Wicks and Freeman (1998) have pointed out, "the key question for pragmatists is whether or not information (scientific data, a novel, a treatise on ethics) is useful-useful in the sense of helping people to better cope with the world, or to create better organizations". In line with this, the research questions focus on the multiple ways that LCC as a process and LCC results can aid companies in moving towards a normative goal, as well as understanding and maximizing their usefulness.

In this research, the ambition is to intervene in the world and not merely to observe it, thus following one of pragmatism's founders, John Dewey who pointed out that "science should overthrow the notion, which has ruled philosophy since the time of the Greeks, that the office of knowledge is to uncover the antecedent real, rather than, as is the case with our practical judgments, to gain the kind of understanding which is necessary to deal with problems as they arise" (Dewey, 1988, p. 14). Therefore, LCC was recommended as a support, and the research questions do not just describe but also prescribe.

\section{Pluralism of perspectives in this research}

In line with a pragmatist approach, reality can only be imperfectly understood, so any conceptualization will be incomplete. Therefore, more than one may be needed. Although an anti-positivist not a pragmatist, this is what Gareth Morgan (2006) means in his landmark book "Images of Organization":

When we approach metaphor in this way, we see that our simple premise that all theory is metaphor has far-reaching consequences. We have to accept that any theory or perspective that we bring to the study of organization and management while capable of creating valuable insights is also incomplete, biased and potentially misleading. [...]

Yet when we recognize this, we can begin to mobilize the true power of metaphor and its role in management. In recognizing theory as a metaphor, we quickly appreciate that no single theory will ever give us a perfect or all-purpose point of view. We realize that the challenge is to become skilled in the art of using a metaphor: to find fresh ways of seeing, understanding and shaping the situations that we want to organize and manage (Morgan, 2006 p. 5)

This thesis makes use of this plurality of perspectives to answer the research questions more comprehensively, namely, from different perspectives or views. These are chosen because the researcher reasons them relevant. In Papers I, III and IV, LCC is primarily viewed as a metric, a method of calculation, and an addition of rigid sums used within what Morgan (2006) described as the mechanistic image of the organization, that is, a state of clearly defined and ordered parts and relations. 
However, $\mathrm{LCC}$ is also viewed as a practice in Paper $\mathrm{V}$, as defined in practice theory ${ }^{3}$ as a routinized set of bodily and mental activities (Reckwitz, 2002) (see glossary). According to practice theory, companies are bundles of practices that are ongoing and recurrent while also existing in specific space and time and thus can change over space and time (Feldman \& Orlikowski, 2011; Nicolini, 2013).

Paper II and Paper VI do not explicitly define the view that is taken on either the organization or on LCC, but there are many elements there that indicate that it is not purely mechanistic. To exemplify this, Paper II describes challenges associated with the mind-set of individuals and misalignment of incentives. Similarly, in Paper VI, by focusing on knowledge management as well as tensions and fights over resources, elements both from the learning and the political conflict view of the organization can be found.

Together, the different perspectives provide a more comprehensive answer to the research questions, thus uncovering uses and methodological considerations that would otherwise not be possible to observe but potentially have far-reaching consequences. For example, in Paper V, by conceptualizing LCC as a practice, we can partially explain why practitioners either do not use or excessively tailor LCC.

However, as pointed out by Gareth Morgan in the quote above, the answers provided are still potentially incomplete as more perspectives, "more realities", are possible.

\subsection{Research overview}

The overarching research approach is based on case studies involving four companies. There are two case studies: the single case study involving Company $\mathrm{X}$ and the multiple case study involving Companies A, B and C. In case study research, a limited number of instances of a phenomenon are studied in depth.

Case studies are chosen because empirical publications using LCC in the context of a circular economy or PSS are few (see Section 2.4). Moreover, to answer the research questions, it was not enough to simply compile an accurate cost model and then use it to compare alternatives. This is a well-documented use in the literature (Korpi \& AlaRisku, 2008). To answer the research questions, LCC had to be integrated into the processes of selecting and implementing circular measures, which are, in essence, social processes, and the researcher either be present to observe or to be able to discuss the process with practitioners close to the events. While using LCC in practice, methodological considerations for the specific context could also be identified. The purpose is to explore, together with practitioners, ways of using the LCC and follow how they reason for various methodological and other choices. In the context of the circular economy, there is a call for more co-creation with industry in the development and validation of tools and methods for supporting a circular economy (Babbitt,

\footnotetext{
${ }^{3}$ Although practice theory is not part of the views presented by Morgan (2006) he states that the ones presented in the book are not exhaustive.
} 
Gaustad, Fisher, Chen, \& Liu, 2018) and sustainability generally (Sakao \& BrambilaMacias, 2018).

That is the predominant logic behind choosing case study research. It is also backed up by the three conditions that Yin (2014) says should be fulfilled to make a case study the preferred method. These are: the focus is on contemporary issues, "how" questions are addressed and the research cannot control the behavioural events. In the case of LCC, there is also another not-so-apparent reason that case studies are used, which has to do with the sensitivity of cost data. One reason for the lack of published LCC studies is that many companies are not willing to share this data without explicit non-disclosure agreements, thereby making studies with many companies hard to arrange.

In both case studies, LCC was prescriptively introduced by the researchers. Multiple cases are used in this study to enhance the opportunity of theory building (Eisenhardt, 1989). They are designed to be complementary. This means that the case studies share the focus on companies using LCC to support the implementation of circular measures but are different enough to provide a more comprehensive answer to the research questions (see Section 3.5). The criterion for choosing the companies was that they wanted to implement or improve circular measures on their products ${ }^{4}$. From each company, specific products were selected to calculate LCC and implement circular measures. Here, the importance of the product to the company's portfolio was the main criteria for choosing the products.

Each paper is based on one of the two case studies. There is no explicit crosspollination between the case studies in the publications. It is within the kappa that this synthesis is done as a kind of, meta-analysis of the two case studies. Table 4 summarizes and depicts the connections between the different elements of this research.

In each research paper, one or more uses of LCC were explored. These uses lead to a preliminary list that was further synthesized for overlaps etc., to arrive at the final list of uses that answer to the first research question, "How can LCC be used to support companies in selecting and implementing circular measures for their offerings?". The second research question, "Why do companies not use LCC?", is a direct outcome from Paper $\mathrm{V}$ and discussed further in this thesis.

Finally, because LCC was applied in practice, methodological considerations pertaining to LCC emerged. These are described mainly in Publications III, IV, and $\mathrm{V}$ and backed up with literature reviews in publications I and IV. To answer the third research question, "What are the core methodological considerations of LCC when used to support companies in the selection and implementation of circular measures for their offerings?", these considerations are gathered together and organised

\footnotetext{
${ }^{4}$ The majority of PhD positions at Swedish Universities are based on externally funded research projects, which predate the commencement of PhD studies. Therefore, the selection of the case studies and definition of the project was the work of the thesis supervisors Mattias Lindahl and Tomohiko Sakao.
} 
according to the basic LCC process, described in Section 2.4. Some of these relate to the specific uses, some try to deal with the reason for not using LCC and some are more generic.

Table 4 Connecting case studies, papers, research questions, data collection and analysis methods

\begin{tabular}{|c|c|c|c|c|c|c|}
\hline Papers & RQ1 & RQ2 & RQ3 & $\begin{array}{l}\text { Case study } \\
\text { (Section 3.3- } \\
3.5 \text { ) }\end{array}$ & $\begin{array}{l}\text { Data } \\
\text { collection } \\
\text { (Section 3.6) }\end{array}$ & $\begin{array}{l}\text { Data analysis } \\
\text { (Section 3.7) }\end{array}$ \\
\hline Paper I & $x$ & & $x$ & - & $\begin{array}{l}\text { Literature } \\
\text { review }\end{array}$ & Theme generation \\
\hline $\begin{array}{l}\text { Paper } \\
\text { II }\end{array}$ & $x$ & & $(x)$ & $\begin{array}{l}\text { Single case } \\
\text { study }\end{array}$ & $\begin{array}{l}\text { Interviews } \\
\text { Focus groups }\end{array}$ & $\begin{array}{l}\text { Theme generation } \\
\text { Comparative analysis }\end{array}$ \\
\hline $\begin{array}{l}\text { Paper } \\
\text { III }\end{array}$ & $x$ & & $x$ & $\begin{array}{l}\text { Multiple } \\
\text { case study }\end{array}$ & $\begin{array}{l}\text { Interviews } \\
\text { Focus group }\end{array}$ & $\begin{array}{l}\text { Theme generation } \\
\text { Comparative analysis }\end{array}$ \\
\hline $\begin{array}{l}\text { Paper } \\
\text { IV }\end{array}$ & $x$ & & $X$ & $\begin{array}{l}\text { Multiple } \\
\text { case study }\end{array}$ & $\begin{array}{l}\text { Literature } \\
\text { review } \\
\text { Interviews } \\
\text { Focus group }\end{array}$ & $\begin{array}{l}\text { Design Research } \\
\text { Methodology }\end{array}$ \\
\hline $\begin{array}{l}\text { Paper } \\
\text { V }\end{array}$ & $x$ & $x$ & $x$ & $\begin{array}{l}\text { Single case } \\
\text { study }\end{array}$ & $\begin{array}{l}\text { Documents } \\
\text { Interviews } \\
\text { Focus groups }\end{array}$ & $\begin{array}{l}\text { Practice theory \& } \\
\text { categorization }\end{array}$ \\
\hline $\begin{array}{l}\text { Paper } \\
\text { VI }\end{array}$ & $x$ & & $(x)$ & $\begin{array}{l}\text { Single case } \\
\text { study }\end{array}$ & $\begin{array}{l}\text { Interviews } \\
\text { Focus groups }\end{array}$ & $\begin{array}{l}\text { Theme generation \& } \\
\text { categorization }\end{array}$ \\
\hline
\end{tabular}

The data collection methods and analysis have been described in detail in the publications and are further elaborated on in the rest of this chapter. In both case studies, it involves a mixed-methods approach that included literature reviews, documents analysis, interviews and focus groups that provided information that was either direct input to calculating the LCC or contributed to how to use the results.

\section{The role of the researcher}

In both case studies, the researcher had a central role in performing LCC. For the multiple case study involving Companies A, B and C, student research helpers started the LCC process closely supervised by the author of this thesis. At all the companies, the author was responsible for driving the process of conducting the LCC, but the methodological decisions and cost data collection were done in collaboration with staff members at the company. Therefore, the research was to some extent participatory; however, it cannot be classified as participatory research in the strict sense.

Participatory research can be used to describe a range of research methodologies, where the subject of the research participate in the research (Given, 2008, pp. 601604). In the case studies, the participants partook in methodological decisions pertaining to LCC, for example, cost estimation, cost inventory compilation and the prioritization of topics on which to obtain complementary information, or discussed the LCC results at dissemination seminars. They also provided feedback on findings, 
for example, the guideline that was created in Paper III, and they verified both the LCC results and the papers prior to publication. However, more often than not, they did not participate consciously in identifying uses for LCC or generating themes from the transcripts, which lead to identification of methodological considerations, or knowledge on the social processes involved. They also did not participate in comparing and synthesising the data from the different companies.

Those activities were led by the author of the thesis together with the respective authors in each publication. This researcher's involvement could result in her subjective views influencing the LCC results or the answers to the research questions (Given, 2008, pp. 60-61). This is addressed in Section 3.8. Alternatively, it could result in the findings being interpreted to meet her predetermined hypothesis. To some extent the opposite is true because based on the literature review (Paper I), performed at the beginning of the studies the researcher's initial expectation was that LCC's main use would be as a detailed economic account of alternatives. The first project with Company $\mathrm{X}$ revealed that although LCC is used for that it also had other uses, which were not expected from the offset. Often scientists try to make the data fit the theory (Given, 2008, p. 60). In this research the use of multiple perspectives, especially evident in Paper V, was introduced later due to an effort of the part of the researcher to find the theory to fit the data.

\subsection{The single case study}

\section{Company $\mathrm{X}$}

Company X (alias) has a long history of designing, manufacturing and selling a relatively complex type of industrial equipment in the B2B market. Through its subsidiaries, the mother company is responsible for design, manufacture, sales, maintenance, operational monitoring and remanufacture. However, in some markets, the offerings are sold via distributors, and maintained, repaired and remanufactured by other actors. Recycling, energy recovery and landfilling are also done by other actors. Company X offers the equipment both through traditional sales and through availability-contracts (PSS) including maintenance, repair and operational monitoring. At the end of the contract, some equipment is remanufactured and then utilized in new contracts or sold. PSS are a substantial portion of Company X's revenue. The circular measures are maintenance, repair and remanufacturing and were already in place before the research commenced. The focus is on improving the implementation of the circular measures.

\section{Research process with Company X}

The research with Company $\mathrm{X}$ was part of the project aiming to use $\mathrm{LCC}$ to improve LCM. The first step was to both conduct LCC for several PSS and customer segments and explore the intangible value of PSS. The latter was done by one of the co-authors, Johannes Matschewsky. The second step was to use this information to understand the challenges, find solutions and identify opportunities to improve management across the lifecycle (Papers II, V and VI). In contrast to Companies A, B and C, LCC 
at Company $\mathrm{X}$ was not used to compare the financial outcome of the implementation of a circular measure for business-as-usual but to learn about the costs over the lifecycle. This was done by identifying costs drivers and influencing factors, comparing LCC of different customer segments and offerings and exploring ways to improve LCM.

LCC research commenced in May 2015, and the first round of LCC results was calculated by May 2016. After discussion in focus groups and interviews, it was refined, and the final LCC results were ready in August 2017. Subsequently, six focus groups were held to assist the researcher in interpreting the results and deriving recommendations and discussing them. In total, 34 interviews and 10 group discussions were held. This was supplemented by emails, datasets and other document exchanges, as well as telephone calls. Although the results presented here cover research conducted from 2015 to 2018, the collaboration with Company X started earlier and is ongoing. It is a longitudinal case study spanning many years. This research lies behind the following publications: Papers II, V and VI.

\subsection{The multiple case study}

\section{Company A}

Company A (alias) is a comprehensive supplier of material and digital visibility solutions, such as signs, flags, and display walls that provide brand exposure. Its operations include graphic design, sourcing parts, assembling an order, sale, arranging distribution, installation and storage. Two offerings were chosen for this study: event tents and beach flags sold for single events, for example, exhibitions. Both items have a similar structure consisting of a supporting metal frame for the tent or fiberglass pole for the flag and custom-printed polyester textile.

In the business-as-usual scenario, the product is sold, and after use, discarded, although technically in good condition. The circular measure selected is refurbishment. This is facilitated through rental or offering the product as a service (PSS). After use, the products are taken back, the frame or pole is cleaned, stored and eventually refurbished with new textile for another customer. The old textile goes to energy recovery. The frame or pole is estimated to be refurbishable at least nine times after original use before reaching the end of its technical lifetime and, subsequently, the metal parts are recycled.

\section{Company B}

Company B (alias) is a supplier of furniture, for example, cabinets and recycling stations, for public spaces. Its main activities are product design, marketing and administration of the supply chain. Manufacturing, transportation and storage are subcontracted to suppliers, and the products are sold via retailers. Two offerings were chosen for this study: recycling bins and lockers. The storage lockers are often customized based on a modular design to fit the office space and needs of the customer, whereas the recycling bins are not customized and are sold in pairs. The recycling bin comprises a steel body and a medium-density fibreboard lid. It is 
discarded due to technical reasons, most often a damaged lid. The circular measure selected is repair by way of replacing the lid. The lockers consist of a hardwood case and doors and some steel hinges. They are discarded for aesthetic reasons, for example, to update the offices' look. The circular measure selected is refurbishment. This is facilitated by collecting, repainting and redistributing the doors on demand. The doors can be refurbished once and the bin repaired twice before reaching the end of their technical lifetime and going to material or energy recovery.

\section{Company C}

Company $\mathrm{C}$ (alias) operates within the waste collection industry. Its main product is vacuum waste collection systems for residential areas, business premises, hospitals, schools and town centres worldwide. This includes, for example, inlets, pipes, collection stations, containers, filters, fans, etc. It provides the technology and the know-how, thereby administrating most of the supply chain including design and development, sales, and sourcing. Construction and maintenance are often outsourced to local sub-contractors.

One specific element of the complex system was examined, the inlet where the system user places waste. In contrast to the other two companies, Company $\mathrm{C}$ already had a circular measure in place, namely, maintenance and repair prior to joining the research. A key source of repair costs is the waste inlet's door, which occasionally gets damaged and breaks. Therefore, instead of exploring new circular measures, the research focused on improving the circular measure and examining the effect of redesigning the door for maintenance. The business-as-usual and circular offering are both based on selling the door and providing a maintenance contract. The difference is the design of the door. The more circular offering includes the newly designed door that requires only part of the door to be replaced and can be done more quickly.

\section{Research process with Companies A, B and C}

The research with Companies A, B and $\mathrm{C}$ was part of the project Circular Economy through Innovating Design (Circularis). It focused on using LCC to help companies select and optimize circular measures for their existing products.

The research started by observing and participating in the process of choosing circular measures at the three companies. In parallel, LCC and LCA were performed for the product before and then after the implementation of the circular measure. LCA was conducted by one of the co-authors, Mohamad Kaddoura. The results of the LCC were then used to compare the alternatives financially, assess their circularity and improve the circular offerings by providing input to design (Paper IV). Finally, LCC and LCA were used in parallel to compare the alternatives from both an environmental and economic perspective (Paper III).

Based on a literature review, observing the company when choosing circular measures initially and using LCC to improve the offerings, a guideline was created. The companies did not actively participate in its creation but did provide feedback. The research with each company was conducted in a similar manner, thus making it possible to build up a body of knowledge through comparison. Data collection was 
carried out between May 2017 and December 2018. The interaction with the case companies cannot be broken down into measurable events as it included interviews, e-mail exchanges, phone calls, comments on documents and a focus group. The research lies behind the following publications: Paper III and Paper IV.

\subsection{The complementarity of the two case studies}

The work with Company $\mathrm{X}$ contributes to answering the research questions by demonstrating how iteratively working with LCC over time can help a company learn and understand costs and profits and overcome challenges on multiple levels, and can strengthen LCM. The work with Company A, B and C shows how LCC at a specific point in time can help companies with selecting appropriate circular measures, designing them, evaluating alternatives and their associated circularity. They are both relevant to using LCC but complement each other by having slightly different objectives within the overarching objective. They are also complementary in other respects, as shown in Table 5. For example, they are different in their size (large vs SMEs) and they bring different types of offerings, that is, active vs. passive product to market. They are also at different stages of the journeys towards circular economy implementation; for example, Company $\mathrm{X}$ works with availability contracts and Company $\mathrm{C}$ offers maintenance contracts.

Table 5 Key attributes of the two case studies

\begin{tabular}{|c|c|c|}
\hline & Single case study & Multiple case study \\
\hline $\begin{array}{l}\text { Case } \\
\text { companies }\end{array}$ & Company $\mathrm{X}$ & Companies A, B and C \\
\hline Description & $\begin{array}{l}\text { Manufacturing company and its sale, } \\
\text { service and remanufacturing } \\
\text { subsidiaries }\end{array}$ & $\begin{array}{l}\text { Companies that design sell and } \\
\text { are the brand of the offering }\end{array}$ \\
\hline Size & Large international company & SMEs \\
\hline Project Title & $\begin{array}{l}\text { LCC and provider value appraisal for } \\
\text { improving LCM (reworded) }\end{array}$ & $\begin{array}{l}\text { Circular Economy through } \\
\text { Innovating Design (Circularis) }\end{array}$ \\
\hline Funding & Company $\mathrm{X}$ & Vinnova via Produktion2030 \\
\hline Offering & $\begin{array}{l}\text { Active products: Five availability- } \\
\text { oriented PSS of industrial equipment }\end{array}$ & $\begin{array}{l}\text { Passive products: beach flag, } \\
\text { event tent, recycling bin, } \\
\text { lockers, waste inlet }\end{array}$ \\
\hline LCC & $\begin{array}{l}\text { LCC for five types of offerings at } \\
\text { several customer } \\
\text { segments/applications }\end{array}$ & $\begin{array}{l}\text { LCC before and after } \\
\text { implementing circular measures }\end{array}$ \\
\hline Market & B2B & B2B \\
\hline Use LCC to & $\begin{array}{l}\text { - identify cost drivers, uncertainties } \\
\text { and changes to PSS's cost } \\
\text { structure }\end{array}$ & $\begin{array}{l}\text { - select circular measures and } \\
\text { guide design } \\
\text { - use with LCA to compare the } \\
\text { environmental and financial } \\
\text { outcomes of products before }\end{array}$ \\
\hline
\end{tabular}




\begin{tabular}{lll}
\hline & Single case study & Multiple case study \\
\hline & $\begin{array}{l}\text { • identify factors influencing } \\
\text { lifecycle costs by comparing LCC } \\
\text { for various offerings at different } \\
\text { customers } \\
\bullet\end{array}$ & $\begin{array}{l}\text { and after implementing } \\
\text { circular measures } \\
\text { offering using LCC } \\
\bullet \text { understand customer costs }\end{array}$ \\
\hline Publications & II, V, VI & III, IV \\
\hline LCC results & $\begin{array}{l}\text { Not published for confidentiality } \\
\text { reasons }\end{array}$ & $\begin{array}{l}\text { Published in III and IV but } \\
\text { agglomerated }\end{array}$ \\
\hline Revenue & Calculated but not published & Calculated but not published \\
\hline
\end{tabular}

\subsection{Methods of data collection}

The relationship between the data collection methods and papers is presented in Table 4. Four separate data collection methods were used: literature reviews, documents, interviews and focus groups. Therefore, it is a mixed-method approach (Creswell \& Clark, 2007), which is typical of case study research (Eisenhardt, 1989).

Literature reviews are an essential academic practice for taking stock of the existing knowledge (Hart, 2001). Therefore, searching and reviewing literature was repeatedly performed throughout the PhD process. Paper I is based solely on a systematic literature review. After an initial search in prominent academic databases and subsequent initial screening, one hundred and sixty-six publications relating to costing in the PSS context were reviewed. This review was conducted at the beginning of the $\mathrm{PhD}$ process and informed the costing work that followed. Paper II included a literature review performed by Matschewsky on challenges and solutions relating to designing and providing PSS. This aided the discussion of the results and strengthened their generalizability. In Paper IV, a literature review started from major publications on LCC and subsequent snowballing to understand the strengths and limitations of using LCC to select circular measures. This acted as a complement to the findings at Companies A, B and C. Two key limitations exist: the first is the difficulty of identifying all relevant research because not everything will be labelled "PSS" or "circular economy", the second is that the majority of literature on costing is theoretical and the published case studies have a low level of detail (Paper I).

Documents were examined by the author, such as sustainability reports, previous research projects with the university and information on the website to understand the companies, their expressed motivation in terms of circular economy and sustainability and to learn about the lifecycle of the offerings. However, these were mainly complementary to help the author understand the context. They were also treated with caution because documents are not simply neutral reports but also can push actor's agendas (Bryman, 2016). The main documents used were cost-data sets for the LCC. These were used to develop the model and calculate the LCC and made reaching the costing results in Papers III and IV possible. A final category of documents included 
the written documentation of the process, such as meeting minutes, project reports and emails with cost-related questions. These were generally used to establish consensus and check that there was a common understanding. For example, minutes of a focus group describing the methodological decisions were confirmed by the participants.

Interviews are the most frequently used data collection method in this research. They were used in both the case studies and all articles except Paper I. However, they were primarily used in Company $\mathrm{X}$ and Papers II, V and VI. Interviews included one participant and one researcher. There were diverse purposes for conducting them. These included deciding the LCC methodology, identifying cost drivers and parameters affecting them, choosing circular measures for the products (Companies $\mathrm{A}$ and B), cost estimation when historical data were unobtainable, discussing challenges of using LCC, the LCC-based circularity indicator, LCA, as well as more general costing challenges. Other topics included an interviewee's needs or wishes in terms of cost knowledge, opportunities for using LCC more systematically and their personal interpretation of the LCC results and opportunities to strengthen LCM (Company X). Finally, other general issues about the company and its products were also discussed.

There was a contact person at each company who suggested interviewees based on the topic of the interview. However, interviewees frequently suggested other interviewees. This means that many of the interviews were embedded into the LCC process. In addition, interviews were connected to LCC by presenting LCC results to see how the outcomes could be used. Two interviewing techniques were used:

- Semi-structured interviews, where the interviewees were asked a series of predetermined but open-ended questions (Given, 2008, pp. 470-472)

- The general interview guide, which involved outlining a set of issues to be discussed with the interviewee and a checklist to make sure that they were discussed (Patton, 2002)

The interviewing style was conversational, but not in the way Patton (2002) describes it as a spontaneous generation of a question; rather, the topics were discussed in a discursive manner (Conrad \& Schober, 1999). This style was chosen because costs and revenue are a sensitive issue for many to discuss. It concerns aspects that they have been taught are confidential, and a formal probing enquiry did not suit data collection in this context; exchange had to take place on a level where the interviewee felt comfortable. Almost all interviews and focus groups were digitally recorded and selectively transcribed. Usually, minutes were provided to the interviewees for confirmation as per the interviewees' request. An effort was made to word the interviews in the language the interviewee was familiar with. The interviews were held in English or Swedish, which meant one of the two participants, was not speaking their mother tongue. However, both could speak both languages, so when something was unclear, the interviewer checked in the other language.

The final method of data collection used is focus groups. As recommended by Patton (2002), they included six to ten participants. One focus group was held as part of the 
multiple case study where all researchers in the Circularis project and the sustainability managers and CEO of Companies A, B and C, were present. The LCA and LCC results were presented and discussed, as well as experiences and learnings of using LCC and LCA as a group (Papers III and IV). Interviews had previously been held with the sustainability managers, so their feedback had been obtained in circumstances where they would not feel under pressure.

The ten focus groups at Company $\mathrm{X}$ were held for similar reasons to the interviews. It quickly became clear that the methodological decisions and interpretation of results needed to be discussed in a group setting because individuals had slightly different perceptions. There was an advantage of getting real-time interaction of stakeholders with different business perspectives that could inform each other about the different stages in the lifecycle. Interviews were used when the knowledge of a specific person sufficed or when there was no foreseeable advantage of having participants interact in real time. The disadvantage with focus groups can be the dominance of certain actors due to the hierarchy or personality (Krueger \& Casey, 2014). This was not a major issue as the participants were usually on a similar level of hierarchy, and the author met or offered to meet participants individually to obtain further feedback in an interview setting. The focus groups always commenced with a short presentation by the researchers, including an update on LCC and a set of issues to be discussed.

\subsection{Methods of data analysis}

Going from the data to some specific outcomes required a qualitative analysis of the content in order to reduce the data (Miles \& Huberman, 1994). In this research, the most common type of data analysis method is the generation of themes from the transcripts of interviews and focus groups or from the literature review and then populating them with content related to research questions in the Papers. Here, patterns are sought in the data by comparing the interview results or the cases, or the LCC costing results or the LCA and LCC results. These themes were not generated from scratch; they were influenced by academic publications by other researchers who had been reviewed in advance, as well as the researcher's past experiences. Theme generation was used in Papers I, II, III and VI. The themes were iteratively discussed and agreed upon with the co- authors in all but Paper VI.

In some Papers, specific analytical frameworks were used, or analytical lenses. More specifically, Paper V makes use of practice theory (Schatzki, 1996) to conceptualize LCC as a practice and LCC methods as prescribed or general patterns of LCC practice, and Reckwitz (2002)'s six elements of the praxiological worldview: body, mind, things or objects, knowledge, discourse, structure/process and the agent/individual are used in order to structure and analyse the data. In Paper VI, Nonaka (1994)'s four modes of knowledge conversion are used: socialization, externalization, combination and internalization to describe how LCC is used to support knowledge creation and knowledge sharing. In Paper III, where a guideline for using LCC is developed, the Design Research Methodology by (Blessing \& Chakrabarti, 2010) guides the process. Details can be found in the publications. When 
the interview and focus group data is organised based on an analytical framework, then it is referred to as categorization in Table 4 rather than theme generation.

Thick descriptions of events associated with practising LCC were also part of the data analysis methods in Paper V. Although thick descriptions are sometimes understood as detailed descriptions, here the term is used to mean that they are interpretative rather than descriptive (Given, 2008, p. 880). When providing thick descriptions, the researcher is interpreting an event, action or decision by providing, for example, context, meanings, intentions and motivations that characterize it (Schwandt, 2014). For example, this helps interpret why an individual makes a methodological choice, even though the individual does not provide a specific explanation. They are suited to practice research (Nicolini, 2009).

Finally, data displays (Miles \& Huberman, 1994) were a critical type of content analyses, both of the LCC results but also of the qualitative data results. Many of the uses of LCC are made possible through the way they are displayed, and these were crucial in Papers III and IV. Other data displays are helpful in communicating the research results to a broader audience, for example, in Paper IV, the discussion of strengths and weakness of using LCC for selecting circular measures is condensed into a table.

\subsection{Validity and reliability}

Case studies, as well as the methods of data collection and analysis, have strengths and weaknesses. The later resulting in concerns regarding validity and reliability. Cook and Campbell (1979) introduced a framework for investigating methodological rigour of research in social settings, that Yin (2014) adapted to case study research. This includes internal validity, construct validity, external validity and reliability.

The first concern focuses on the accuracy and plausibility of the conclusions, including issues such as causality and comprehensiveness, also known as internal validity (Cook \& Campbell, 1979). This mainly concerns the data analysis stage and reaching a conclusion. The following measures were taken to enhance internal validity: firstly, as recommended by Yin (2014), analytical frameworks were used (Papers V, VI and IV). Secondly, literature reviews were used to learn from previous work. To this end, Paper I was a literature review, and Paper II explicitly matched the findings to those identified by other authors. Furthermore, all publications, including this kappa, discussed the findings in relation to other researchers' work. Finally, as recommended by Yin (2014), various perspectives, both of the organization and of LCC, were used to approach the questions (see Section 3.1).

The second concern is about construct validity, that is, whether something investigates what it claims to (Cook \& Campbell, 1979). The measures taken to enhance construct validity first included sending minutes or transcripts to the participants to confirm, as well as project reports. Papers I, II, III and IV included co-authors who separately reviewed the work. The published articles were also subject to peer review and presented at division seminars or conferences to obtain feedback prior to publication. Finally, mixed-method research supports triangulation (Creswell \& Clark, 2007). 
Concerning the LCC results themselves, the work was performed with practitioners, and as many sources of data as possible were used, for example, invoices, data from CRM and more than one expert opinion.

The third concern relates to the generalisability of the findings and their external validity (Cook \& Campbell, 1979), which for case studies needs to be approached with caution. Case studies provide knowledge on a limited number of instances of a phenomenon so they can be context specific (Eisenhardt, 1989). Moreover, pragmatism emphasizes that reality is grounded in the environment. However, case study research can bring generalised theories into question (Flyvbjerg, 2006). Although not a theory, the generalised understanding that LCC provides cost results and little else is shown to be limited because LCC can be used to facilitate discussion and create awareness about the circular economy business case and strengthen the practice of LCM. One way to enhance generalisability is to use multiple case studies (Eisenhardt, 1989) therefore, the multiple case study included three companies (Papers II and IV). In line with this, Paper II is based on two case companies, Company $\mathrm{X}$ and Navitas (alias). The findings at Company $\mathrm{X}$ were corroborated by the findings at Navitas based on other methods of data collection and analysis conducted by the first and third authors thus enhancing generalisability. The identified uses can be seen as possible uses, not as necessary uses. Due to the problem of generalisability, neither the uses nor the methodological considerations should be viewed as exhaustive.

Reliability, sometimes referred to as replicability, is another key issue, that is, the ability to reach the same conclusions by reassessing the data (Yin, 2014). This research does not name any of the companies involved and provides either agglomerated cost data (Companies A, B and C) or none at all (Company X). However, the LCC and LCA results from the multiple case study can be found as supplementary materials attached to Papers III and IV online. Moreover, in Company X, the focus was on how the LCC results were used rather than the cost data. The process of the research at Company $\mathrm{X}$ is described in Paper $\mathrm{V}$, which includes a historical account of the interviews and focus groups, dates and topics, as well as thick descriptions of some of these. Concerning the process of the research at Companies A, B and C, this was similarly described in Paper IV. Additionally, an overview is presented in this thesis. 


\section{APPENDED PAPERS}

In this chapter, the appended papers of this thesis are presented in chronological order of publication. For each paper the background, method and findings are presented as well as its connection to the projects.

\subsection{Paper I}

Kambanou, M.L., \& Lindahl, M. (2016). A Literature Review of Life Cycle Costing in the Product-Service System Context.

Background and motivation: This paper is peer-reviewed and published in Procedia CIRP, which publishes proceedings from CIRP conferences. The work was conducted between late 2015 and early 2016. The motivation for writing the paper stems from costing practices, for example, methodological choices, being influenced by context. Therefore, the aim was to create an overview of how LCC has been used in the PSS context in order to have a solid theoretical foundation for conducting LCC in the next step of the research.

Summary: A systematic literature review was used in order to determine how LCC is used and described in the PSS context and, more specifically, to answer the following questions:

RQ1. Is there a clear and common approach to conducting LCC in the context of PSS literature?

RQ2. What parameters of LCC are included in the context of PSS literature, both from a lifecycle stage and actor perspective?

RQ3. What data challenges are faced when conducting LCC in the context of PSS?

The paper determined that LCC and its variants are often used in PSS literature to provide cost information to a variety of stakeholders. There are similarities between the LCC approaches: for example, operational costs are generally included, and a key theme is to develop methods for estimating costs and uncertainty related to the service component of the PSS. However, there are also a number of inconsistencies in the different approaches. For example, some studies only include costs accrued by a specific actor, for instance, provider or customer, and it is unclear whether and how end-of-life or second life, for example, remanufacturing and subsequent reuse, are included. This leads to etymological confusion as LCC, and indeed other words such as total cost of ownership (TCO) or through life costing (TLC), refer to different approaches.

Most of the published literature is theoretical, and there is a lack of empirical studies. Moreover, due to data secrecy or limited work count, it is not uncommon for empirical examples to lack detailed explanations of methodological choices. This means that methodologies are described on a general level, making it hard to uncover the choices or reasons for them. Most research relates to availability- contracts, so these findings relate mainly to availability-oriented PSS. 
Many authors describe challenges with obtaining quality costing data, which increases the uncertainty of the cost estimates. Firstly, there is a lack of collected data or an unwillingness to share it with others in the value chain. Secondly, the historical data may not be relevant because it does not reflect the outcomes of the redesign of products and services to fit into a PSS, for example, (re)design for durability. Finally, the service is often designed after the product, leading to a reduction of freedom in service design and a time delay in obtaining data about services.

In order to move forward, the article recommended that authors be clearer when using LCC about i) the type of PSS being studied, ii) their approach and iii) the parameters, for example, lifecycle stages and actors' perspectives, and to add descriptions of methodological details.

\subsection{Paper II}

Matschewsky, J., Kambanou, M.L, \& Sakao, T. (2018). Designing and providing integrated product-service systems - challenges, opportunities and solutions resulting from prescriptive approaches in two industrial companies.

Background and motivation: The International Journal of Production Research (IJPR), which published this article, covers research on manufacturing, operations, logistics and management science with a strong focus on real-life applications. The paper reports on two case studies of Swedish industrial companies, with the aliases "Navitas" and "Levor" in the article. The author of this thesis was not involved in the work at "Navitas" but the "Levor" findings came from the joint project with Company $\mathrm{X}$. The main work connected to "Levor" took place between the summer of 2015 and that of 2016 .

The motivation for the research came from the case companies, who recognized that they faced challenges in servitizing and were willing to explore prescriptive solutions together with $\mathrm{LiU}$ as an academic partner. During the research, challenges were identified, the prescriptive solutions were tested and new solutions emerged. These challenges and solutions had not been extensively documented in the literature and thus motivated us to write the article. Equally importantly, an opportunity was seen to increase learning by analysing the two cases, which had not been designed to be complementary.

Summary: Many industrial companies are making the transition towards providing PSS, but there is still little literature that provides a deep understanding of the challenges associated with this transition while suggesting approaches to overcome these challenges. Based on a multiple case study of two manufactures where prescriptive approaches such as a lifecycle costing and a PSS design method were applied over an extended time frame, the following research questions were answered:

RQ1. What are the challenges faced by two industrial companies undergoing the transition to designing and providing PSS?

RQ2. What opportunities and solutions towards meeting these challenges have been identified and implemented? 
RQ3. How can these solutions benefit other industrial actors experiencing challenges during their transition to PSS?

The methods of data collection were interviews and focus groups. Prescriptive approaches were applied, for example, actor mapping or conducting LCC. Four major challenges were identified. These included a persisting product-centred mind-set, which focused on products and technological innovations rather than the integration of product and service into a joint offering that meets customer needs. This was exacerbated by the second identified challenge, of having product and service design departments separated or sequentially organized without in-depth collaboration. Additionally, the new incentives resulting from PSS, such as service costs being a loss rather than source of revenue, were either not understood or not used in decisionmaking. This challenge was closely linked to the fourth challenge concerning productfocused information and costing structures. Such structures do not help with capturing and concretizing the change in incentives.

The opportunities arising from and solutions to these challenges were also identified. Three of these solutions are the prescriptive approaches that were validated and extended during the course of the projects, namely, the use of PSS design methods, conducting LCC from the provider and customer perspective and actor mapping of internal relationships. The other three solutions, which were directly derived from the research, were measuring value, introducing a PSS facilitator and focusing on the customer-centric, business-driven design of PSS. The article also demonstrates the applicability of prescriptive approaches and methods to detect, understand and alleviate the challenges of PSS design and provision. Further, the article provides broadly applicable learning for industrial companies undergoing this process.

\subsection{Paper III}

Kaddoura, M., Kambanou, M.L., Tillman, A.M., \& Sakao, T. (2019). Is Prolonging the Lifetime of Passive Durable Products a Low-Hanging Fruit of a Circular Economy? A Multiple Case Study.

Background and motivation: Sustainability is an open-access journal covering topics on the three main pillars of sustainability, namely, environmental, economic and social. The article reports on LCC and LCA results of the business-as-usual and more circular offerings from the "Circularis" project, and most of the work was conducted from May 2017 to December 2018.

The motivation of the paper was driven by the realization that the companies participating in the "Circularis" project all brought passive and durable products to the market, and after consultation with them, they all choose a similar approach, namely, to prolong their passive and durable products' lifetime by adding services. This essentially meant that we had LCC and LCA data for "five cases" to learn from. Therefore, we could use this data and the discussions with the company to reach some conclusions about the economic viability and environmental benefits of such measures and the parameters affecting them. There was also an opportunity to add to the methodological discussion of using LCC and LCA in parallel. 
Summary: This research documents, by using LCA and LCC for the manufacturer, the environmental and economic outcomes of prolonging the lifetime of five existing products by implementing circular measures, for instance, repair and refurbishment. The lockers were repainted and therefore reused as whole products, whereas the tent, beach flag, recycling bin, and waste inlet were partially reused by replacing some components. By comparing the results of the cases to each other but also LCA and LCC of each case and using sensitivity analyses some conclusions about the circular measure of prolonging the lifetime for passive durable products were reached.

Table 6 Reduction of LCA and LCC of circular offerings compared to business-as-usual Negative sign indicates reduced impact/cost, LCA and LCC are respectively measured in global warming potential and SEK

Based on Kaddoura, Kambanou, Tillman, and Sakao (2019)

\begin{tabular}{lcclcc}
\hline Assessment & Flag & Tent & Bin & Locker & Inlet \\
\hline $\begin{array}{l}\text { Global Warming } \\
\text { Potential }(\mathrm{kgCO}-e q)\end{array}$ & $-74 \%$ & $-45 \%$ & $-47 \%$ & $-38 \%$ & $-1 \%$ \\
\hline $\begin{array}{l}\text { LCC manufacturer } \\
\text { (SEK) }\end{array}$ & $-12 \%$ & $-18 \%$ & $-9 \%$ & $-37 \%$ & $-12 \%$ \\
\hline
\end{tabular}

The main findings, presented in Table 6 , confirmed the premise of the research, that because raw material extraction and production of the products' durable components cause the greatest environmental impacts, extending their lifetime can yield significant environmental improvements. The size of the improvement depends heavily on the relative contribution to environmental impacts of the component whose lifetime is prolonged and the number of times it gets reused. This means that companies bringing passive durable products to market can implement such measures with a high level of certainty that environmental impacts per unit of delivered function will be lowered.

Although LCC for the manufacturer showed that these circular economy measures also reduced costs, the savings were less pronounced, as can be seen in Table 6 . The first reason is that although environmental impacts are very closely related to production, substantial costs are incurred by other activities that do not carry a high environmental burden, such as administration, marketing and design. These are essentially labour costs. Moreover, circular measures generally result in increased labour activities like maintenance. The second reason is that neither are costs and environmental impacts directly proportional nor is price a precise indicator of environmental impact. For example, the textile component of the event tent, which was replaced for every use cycle, was more expensive but produced less environmental impact than the aluminium frame that was reused resulting in a larger environmental impact reduction than cost reduction.

The take-home message for companies is that there is a potential for reducing LCC for the manufacturer, and this potential can be enhanced by redesign, as in the case of the waste inlet, where design for maintenance significantly reduced maintenance labour costs. However, apart from looking at their own costs, it is very important for companies to assess how the customers' willingness to pay and costs are affected by 
prolonging the lifetime. They will not necessarily be interested in paying the same price for new and refurbished, as they may perceive the latter to be of less value.

Finally, the experience with case companies showed that prolonging the lifetime of passive durable products through PSS is relatively straightforward compared to other measures and can be done within the current socioeconomic context. Therefore, it can be considered a low-hanging fruit of the circular economy.

\subsection{Paper IV}

Kambanou, M.L., \& Sakao, T. (2020). Using life cycle costing (LCC) to select circular measures: A discussion and practical approach.

Background and motivation: This paper was published in a special issue "Advances in the Circular Economy", in Resources, Conservation and Recycling (RCR). The motivation for writing the article was firstly to use the learnings from using LCC to choose circular measures at the three participating companies in the "Circularis" project, and secondly, literature on LCC, to create a guideline for other companies to use LCC to inform such choices. Development ran from May 2017 to May 2019.

Summary: The implementation of circular measures by companies is still slow. Although there are many challenges, companies need help to select and define circular measures appropriate for their existing offerings and understand the financial outcomes of implementing them. To fill this gap, this research proposes to use LCC to guide companies in choosing circular measures. Therefore, two research questions are formed.

RQ1. What are the strengths and limitations of companies using LCC to select circular measures for their offerings?

RQ2. How can a guideline to choose circular measures using LCC be formulated?

Research Question 1 is answered based on the conceptual exploration of LCC as well as using LCC at the case companies and summarized in Table 7. It focuses on four topics: LCC's relevance and implementability to this level of decision-making, its comprehensiveness in covering financial information and its ability to provide an environmental or a circularity performance perspective. The outcome of the conceptual discussion is that LCC is well-suited to product or offering level decisionmaking, although it is just a method for calculating economic outcomes, so it needs to be integrated into decision-making processes. Furthermore, although profitability is a key factor for businesses, comparing the LCC of alternatives is only an adequate measure of profitability if they are functionally equivalent and of equal value for the customer; otherwise, revenue and potential customer costs need to be calculated. A principal limitation is that LCC is a poor indicator of environmental impacts due to market information failures, existence of externalities etc. Despite this, circularity, which is more narrowly defined as material use, can be understood by LCC, in this comparative context. "The difference in material cost between the alternatives" is used as a circularity indicator for the guideline. 
Table 7 Strengths and limitations of using LCC to select and implement circular measures Adapted from (Kambanou \& Sakao, 2020)

\begin{tabular}{|c|c|c|c|}
\hline & Strengths & Limitations & Considerations \\
\hline Relevance & $\begin{array}{l}\text { - Suited to product } \\
\text { level decision-making } \\
\text { - Familiar monetary } \\
\text { metric } \\
\text { - Broadens decision- } \\
\text { makers' perspective } \\
\text { - eLCC has a lifecycle } \\
\text { perspective and helps } \\
\text { avoid burden shifting }\end{array}$ & $\begin{array}{l}\text { - Only valid on the } \\
\text { micro level }\end{array}$ & $\begin{array}{l}\text { - fLCC for simplicity or } \\
\text { eLCC for a } \\
\text { comprehensive view } \\
\text { of the lifecycle } \\
\text { - Just an assessment } \\
\text { method so it needs to } \\
\text { be part of a } \\
\text { framework or a } \\
\text { guideline }\end{array}$ \\
\hline $\begin{array}{l}\text { Implement- } \\
\text { ability }\end{array}$ & $\begin{array}{l}\text { - Low to medium } \\
\text { complexity } \\
\text { - Limits knowledge and } \\
\text { time input } \\
\text { - Availability of data }\end{array}$ & $\begin{array}{l}\text { - Other stakeholder } \\
\text { cost data hard to } \\
\text { obtain } \\
\text { - Need to build cost } \\
\text { models } \\
\text { - Uncertain discount } \\
\text { rates }\end{array}$ & $\begin{array}{l}\text { - Discounting rates vs. } \\
\text { steady state }\end{array}$ \\
\hline $\begin{array}{l}\text { Financial } \\
\text { aspects and } \\
\text { profitability }\end{array}$ & $\begin{array}{l}\text { - Assessment of } \\
\text { profitability if } \\
\text { alternatives are } \\
\text { functionally } \\
\text { equivalent and of } \\
\text { equal value } \\
\text { - Focus on costs that } \\
\text { can be influenced }\end{array}$ & $\begin{array}{l}\text { - Uncertainty attached } \\
\text { to calculations }\end{array}$ & $\begin{array}{l}\text { - Revenues and } \\
\text { customer costs may } \\
\text { need to be included if } \\
\text { alternatives are not } \\
\text { functionally } \\
\text { equivalent and of } \\
\text { equal value } \\
\text { - Profit maximization } \\
\text { vs. profit optimization }\end{array}$ \\
\hline $\begin{array}{l}\text { Environmental } \\
\text { impacts }\end{array}$ & $\begin{array}{l}\text { - Can be used with LCA } \\
\text { and other } \\
\text { supplements, e.g., CE } \\
\text { hierarchy }\end{array}$ & $\begin{array}{l}\text { - Cannot } \\
\text { comprehensively } \\
\text { cover environmental } \\
\text { impacts due to market } \\
\text { and information } \\
\text { failures etc. }\end{array}$ & $\begin{array}{l}\text { - The offering's } \\
\text { physical } \\
\text { characteristics, e.g., } \\
\text { durable determine } \\
\text { the CE measures that } \\
\text { are applicable }\end{array}$ \\
\hline $\begin{array}{l}\text { Circularity } \\
\text { performance }\end{array}$ & $\begin{array}{l}\text { - Indicator of material } \\
\text { reduction in } \\
\text { comparative context } \\
\text { (eLCC) } \\
\text { - Employment indicator } \\
\text { - Includes labour costs } \\
\text { - Identification of cost } \\
\text { barriers to CE } \\
\text { measures, e.g., post } \\
\text { use transport }\end{array}$ & $\begin{array}{l}\text { - Upstream costs are } \\
\text { not detailed } \\
\text { Only relevant for } \\
\text { comparison of } \\
\text { alternatives }\end{array}$ & $\begin{array}{l}\text { - Categorization } \\
\text { required to support } \\
\text { cost exchangeability } \\
\text { of materials and } \\
\text { energy costs with } \\
\text { labour costs }\end{array}$ \\
\hline
\end{tabular}

The guideline was based on the learnings from choosing circular measures with the case companies, which are also described as well as the outcomes of the discussion on strengths and limitations. It guides companies towards measures at the top of the 
circular economy hierarchy, which hold the highest potential of environmental improvements, while taking into consideration choices that are suitable to their products' characteristics. LCC is used to check the profitability and provide input to design by identifying cost barriers and parts to be prioritized for recirculation. In addition, because labour costs are included in LCC, it can help companies understand and visualize the underlying circular economy $(\mathrm{CE})$ principle of exchanging material costs with labour costs. Using LCC to choose appropriate circular measures was perceived as relevant and informative by the participating companies.

\subsection{Paper V}

\section{Kambanou, M.L. (2020). Life Cycle Costing: Understanding How It Is Practised and Its Relationship to Life Cycle Management-A Case Study.}

Background and motivation: This paper was published in Sustainability, the same journal as Paper III. The data used in the article was collected between June 2015 and May 2018. The article was written later, between August 2019 and April 2020. The motivation was to explore some of the initial observations made in Paper II in greater depth and to try to use theory to understand some observations the author had made without explicitly researching them, such as tailoring LCC and conflicting scopes suggested by participants. Once the analytical lens of practice theory was chosen, the data was revisited and analysed based on that lens.

Summary: This work departs from the observation that LCC is not widely adopted, that practitioners excessively tailor LCC methods and that LCC is used for LCM but not developed with LCM in mind. The introduction of LCC in a company in order to support LCM is analysed using a practice theory analytical lens. Following are the research questions:

RQ1: How can a lack of adoption and tailoring of LCC methods be understood to be the result of contestation and conformity between LCC practice and extant practices?

RQ2: How does the practice of LCC propel an emergent LCM?

LCC and LCM are viewed as practices, that is routinized sets of bodily and mental activities (Reckwitz, 2002). Although a unanimous view of practice theory does not exist, the understanding in this research is that new practices such as LCC will contest extant practices.

To answer the first research question, the research presents based on thick descriptions that are interpretative rather than just descriptive, the various ways that LCC was found to both contest and conform to extant practices. This affects methodological choices, such as what lifecycle stages are included or what data is used to estimate a specific cost element. Ultimately, practitioners' methodological choices are not governed solely by logic, but also influenced by the routine activities their minds and body perform. These practices are the crossover of a variety of elements, such as material and symbolic objects or collective knowledge; for example, that the path towards success is the outcome of continuous improvement in the domains of engineering. This provides some explanation behind the tailoring and uptake of LCC 
methods. Some of these choices can have a profound influence on the results, for example, how to estimate the value of a piece of equipment returning from a contract to be remanufactured.

To answer the second research question, a primarily theoretical exploration backed up with evidence from the case study was conducted. This focused on analysing how the contestation and conformity of LCC with extant practices can propel an emergent LCM, which is not yet a generalised and established practice. LCC was found to positively propel LCM by initiating lifecycle thinking and employing a familiar monetary value, and its practice can be a forum to connect people and build up networks. It may lead though to a narrower understanding of the term lifecycle because LCC is usually focused on the costs that a company is responsible for, potentially resulting in the sustainability focus of LCM being undermined. Additionally, because LCC focuses on real cash flows, resources are in focus and not environmental or social impacts, which do not translate into cash flows. This can also potentially undermine sustainability focus. Finally, Table 8 presents how these findings and the conceptualization of LCC as a practice can inform future LCC methodology development and use.

Table 8 Implications of conceptualizing LCC as a practice on future methodological development Adapted from Kambanou (2020b)

Findings

1 LCC is tailored based on the outcome of its contestation and conformity with extant practices

2 LCC is an emergent practice

3 LCC becomes practice through repetition

\section{Considerations for LCC method development}

Limit flexibility of LCC method on key issues (especially important if LCC is used for LCM)

Include different LCC stages or levels that a company advances to over time

- Engage individuals repetitively during the LCC process

- Disseminate intermediary LCC results

4 Individuals practice LCC differently - Include individuals from across the lifecycle influenced by the extant practices they perform

- Clearly define key concepts, e.g., lifecycle

- Carefully match appropriate individuals to LCC activities

- Carefully consider how extant practices might constrain an individual from following the LCC method

5 For traditional product manufacturers, the "product" is in the centre

Emphasize the service aspect and provide detailed advice on how to include it

6 The perception of the "company" constrains the lifecycle perspective 
7 Reports and presentations of results - Emphasize wide dissemination of results are important objects for reproducing $L C C$ practice

- Include opportunities for crossdepartmental discourse about results

8 Demonstrating plurality of the lifecycle supports a deeper

- Do not encourage generic LCC cost models understanding of the lifecycle

9 Limitations of using precise data when conducting LCC

- Explain potential data limitations

- Provide good examples of companies who have successfully used LCC despite data limitations

10 Limitations of using extant costing - Explain current costing methods' limitations methods when conducting LCC, e.g., • Suggest relevant costing methods "book value" vs. "market value"

11 Common words are ascribed Clearly define key concepts, e.g., lifecycle diverging meanings

12 Discussions are crucial to making Include discursive activities methodological decisions for LCC

$13 R \& D$ engineers have the capabilities Include $R \& D$ engineers if relevant to perform LCC

\subsection{Paper VI}

Kambanou, M.L. (2020). Additional uses for life cycle costing in life cycle management. Procedia CIRP, 90, 718-723.

Background and motivation: This paper is peer-reviewed and published in Procedia CIRP, similarly to Paper I. The motivation behind this paper was to formulate and test some of the ideas, which were presented in this thesis to an audience to receive early feedback and to add some of the learnings from the joint project with Company $\mathrm{X}$, which had not been covered in previous publications. More specifically, this paper elaborates on some concrete solutions that, using LCC to overcome the challenges presented in Paper II, lead to "identify improvement areas in information systems". It also uses a slightly different analytical lens - "four modes of knowledge conversion" by Nonaka and Takeuchi (1995) - to present another perspective on a portion of the findings presented in Paper V. Another use is also described.

Summary: The paper aimed to explore within a case study context additional ways of using LCC to improve LCM. By "additional uses" what is meant is uses that go beyond the well-known objectives of comparing alternatives and identifying cost uncertainties and hot spots. These additional uses are:

- identify improvement areas in formal information systems

- $\quad$ support knowledge creation and knowledge sharing 
- identify and quantify mismatches in financial incentives between company departments or daughter/sister companies or supply chain actors.

Although many authors describe challenges with finding adequate costing data and calculating estimates, in the case study this lack of data was systematically recorded and then transformed into a list of requirements for information systems. These were then transformed into a list of recommendations on how to meet those requirements. Therefore, an additional use is identify improvement areas in formal information systems.

The second additional use pertained to tacit and explicit knowledge that was both created and shared within the LCC process. At the case company, three knowledge conversion processes were observed, while the members of the case company either discussed methodological choices and were presented with intermediate and final results: "Externalization", where hunches became precise costs estimations; "Combination", where known costs were combined to create a different unknown lifecycle view; and "Internalization", where information shared in discussions was individually interpreted.

Finally, LCC was found to be useful in identifying tensions and conflicting financial incentives between departments and groups of people within the organization as well as along the supply chain. Some previous research had documented such tensions, but this work demonstrated how LCC could be useful in identifying them. 


\section{DisCUSSION: IDENTIFIED USES OF LCC}

This chapter answers the first research question. It starts with a brief overview of the identified uses for LCC to support companies in selecting and implementing circular measures and then discusses each one and how it relates to other literature.

\subsection{Overview}

This research departed from the hypothesis that LCC can be a useful method to support existing companies in selecting and implementing circular measures for their offerings. Although the LCC objective is to deliver financial information, it transpires that the attendant findings together with the process of conducting the LCC can support companies in more ways than one. Four different types of uses for LCC were identified: "comparing alternatives", "providing input to design", "understanding and overcoming challenges" and "propelling an emergent LCM". These are presented in Table 9 together with their sub-categories and the related Papers.

Table 9 The LCC uses identified in this research

\begin{tabular}{lll}
\hline Main use & Specific focus & Contributing Publication \\
\hline \multirow{2}{*}{$\begin{array}{l}\text { Comparing } \\
\text { alternatives }\end{array}$} & $\begin{array}{l}\text { From a financial perspective } \\
\text { From a circularity performance } \\
\text { perspective }\end{array}$ & Papers I, IV, III \\
\cline { 2 - 3 } & $\begin{array}{l}\text { From a parallel financial (LCC) and } \\
\text { environmental perspective (LCA) }\end{array}$ & Paper III, IV \\
\hline $\begin{array}{l}\text { Providing input to } \\
\text { design }\end{array}$ & For a product and/or service & Papers I \& IV \\
\hline & $\begin{array}{l}\text { Alignment with the changing } \\
\text { incentive structure }\end{array}$ & Papers II, V \& VI \\
\cline { 2 - 3 } $\begin{array}{l}\text { Understanding } \\
\text { and overcoming } \\
\text { challenges }\end{array}$ & $\begin{array}{l}\text { Understanding uncertainty and } \\
\text { identifying improvements in } \\
\text { information systems }\end{array}$ & Papers II \& VI \\
\hline $\begin{array}{l}\text { Propelling an } \\
\text { emergent LCM }\end{array}$ & Desired and undesired propulsion & Paper V \\
\hline
\end{tabular}

There is to some extent a progression to the identified uses starting from using LCC as a metric, which quantifies and measures, to its use as a practice, which influences people, and other practices. The first use "comparing alternatives" relates to measuring the difference between business-as-usual to a more circular offering in order to make a decision, for example, to proceed or not, whereas "providing input to design" relates to using the information of a stand-alone LCC to design the more circular offering. The third use, "understanding and overcoming challenges", is learning-oriented and focuses on how both the process of conducting LCC but also 
the information obtained can help companies deal with mind-set, cultural, administrative and other challenges relating to a circular economy. The fourth use relates to the effect that LCC has or its ability to propel LCM.

This variety of uses was elicited by using different conceptualizations of LCC, for example, as a metric (Paper III) and, as a practice (Paper V), as well as considering companies from a broader set of perspectives than that which Morgan (2006) would call a mechanistic view, for instance, as bundles of practices or as political systems (see Section 3.1).

The uses are not mutually exclusive. For example, Company $\mathrm{X}$ primarily wanted to identify cost drivers across product ranges. However, they also wanted companywide dissemination activities to include persons who would not directly have use of the LCC results, in order to "disseminate" and "educate" them. This shows that the project leaders at Company X intuitively understood, and wanted to use LCC to "understand and overcome challenges" as well. Therefore, although LCC is primarily used to compare alternatives and provide input to design, when conducting LCC, it can or will have other uses, regardless of how aware the practitioners are that they exist. By being aware of them companies can maximize the support they elicit from using LCC.

\subsection{Comparing alternatives}

\section{Comparing alternatives from a financial perspective}

"Comparing alternatives from a financial or economic perspective" is a welldocumented use in academic literature because it is a key reason LCC was developed (Asiedu \& Gu, 1998; Woodward, 1997). This thesis elaborates on the exiting knowledge of LCC as a metric of financial comparison by using it in the context of comparing a business-as-usual alternative with a more circular one.

LCC is found to be relevant to product-level decision-making in the context of the circular economy. Similar to other authors, such as Allwood et al. (2011) and Nußholz, Rasmussen, Whalen, and Plepys (2020), this research found that economic benefits from circular economy are often not easy to obtain (Paper I \& III) and that making circular offerings profitable is a major concern for companies (Paper IV). Some reasons behind this are that costs shift between different constituents of the value chain, for example, from customer to manufacturer, so that retaining the value of products is often labour-intensive and thus costly, and large investments are required. LCC was found by the companies involved to be useful in capturing these changes to costs and profits between business-as-usual and the more circular offering along the lifecycle and thus useful to decision-making (Paper IV). Moreover, the literature review also revealed LCC to be a method of choice in PSS research (Paper I). LCC's strength lies in the monetary unit, which is familiar and easily understood by practitioners as well as in the lifecycle perspective that it offers. In addition, in terms of implementation, LCC has medium complexity and can make use of existing data (Paper IV), thus confirming the reasons for its initial selection in this research. 
These findings are in line with recent publications, for example, Jansen, van Stijn, Gruis, and van Bortel (2020); Kerdlap and Cornago (2021), who stress LCC's potential in circular decision-making with Bradley et al. (2018) going a step further to describe LCC as the primary cost-engineering tool for a circular economy. This thesis, however, identifies additional methodological considerations associated with using LCC to compare a business-as-usual alternative with a more circular one from a financial perspective, further explained in Chapter 7.

\section{Comparing alternatives from a circularity performance perspective}

Using LCC to compare business-as-usual to a more circular offering from a circularity performance perspective has not been explicitly explored in the literature. However, there has been a call for more research on circularity indicators and ways of assessing circularity performance (Saidani, Yannou, Leroy, \& Cluzel, 2017). Elia, Gnoni, and Tornese (2017) identified only three circularity performance indicators at the product or single company level, and more recently, Kristensen and Mosgaard (2020) identified thirty such indicators, but still concluded that single companies need more support in measuring and documenting progress towards a circular economy. With regard to this thesis, Companies $\mathrm{A}, \mathrm{B}$, and $\mathrm{C}$ also stated that measuring and documenting progress towards a circular economy was of interest to them for both motivational and guidance purposes. Therefore, a further focus of this research is to explore whether the pertinent elements of LCC could be used as indicators of the comparative circularity performance of business-as-usual and a more circular offering.

First of all, neither LCC nor eLCC can be used to reliably or accurately measure environmental impacts across the lifecycle (Gluch \& Baumann, 2004; Hunkeler et al., 2008). The most reliable tool for assessing environmental impacts at the product level in a circular economy context is LCA (Scheepens, Vogtländer, \& Brezet, 2016; Walker et al., 2018). However, LCA is relatively complex to perform. Therefore, companies need simpler circularity performance indicators that help them evaluate progress towards a circular economy.

Circularity performance, even on the product level, is not well defined and changes according to how a circular economy is conceptualised or what strategies are covered, for instance, recycling, or the context, for example, the specific sector (Saidani, Yannou, Leroy, Cluzel, \& Kendall, 2019). Measuring and tracking physical resource flows seems to be inherent to many indicators, the main argument being that the circular economy aims at reducing the flow of new resources into the economy but at the same time keeping the existing ones (Kristensen \& Mosgaard, 2020).

In Paper IV, circularity performance at the product level is defined as a change in materials needed to provide a unit of function from a lifecycle perspective. The underlying premise of circularity in this statement is limited to material ${ }^{j}$ flows. These material flows can be measured in terms of costs. Therefore, when the scope for the LCC includes all actors and is associated with a functional unit, i.e. it is an eLCC, then

\footnotetext{
${ }^{5}$ Material can mean different things in different contexts. Here it includes not only raw material, but also manufactured components.
} 
the LCC results pinpointing "the difference in material costs between the two alternatives" can act as an indicator of comparative circularity performance for the alternatives. The comparison of material costs indicates the reduction or increase of material needed to fulfil the same unit of function expressed in terms of economic value. One type of circular measure, namely, replacing virgin materials with recycled materials, will not be identified by this indicator if the recycled materials are of an equal or higher price to virgin materials, which is highly unlikely unless it is a legal requirement.

For companies adopting LCC to compare the financial perspective, the use of the above indicator, namely "the difference in material costs between the two alternatives", will save them time and effort because they will be able to fulfil "two needs with one deed". Companies A, B and C found it a practicable indicator that did not require massive input to calculate and provided them with a clear goal for decision-making, namely that:

\section{material costs in $B A U$ - material costs in circular offering $>0$}

This is not the first product-level circularity performance indicator to base itself on the cost of materials (Kristensen \& Mosgaard, 2020). For example, the "ratio of recirculated economic value to total product value" is suggested by Linder, Sarasini, and van Loon (2017), arguing that costs are one of the best available indicators of material scarcity even though limited by market failures. Another example comes from Di Maio, Rem, Baldé, and Polder (2017), who propose to measure circular economy in terms of the market value of "stressed" resources.

\section{Comparing alternatives from a parallel financial (LCC) and environmental perspective (LCA)}

Despite LCA and LCC having initially been developed independently of each other, they are frequently used in conjunction to understand the environmental and economic perspective in parallel (Finnveden \& Moberg, 2005; Hoogmartens et al., 2014). The reason for specifically using LCA is that it is one of the most accurate tools for calculating the environmental impacts of a product or offering (Baumann \& Tillman, 2004), and LCC and LCA have similarities in their set-up that make them relatively complementary. Therefore, this use of "comparing alternatives from a parallel financial (LCC) and environmental perspective (LCA)" is familiar from the outset, its value having subsequently been confirmed through the multiple case study. It is worth noting, however, that Companies A, B and C said they did not necessarily always need the detail and accuracy of an LCA; in some cases, knowing the circularity performance is enough. To align LCC and LCA is not entirely straightforward (Neugebauer et al., 2016; Settanni, 2008), and the contribution of this thesis with respect to this practice is in the methodological considerations of using LCC and LCA in parallel as discussed in Chapter 7 . 


\subsection{Providing input to design}

When LCC is used to evaluate the relative costs of two or more design alternatives, then it is used in the same capacity as detailed in the previous chapter, namely "to compare alternatives". A further use is discussed in this chapter: companies use LCC to generate rather than evaluate design ideas. This is not a novel use. For example, the application guide to lifecycle costing developed by IEC (2017) describes using LCC to identify cost hotspots or drivers that should be targeted for optimization, and Knauer and Möslang (2018) found that the greatest benefit of LCC is in identifying cost drivers and thus improvement potential within an offering's lifecycle. The novelty in this thesis lies in putting this use into the specific context of the selection of circular measures and providing input to the design of circular offerings.

As presented in Paper IV, the LCC of the existing offering or business-as-usual can be used at the stage of initial ideation or formulation of the circular offering in order to guide practitioners towards design choices that have a higher likelihood of making the circular offering financially viable. It is based on the premise of exchangeability, meaning cost elements are exchanged to fulfil the same function (Sakao \& Lindahl, 2015). This can be exemplified in Figure 3.

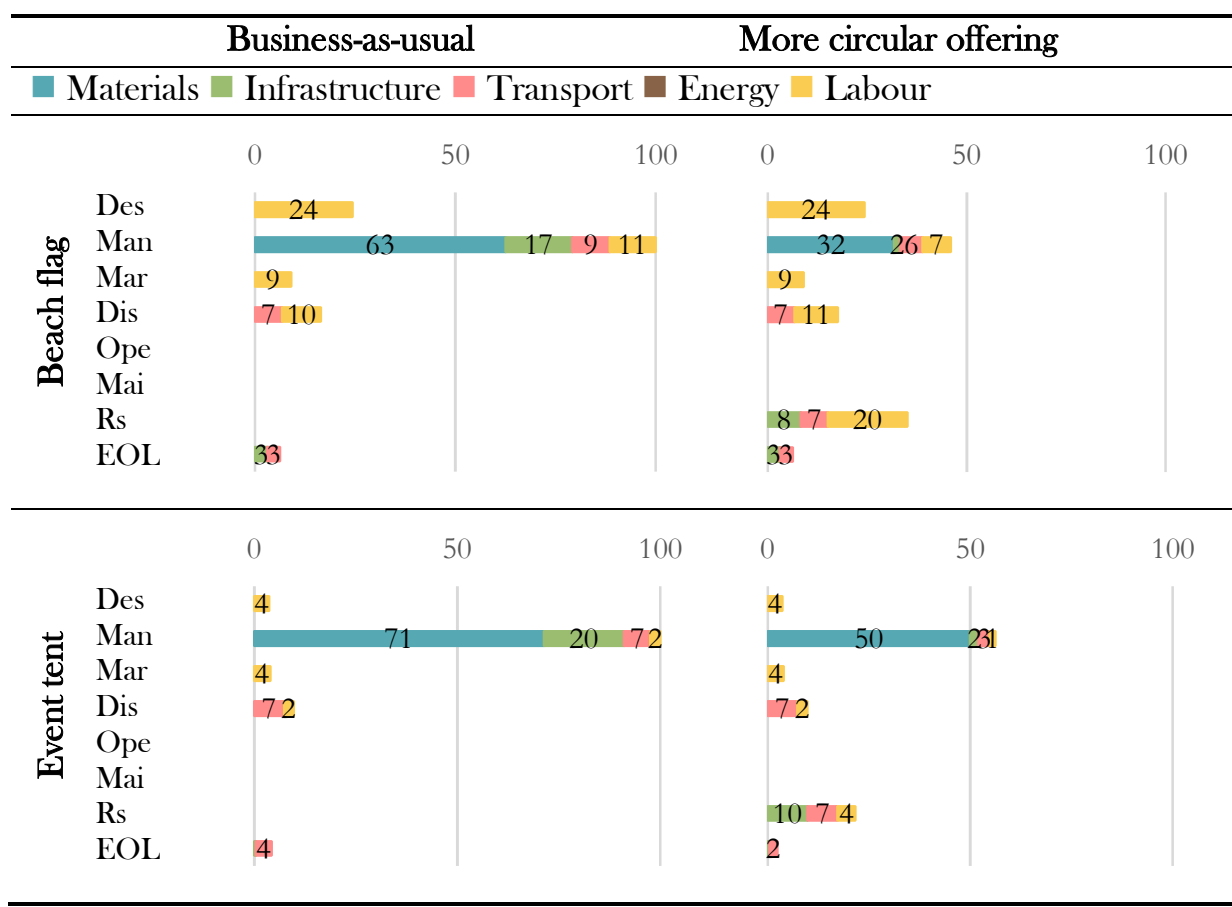

Figure 3 Results for LCC of beach flag and event tent before and after implementing the circular measure (Company A)

Based on Kambanou and Sakao (2020) / Design (Des), Manufacturing (Man), Sales and Marketing (Mar), Distribution (Dis), Operation (Ope), Maintenance and Repair (Mai), Refurbishment and Remanufacture (Rs) and Recycle and Recover (EOL)

Cost data have been agglomerated due to confidentiality and rounded to the nearest integer 
By identifying cost drivers, in other words, costs that have a major influence on the LCC results of the business-as-usual, practitioners can try to exchange them with different costs that fulfil the same function. More specifically, practitioners should aim to replace material and energy costs in the business-as-usual alternative with labour costs in the circular offering. For example, the LCC results of Company A's businessas-usual showed that direct materials in manufacturing are major cost drivers (Figure 3) for both the event tent and the beach flag. They sought to replace those costs with labour costs associated with collecting, examining and cleaning used components as well as administrating the process.

However, this also incurred other costs, such as transport and infrastructure costs. In order for the circular offering to be financially viable, the following should be true: avoided costs from production > induced costs from treating returned product. This should be a target when exchanging costs. To do this, companies should firstly select the durable material components found in the LCC to have the highest production cost to keep in circulation. An example of this is as follows: Company B choose to recirculate the body of the recycling bin and replace its lid, and to recirculate the wooden parts of the lockers and repaint the doors (Figure 4).

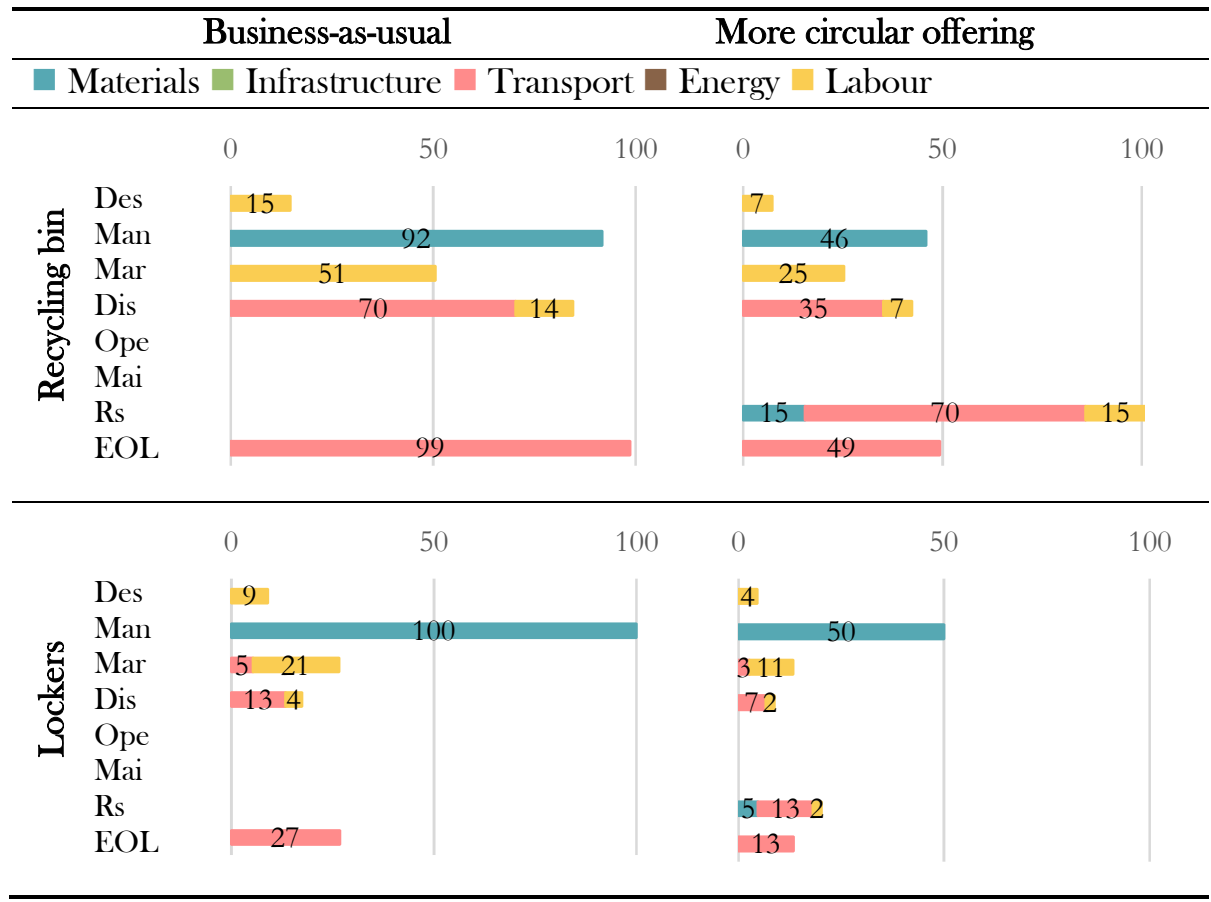

Figure 4 Results for LCC of recycling bin and lockers before and after implementing the circular measure (Company B)

Based on Kambanou and Sakao (2020) / Design (Des), Manufacturing (Man), Sales and Marketing (Mar), Distribution (Dis), Operation (Ope), Maintenance and Repair (Mai), Refurbishment and Remanufacture (Rs) and Recycle and Recover (EOL)

Cost data have been agglomerated due to confidentiality and rounded to the nearest integer 
Secondly, companies should identify costs from treating the returned products that need to be optimized. For example, the LCC of the recycling bin shows that "distribution" costs in the business-as-usual almost outweigh "manufacture". Since most circular measures require return logistics and the transport of parts and people, then, for the circular measure to be financially viable, it will be crucial to optimize “distribution costs" generally and "transport" costs specifically.

Apart from these above-detailed ways of using LCC to provide input to the design of the circular offering, it can also be used on an offering to which a circular measure has already been applied to improve or optimize it. This is similar to the uses described in IEC (2017) and builds upon cost driver identification. For example, Company C had already introduced maintenance to the door of the inlet as a circular measure prior to joining this research. As identified in the LCC of the business-as-usual alternative (Figure 5), maintenance associated with replacing a broken door incurred a high labour cost. Therefore, with design-targeted optimizing maintenance costs for the door, the outcome is that the new door requires less material and is quicker to replace.

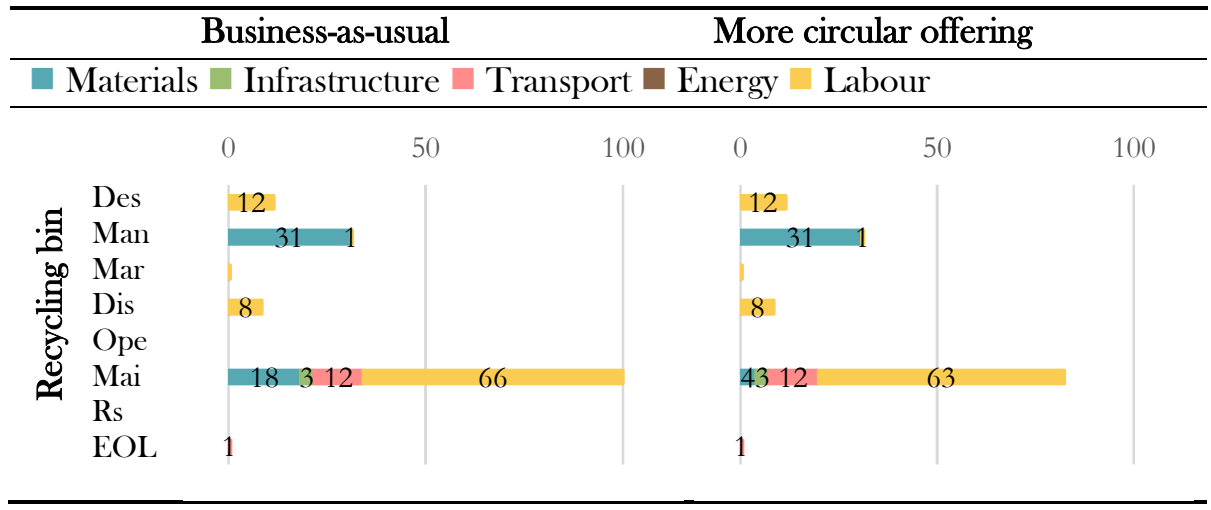

Figure 5 Results for LCC of the inlet before and after redesign (Company C)

Based on Kambanou and Sakao (2020) / Design (Des), Manufacturing (Man), Sales and Marketing (Mar), Distribution (Dis), Operation (Ope), Maintenance and Repair (Mai), Refurbishment and Remanufacture (Rs) and Recycle and Recover (EOL)

Cost data have been agglomerated due to confidentiality and rounded to the nearest integer

The publications pertaining to the use of LCC in the context of design and the circular economy focus on using LCC as an evaluation tool of design ideas and not for ideation (see, e.g., Zhang et al. (2018) and Giorgi, Lavagna, and Campioli (2019). Thus, there is limited literature with which to compare these findings.

Even though LCC can provide input to design, it needs to be integrated into an overall design process. It does not provide design alternatives; these are given by connecting LCC results to circular measures within the design process. Therefore, a design process or guideline was created as part of this research and is presented in Paper IV. In the guideline, LCC of the business-as-usual alternative is first used to provide input to the design of the circular offering, and then LCC of the business-as-usual and the more circular offering are compared to understand the comparative financial and 
circularity performance. Although a lack of tools and guidelines to help companies design business models or circular offerings is noted by Bocken et al. (2019), new guidelines are emerging to fill this gap, for example, Willskytt and Brambila-Macias (2020). The guideline presented in Paper IV is one of the few that is based on financial criteria for decision-making.

Another way LCC can support design concerns the identification of cost drivers that are relevant across product ranges. Although LCC focuses on one product, companies have a large variety of products and might be interested in finding circular measures that can be applied across product ranges in order to build "economies of scale". The business-as-usual alternative for Company A's beach flag and event tent have a similar cost structure (Figure 3). This means that it is likely that the same circular measure can be applied in both cases. For Company X, LCC costing was conducted for five different product ranges, as well as one to four customer segments. This made it possible for patterns to emerge both within and across product ranges, highlighting improvement opportunities to the pre-existing circular measures that could be relevant to more than one product range and, consequently, thereby facilitating prioritization. Given that there are large investment costs involved in many circular measures, for example, starting remanufacturing, economies of scale may be the solution to making them viable (Mont et al., 2017).

\subsection{Understanding and overcoming challenges}

Companies are faced with a large variety of both internal and external challenges when transitioning to a circular economy (Mont et al., 2017; Werning \& Spinler, 2020). LCC is found to help companies understand and learn about some of the challenges they face, thus helping them build up knowledge and capabilities to overcome them. LCC is also found to provide a point of departure for discussing the challenges. Although improving awareness, building knowledge and other learning outcomes are listed as uses or aims in the introductory chapters of LCC methodologies, for example, (DLM Consulting, 2007), IEC (2017), they are seldom elaborated on. However, in this thesis, such uses of LCC are discussed and anchored in the circular economy and PSS contexts.

\section{Alignment with the changing incentive structures}

Implementing circular measures may mean adding services, offering products-as-aservice and embarking on remanufacturing. As a result, the cost and revenue structures for the company change significantly, creating a different set of economic drivers and incentives to business-as-usual (Mont et al., 2017). This change was verified in all the cases. A key finding of the research at Company $\mathrm{X}$ is that individuals struggled with understanding this change, both in terms of how costs and revenue change and in how that influences Company X's incentives (Paper II). Some people were unaware that this change was taking place, others were unmindful of what specifically was changing and others were unsure of the magnitude of the change. As detailed in Paper II, this led to a problematic set of circumstances in the form of a misalignment of the 
company, departments and individuals with the changing incentive structures. This is exemplified in the following quote:

\section{Do you know who every salesman's best friend is. "Bill Spare-parts". They still don't get that it is a cost for us. (PSS \& Leasing Manager, Company $\mathrm{X}$ )}

The speaker is referring to an individual not understanding the new structures and incentives. Another example from Company $\mathrm{X}$ is the misalignment between the financial incentives of different departments (Paper VI). For example, sales personnel might aim to "sell" highly customized offerings because it brings in higher revenue and thus higher commission for the sales team, whereas selling a less customized-or rather more standardized-offering would bring in higher revenue to the remanufacturing department because it has a higher potential of being sold on the second-hand market. The standardized offering would also result in higher revenue and profit from a lifecycle perspective. This misalignment at Company $\mathrm{X}$ was found to be partially brought about by another challenge: a product-centred mind-set that partially blinded individuals to the new business case (Paper II).

Martinez, Bastl, Kingston, and Evans (2010) also found that a strongly embedded traditional manufacturing culture in established companies hinders the transition towards PSS. Similarly, Kirchherr et al. (2018) in a survey of 153 exiting businesses found that their most pressing barrier to transitioning to a circular economy is a hesitant company culture, and Rizos et al. (2016) also mention lack of awareness and information as barriers for SMEs. Misalignment with the changing incentive structures is different from the challenge of not having a financially viable circular economy business case, the latter with which the literature has mostly concerned itself, for example, Govindan and Hasanagic (2018).

LCC can enable the overcoming of this challenge of mind-set and culture as well as the challenge of alignment with the changing incentive structures in two ways. Firstly, the process of conducting the LCC can provide a forum for discussing costs, revenues and incentives from a lifecycle rather than a departmental perspective. To do this, a multidisciplinary team needs to be part of the LCC scoping and provide feedback on model building and cost estimation (Paper V). Along similar lines, Gluch et al. (2018) found the LCC in buildings projects was used to facilitate conversations around incentives for renovation. Secondly, LCC results can help companies understand the new incentives and new business case by translating them into the language of money. More specifically, through data displays that are widely disseminated, LCC results can concretize the lifecycle idea, enhance individuals' perception of the scope of company responsibility over the lifecycle, visualise the changing incentive structure in terms of costs and revenue and highlight the importance of services (Paper V). These findings are supported by the work of Knauer and Möslang (2018) who, based on a survey of German companies, found that companies have cognition related goals when adopting LCC such as increased cost awareness and transparency, and cost driver identification. Moreover, the companies perceived that they obtain many benefits from using LCC in relation to those goals (ibid.). 


\section{Understanding uncertainty and identifying improvements in information systems}

Normally, companies have good control over the manufacturing, sales and distribution phases and can calculate their costs with high accuracy. However, once products enter their operational phase, there are unforeseeable external parameters that start to affect the operation, maintenance and remanufacturing costs. As mentioned, many circular measures involve companies taking over these costs that are highly uncertain both in terms of source and magnitude. This uncertainty has been well-documented in the literature (Paper I). This uncertainty was observed at Company X, and the following quote sums it up nicely:

For the same contract, for the same customer, for the same type of product at two sites with a similar environment, the profits can differ greatly. Firstly because of the [state of] product itself, secondly because of how the service technician behaves and thirdly because of how the person operating it behaves, this information isn't collected anywhere and doesn't show in our cost models, and it is very hard to put this in money. (Senior Manager Business Solutions, Company $X)$

What is clearly expressed by the interviewee, however, is not common knowledge in Company X. LCC provides a structure for documenting the uncertainty. Additionally, this research uncovered that LCC is a strong tool for communicating and helps individuals understand, through data displays, this uncertainty (Paper II \& Paper V). At Company $\mathrm{X}$ non-generic LCC results, that is, specific configurations of similar products deployed at specific customers, were presented. The diversity of the LCC results, including size, dispersion over the lifecycle stages and profit, emphasized plurality, context specificity and uncertainty of costs. This also initiated a discussion of whether the lifecycle of PSS can be accounted for and managed through generic models or whether case-by-case decisions should be the focus.

LCC can also help identify and overcome another challenge connected to uncertainty. Epistemic uncertainty can result from a lack of data from a new offering, but since LCC revealed that uncertainty derived from a lack of data due to the prevalence of product-focused information and costing structures, this also means that there is a lack of appropriate structures with which to populate data (Paper II). LCC can help overcome this challenge by identifying areas of improvement at various levels of application in information systems (Paper VI). Using LCC for this purpose was not identified as a suggestion in other literature.

\subsection{Propelling an emergent life cycle management}

When systematically reviewing the literature, Roda, Macchi, and Albanese (2020) found that total cost of ownership (TCO), a variant of LCC with a single-actor perspective, supports decision-making in asset-LCM by way of comparing alternatives or providing input to design. These are the most frequently or even exclusively discussed uses of LCC and its variants in academic literature. In this thesis, though, a 
different type of use is identified. By conceptualizing companies as bundles of practices (Nicolini, 2013), LCC is seen as a new practice whose introduction in a company will contest and conform with extant practices. The outcome of this contestation and conformity, as well as the activities needed to perform LCC, will influence the practice of LCM, propelling it towards desired or less-desired ways of practice. Here, both LCC and LCM are conceptualized as emergent, that is, how they are practised and understood in a company's changes over time. LCM is thus viewed as a practice situated in other practices that emerges over time. This use is a direct outcome of Paper V, with no cross-pollination with other parts of this research.

At this point, it may be useful to remind the reader that LCM in this thesis refers to managing offerings across the lifecycle towards the normative goal of positive environmental outcomes. LCC at Company $\mathrm{X}$ was found to propel towards LCM in a positive way. Firstly, after disseminating LCC results, the ensuing discussions were framed by a common understanding of "an eminent need to manage costs and profits across the lifecycle through LCM.” Thus, LCC created legitimacy for LCM and spread the notion of lifecycle thinking. Secondly, LCC contests various elements of extant practices, and by doing so, aligns or prepares them for LCM. To this end, LCC introduces more cooperation and discussion between people from different departments and initiates a process of developing a common understanding of the business cases, which is critical for LCM. It can also help with networking and identifying individuals who can take LCM further.

There are also aspects of LCC that make it more relatable than other lifecycle practices. The first is the monetary metric, which is familiar and that helps create engagement, or, as a member of the staff at Company $\mathrm{X}$ said:

\section{...we come back to the same point: money talks. (Product Group Manager at Company $X)$}

Also, LCC can be connected to other crucial practices, such as product development. This makes LCC a very useful lifecycle practice to introduce at the initial and intermediary stages of an emergent LCM that matures over time.

There were two ways that LCC was observed to propel LCM away from its idealized practice. The first way concerns the understanding of a lifecycle. Due to the versatility and methodological freedom in LCC, individuals can put their own interpretation on the boundaries of the lifecycle and the activities to be included, resulting in a narrow understanding of the lifecycle concept. Secondly, due to LCC's focus on costs and materials, it can propel an understanding of LCM centred on resource or material efficiency, which does not include the breadth of environmental burdens associated with an offering. Thus, LCC can propel towards a narrower understanding of LCM and potentially negate LCM's goal of environmental improvements by making space for burden shifting and sub-optimization or exclusion of crucial environmental burdens.

Although no other research was identified to discuss the relationship between LCM and LCC as practices, some publications do touch upon the more subtle effects, which go beyond decision-making between LCC, LCM and other practices. De Giacomo, 
Testa, Iraldo, and Formentini (2019) describe how public administrators' experience with green public procurement stimulates LCC learning and capabilities. Additionally, Nilsson-Lindén et al. (2020) conceptualized LCM as emergent and situated in lifecycle practices but did not include LCC explicitly, and, therefore, this thesis confirms their findings and demonstrates their applicability to LCC as well. 


\section{DisCUSSION: REASONS FOR NOT USING LCC}

One reason that $\mathrm{LCC}$ is not used is that it is not relevant in a given decision-making context. Putting that reason aside, the focus here is on identifying reasons that it is not used or not used as prescribed when it is relevant.

One of the main findings in Paper $\mathrm{V}$ is that a lack of adoption and tailoring of LCC can be the result of its contestation and conformity as a new practice with extant practices. According to some researchers using practice theory, new and innovative practices contest extant practices, and the outcome of this contestation will influence if and how they are practised in an organization (Nicolini, 2013; Palo et al., 2019). The elements of practice defined by Reckwitz (2002), including mental and bodily activities, collective knowledge in the organization, discourse, symbolic and material objects, other practices performed by individuals and processes, were found to influence methodological decisions and how LCC was practiced at Company X. For example, the collective knowledge in the company manifests itself as an expected level of control and a desire for countable knowledge derived from precise and reproducible measurements. However, due to the current lack of data, LCC cannot conform to this expectation, possibly leading to its rejection either expressed or inwardly rejected. Alternatively, it can result in choosing inappropriate data ${ }^{6}$, that is, not the data that fits the objective but the data that is known to the practitioners to be precise or that they have agreed to use in other cost accounting activities.

It is known that LCC is not widely used and that when it is, it is usually based on a company-developed model but few researchers have engaged in investigating the reasons (Hochschorner \& Noring, 2011; Korpi \& Ala-Risku, 2008) or have been discouraged from creating new methods and models. Some reasons that come from the building and construction industry are a lack of data, standard methodologies, customer demand, cost and uncertainty estimation methods, software and understanding and awareness of LCC's methods and benefits (Higham et al., 2015; Opoku, 2013). LCC was also found to be time-consuming and complex (ibid.). Although these are valid reasons, only the final point comes close to understating lack of adoption and tailoring as the outcome of a complex social process as in Paper $\mathrm{V}$.

However, D'Incognito et al. (2015) found that although technical and financial barriers are important, the most vital is organizational culture, the collective mind that distinguishes a group. Gluch et al. (2018) determined lack of data, knowledge and skills as a barrier, but then go on to say that effort is not made to build them up, so they lie fragmented and dispersed. They also found that LCC adoption is also affected by partially competing institutional logics such as long-term planning and short-term project groups. They suggested that companies should aim to "establish a culture of continuous use".

Parallels can be drawn between the work by D'Incognito et al. (2015), Gluch et al. (2018) and Paper V. Firstly, there is a lot to learn about why LCC is not used or not

${ }^{6}$ An example is provided in Section 4.4 of Paper $\mathrm{V}$ concerning estimation of residual value. 
used as prescribed, and research should draw on the social sciences to explore this question. The answer is most probably not a lack of detailed LCC methods. Secondly, the research indicates that companies should focus on and need help in moving LCC from being a niche, one-off activity to a routine practice. Thus, the conceptualization in Paper V of LCC as an emergent practice that is established over time is supported. Rather than handing over method manuals that are "dispersed" by some automated, magic process through an organization, research may have to provide more structured support so that LCC becomes established practice. Companies should also have the same approach, so that LCC becomes routine. 


\section{Discussion: Methodological CONSIDERATIONS OF LCC}

This chapter answers the third research question. It starts with an overview of the identified methodological considerations connected with using LCC to support companies with selecting and implementing circular measures for their existing offerings. Some of these apply to all uses, and some are specific to a particular use detailed in Chapter 5, for example, comparing alternatives from a financial perspective. Then, the key methodological considerations are presented in further detail and discussed in the context of other literature.

\subsection{Overview}

Methodological considerations and issues that should be reflected upon when performing LCC were identified through empirical studies and explored in relation to the literature. These methodological considerations are mapped out, in Table 10, against the generic methodology presented in Section 2.4. There, it is indicated whether a methodological consideration is specific to a particular use or is generally applicable, as well as which appended publication it is the result of.

If LCC is used to support the selection and implementation of circular measures due to normative reasons, it is good that these are documented, even if in brief format, for example, concerns about the state of the environment or intentions to contribute to a circular economy. Then, the objective and intended uses need to be defined. One key finding from this research is that a company can have more than one uses for the LCC as presented in Chapter 5, thus deriving more utility from it. The ensuing methodological choices will have to fulfil the requirements of all uses.

One identified methodological consideration, relevant throughout the LCC process, concerns who and how the methodological decisions are made. When conducting LCC a number of assumptions and decisions need to be made, for example, scope and discount rate. Looking into one of those decisions, namely, scope, a literature review on the PSS cost estimation process by Rodríguez et al. (2019) concludes that when deciding on the scope, authors choose cost objects in lifecycle stages relevant to the estimate's purpose. This supposes that when conducting LCC, practitioners or academics have the capability to make these choices.

Findings at Company X, however, paint a slightly different picture. When discussing the scope and essentially what to include in the LCC, one individual considered the boundary of LCC to be at the end of the first contract (product manager), two individuals included subsequent contracts with the same customer (service managers) and one individual all contracts even after remanufacturing (regional sales director of new and remanufactured offerings), while another offered no opinion (R\&D). This perspective of where to set the LCC's boundaries coincided largely with each individual's area of responsibility. 


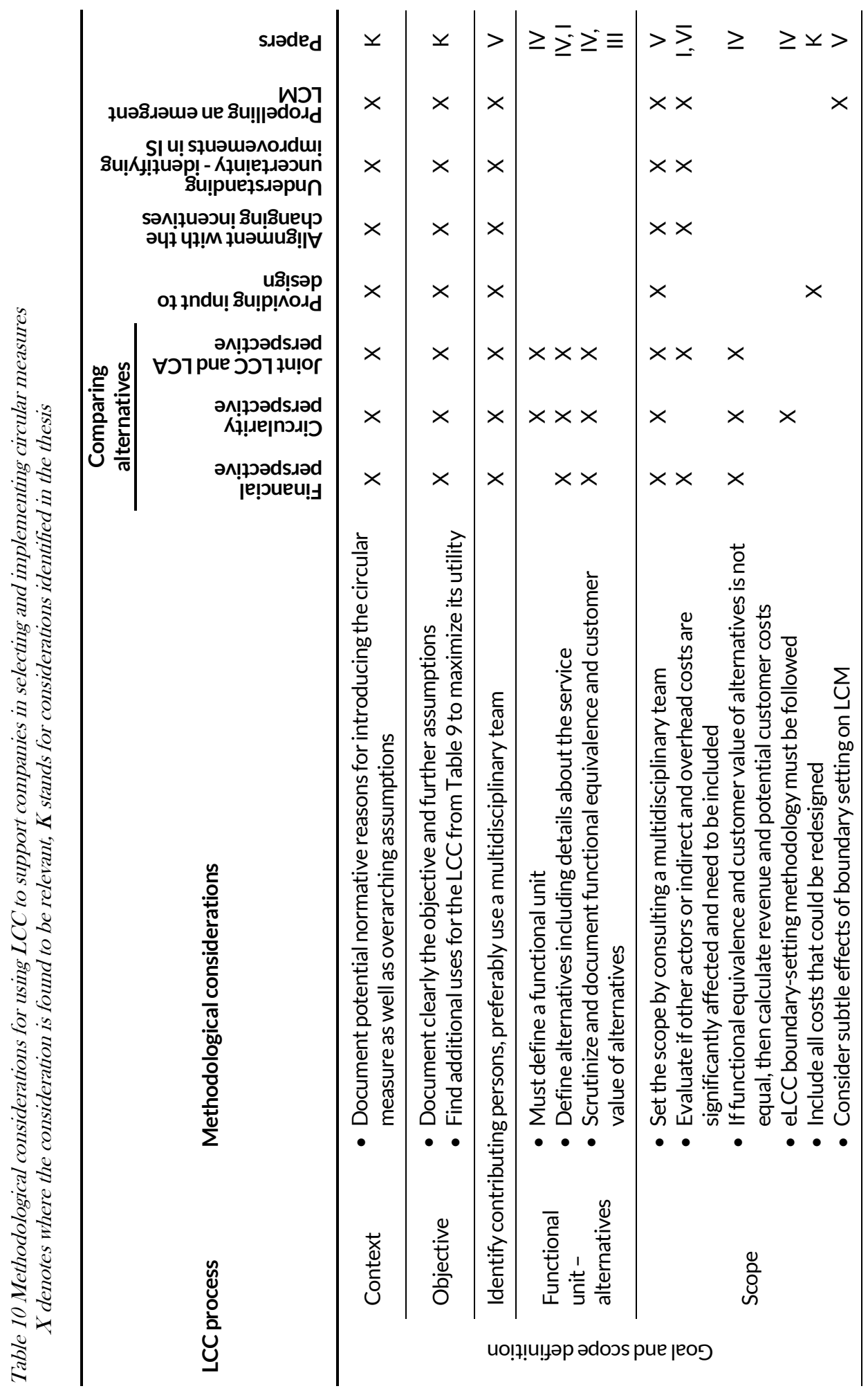




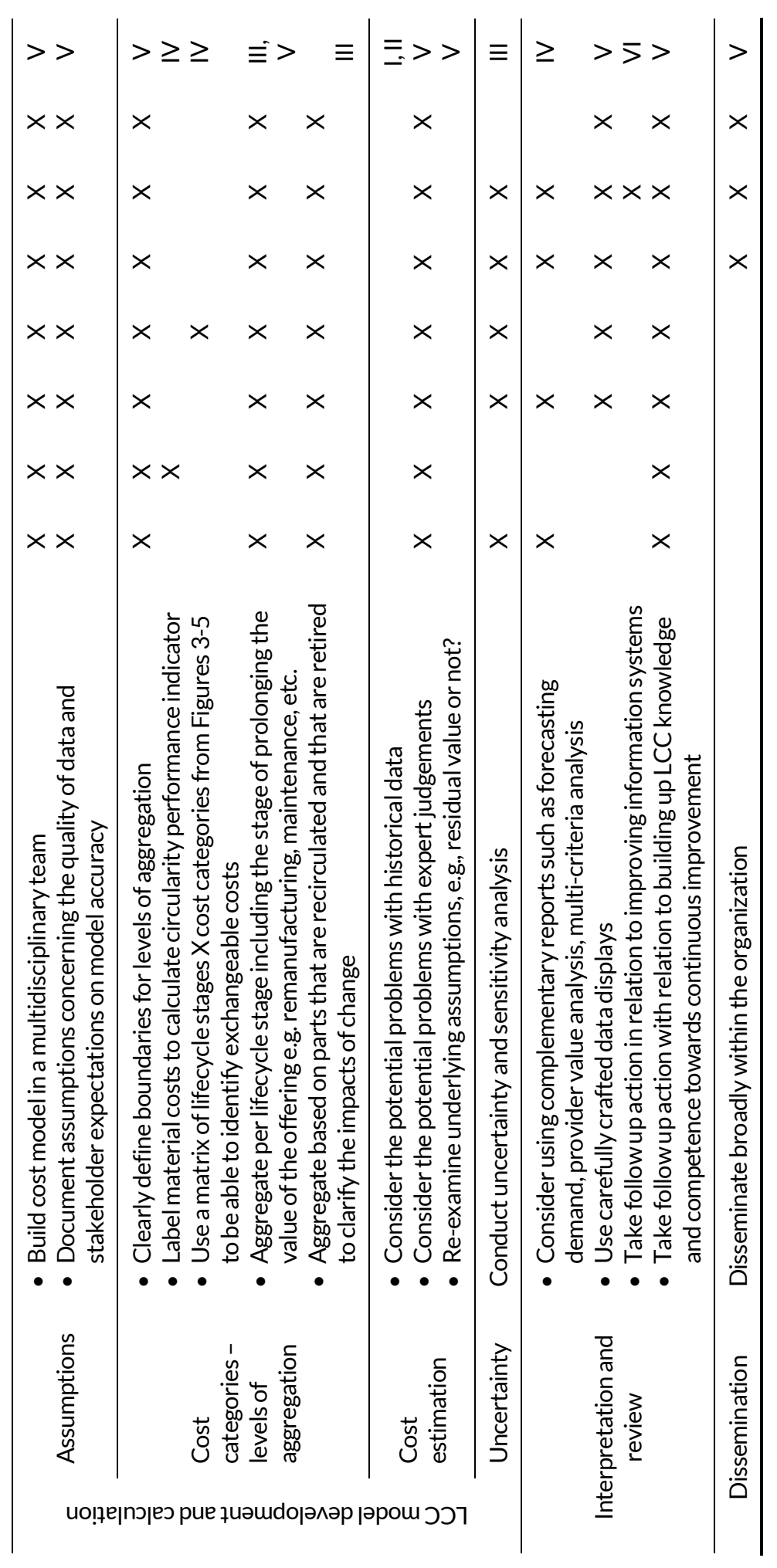


Going beyond scope, the findings in Paper V show that methodological LCC choices are not just the outcome of sound reasoning on behalf of the practitioner as the best way of fulfilling the objective but also the outcome of LCC's contestation and conformity to extant practices, as per the example given on scoping.

Other authors have also suggested that various motivations can influence methodological decision-making in LCC. As such, Gluch et al. (2018) discerned that project groups may develop ways of conducting LCC to legitimize their decisions and strengthen support for a preferred solution. Kreye, Goh, and Newnes (2018) found that during bidding decision-makers changed their evaluation of the cost estimate when competition was introduced. Logically, the cost estimate should not be affected by competition and the authors put the change down to behavioural factors or hope of improvement over time.

Therefore, an overarching methodological consideration recommended in this thesis based on Paper V is to include a broad set of stakeholders who have knowledge from across the lifecycle to make methodological decisions, unless these decisions are precisely defined by the LCC methodology or guideline. Such decisions relate to the definition of scope and system boundaries in terms of lifecycle stages, actors' perspectives, types of costs (e.g., consequential, indirect costs or the choice of cost models), cost estimation methods, discount rate, markdowns and price reductions. That is why in Table 10, there is a specific step in the goal and scope section called "identify contributing persons", and in many other steps in the process, it is recommended to discuss in a multidisciplinary team.

\subsection{Alternatives and functional unit}

The literature on LCC methods for engineers, for example, Dhillon (2009) and Blanchard and Fabrycky (2006), emphasizes the importance of equivalence between the alternatives that are being compared. When LCC is carried out at the bidding stage of complex systems, the alternatives are created to fulfil the required function as defined by the customer in the most cost-efficient way (Erkoyuncu et al., 2013). When LCC is used together with LCA, then they both need to be built around a functional unit, that is the unit of function that the system delivers (Swarr \& Hunkeler, 2008).

However, the context explored in this thesis has a slightly different starting point. Here, the companies, rather than starting with a function and finding different ways to fulfil it (for example, the function "distance travelled" can be fulfilled with train or airtransport), start with an existing offering, for example, "air-transport", which they want to apply circular measures for. Thus, a company uses LCC to compare an existing offering with an offering where circular measures have been applied; for example, the product is now offered in a PSS. Pagoropoulos (2017) stated that when using LCC to compare PSS to other pre-defined alternatives, functional equivalence cannot be taken for granted because there is substantial evidence that the users perceive availability and use contracts or renting or leasing to be of lesser value because they lose ownership. Similarly, Tukker (2015) concluded, based on a review of PSS publications, that not 
only does the value associated with PSS generally differ compared to business-as-usual, but often consumers' perceived value in terms of comfort, convenience and ownership may decrease. The perceived value might also be higher, especially for business-tobusiness transactions (Meier et al., 2010). The provider or company offering the PSS may also experience a change in the value they experience (Matschewsky, Lindahl, \& Sakao, 2018).

The findings of this thesis evidence that when companies apply circular measures for existing products, the functional equivalence of the more circular offerings compared to business-as-usual cannot be taken for granted. If the functionality and value for the customer change, so might the customers' willingness to pay and essentially even to buy (Paper IV). Table 11 summarizes the findings from Companies A, B and C.

Table 11 Functional equivalence and customer value of the compared alternatives at the multiple case study

\begin{tabular}{|c|c|c|c|c|}
\hline $\begin{array}{l}\text { Product } \\
\text { system }\end{array}$ & $\begin{array}{l}\text { Functional } \\
\text { unit }\end{array}$ & Reference flows & $\begin{array}{l}\text { Functionally } \\
\text { equivalent? }\end{array}$ & $\begin{array}{l}\text { Of equal } \\
\text { customer } \\
\text { value? }\end{array}$ \\
\hline \multirow{2}{*}{$\begin{array}{l}\text { Event tent } \\
\text { and beach } \\
\text { flag }\end{array}$} & \multirow{2}{*}{$\begin{array}{l}1 \text { item used for } \\
1 \text { event }\end{array}$} & $\begin{array}{l}\text { BAU: new frame/pole } \& \\
\text { new textile }\end{array}$ & \multirow{2}{*}{ Yes } & \multirow{2}{*}{$\begin{array}{l}\text { Possibly } \\
\text { not }\end{array}$} \\
\hline & & $\begin{array}{l}\text { C: reused frame/pole } \& \\
\text { new textile }\end{array}$ & & \\
\hline \multirow{2}{*}{ Lockers } & \multirow{2}{*}{$\begin{array}{l}1 \text { locker used } \\
\text { for } 20 \text { years }\end{array}$} & $\begin{array}{l}\text { BAU: after } 10 \text { years } \\
\text { provide new lockers }\end{array}$ & \multirow{2}{*}{ Yes } & \multirow{2}{*}{$\begin{array}{l}\text { Possibly } \\
\text { not }\end{array}$} \\
\hline & & $\begin{array}{l}\text { C: after } 10 \text { years repaint } \\
\text { locker door }\end{array}$ & & \\
\hline \multirow{2}{*}{$\begin{array}{l}\text { Recycling } \\
\text { bin }\end{array}$} & \multirow{2}{*}{$\begin{array}{l}2 \text { bins used for } \\
15 \text { years }\end{array}$} & $\begin{array}{l}\text { BAU: after } 7.5 \text { years } \\
\text { provide new bins }\end{array}$ & \multirow{2}{*}{ Yes } & \multirow{2}{*}{ Yes } \\
\hline & & $\begin{array}{l}\text { C: after } 5 \text { years } 10 \\
\text { provide new lids }\end{array}$ & & \\
\hline \multirow{2}{*}{ Inlet door } & \multirow{2}{*}{$\begin{array}{l}1 \text { inlet used for } \\
30 \text { years }\end{array}$} & $\begin{array}{l}\text { BAU: replace whole door } \\
\text { when broken }\end{array}$ & \multirow{2}{*}{ Yes } & \multirow{2}{*}{ Yes } \\
\hline & & $\begin{array}{l}\text { C: replace part of door } \\
\text { when broken }\end{array}$ & & \\
\hline
\end{tabular}

For the beach flag and event tent, both items fulfilled the same function, but the company thought that the customer might not be willing to pay the same price for buying new as renting refurbished. Company $\mathbf{B}$ had a similar perception concerning repainting the lockers rather than replacing the whole lockers. An interesting observation regarding the bins is that although they are replaced after 7.5 years, mainly because the lids become battered, replacing the lid instead would be functionally equivalent but not deliver equal value, thus lowering willingness to pay and revenue. In this case, however, the company saw a way around it, and to keep customer value on the same level, the alternative was formulated to replace the lid twice, that is after 5 and 10 years because it would increase its aesthetic value, and thus the customer 
would be willing to pay the same price. For Company $\mathrm{C}$, the change did not affect functionality or customer value.

Herein lies a very important methodological consideration. A lack of functional equivalence and/or of perceived value for the customer does not negate the importance of using a lifecycle perspective, nor does it make using LCC invalid. LCC is still a valid way of assessing the financial perspective for the company considering implementing a circular measure as long they have enough functional overlap that a user could be willing to replace one alternative with the other. In such cases, revenue and potential customer costs must be calculated and only including company costs in the LCC can mislead decision-makers. Although called Life Cycle Costing, it does not exclude the calculation of revenue per cost object (Lichtenvort et al., 2008). Therefore, to properly depict the financial perspective and compare alternatives, it is crucial that practitioners decide on a case-by-case basis whether to calculate revenue and customer costs (Paper IV). The decision should be based on what extent the alternatives are functionally equivalent and/or of equal value for the customer. If we demand functional equivalence and equal customer value from the alternatives, then many viable alternatives will be excluded. Ii is important to note that when using LCC and LCA together, the functional equivalence has to conform to the level required by the LCA method.

This opens a discussion on semantics of "the same effect", "functional equivalence", "functional unit" and "functional overlap", and their relationship to received value and subsequent willingness to pay. Concerning the concept of "functional unit" taken from LCA, it is known that it is difficult to define, often representing the least common denominator between the alternatives (Baumann \& Tillman, 2004). For PSS, the difficulty of defining the functional unit in LCA (Kjaer, Pagoropoulos, Schmidt, \& McAloone, 2016) or the function of alternatives for LCC (Settanni et al., 2014) is magnified due to the nature of services. Also defining customer value is complex and difficult to predict as it changes per customer (Scheepens et al., 2016). This research does not try to define or say how to measure functional equivalence, perceived value or willingness to pay - that is a topic for future research. It stops at the point of highlighting the important methodological consideration that when companies use LCC they need to also calculate revenue if the alternatives are not of equal functional equivalence or perceived value.

Recently, methodologies for using LCC in circular economy decision-making have emerged, such as the "total LCC model" for the circular economy by Bradley et al. (2018), the circular economy LCC method for building components by Jansen et al. (2020) and how to apply LCC in a circular economy by Kerdlap and Cornago (2021). All three target LCC as a decision-tool to be used by companies but focus on costs and not on revenue or benefits. Jansen et al. (2020) and Bradley et al. (2018) present the price the customer pays as the product of manufacturer costs multiplied by a profit margin, rather than discussing it as an outcome of customer value and willingness to pay. One possible explanation is that functional equivalence and equal value of alternatives are always assumed, but this would render the methods invalid in a 
number of instances where comparing before and after circular measure implementation. Schaubroeck, Petucco, and Benetto (2019) have also expressed concern that benefits are often not clearly accounted for in the financial analysis of circular economy initiatives and have called for a change in research.

There are, of course, cases when a circular economy measure is more or less completely functionally equivalent and does not lead to a change in user value, such as replacing aluminium and tinplate packaging for food cans (Albuquerque, Mattos, Scur, \& Kissimoto, 2019) or PSS optimization which entails only small changes (Kjaer et al., 2016).

\subsection{Scope and system boundaries}

Lifecycle is an analogy taken from biology, but it is interpreted differently depending on the context and person (Diener, 2017)(see Section 2.4). Concerning PSS, the key learning from Paper I is that LCC in PSS research has inconsistent boundaries, covering a variety of lifecycle stages and actors and types of costs. Therefore, what to include from the following list becomes a key question:

1. lifecycle stage, for example, "operation" but also actors in a lifecycle stage, for example, provider, third-party maintenance or user

2. comprehensive or comparative costs, that is, the costs that are expected to be different

3. consequential costs, for example, the cost of a breakdown of machinery on the customer's production

4. indirect and overhead costs

It is a question about which information is needed to meet the objective of the LCC. As discussed in the overview, it is highly recommended that these decisions be made by a multidisciplinary group (Paper V). Rodríguez et al. (2019) also say that a variety of sources of information should be sought on which to base the decision. There were, however, some considerations identified in this research worth highlighting. Firstly, circular measures intentionally change the flows of physical goods, thus potentially influencing the profitability and subsequent behaviour of other actors both upstream and downstream in a supply chain (Paper III). For example, primary production is displaced, affecting upstream suppliers, or remanufacturing might reduce the throughput of material in a recycling facility. Secondly, indirect costs or overheads or financing costs can change significantly in the context of implementing circular measures, for example, costs of building and operating a remanufacturing plant or getting loans from the banks to be able to finance rental or different taxation of the offering (Paper I). For example, when applying the circular measures, Company A needed to increase warehouse space to store the returning pole and frame, and there were added administrative costs, such as invoicing (Paper III). 
Thirdly, different types of uses require different boundaries; see the following nonexhaustive list:

- comparing alternatives from a financial perceptive may require revenue and customer cost calculation (Paper IV)

- $\quad$ using LCC results to calculate the suggested circularity indicator requires boundaries from eLCC methodology, with the difference that upstream costs can be aggregated (Paper IV)

- when using a stand-alone LCC to provide input to design, the exclusion of costs precludes the option of rethinking or redesigning them

- when using LCC to overcome challenges such as alignment with a changing incentive structure, understanding, for example, misalignment in the supply chain requires modelling other stakeholders' financial perspectives (Paper VI)

- the more subtle ways in which LCC propels an emergent LCM towards idealized practice or not is influenced by where the lifecycle's system boundaries are drawn (Paper V)

In closing, it is important to reiterate what was presented in Chapter 2, that LCA and LCC define the term lifecycle differently. LCA models the product lifecycle, which is required to deliver a unit of function (Baumann \& Tillman, 2004). LCC allows the practitioner more freedom when choosing the scope. Financial flows and physical flows do not always overlap, making the choice of system boundaries two separate conversations, even if both are based on the same functional unit. The reason is that the decision-making perspective can be different; LCC is used to help the company decide about itself, whereas LCA informs about the impacts on the environment.

\subsection{LCC model development and calculation}

\section{Cost categories and elements}

One part of building a cost model is to decide the cost categories or levels of aggregation. Categorization and labelling enable visualization and building data displays, which form the backbone of creating awareness and understanding of the challenges and eventually overcoming them. Following are some categorisations, which either support a specific LCC use or are a prerequisite of them:

- Labelling material costs is necessary if LCC is used as a basis for calculating an indicator circularity performance (Paper IV).

- Categorizing costs as materials, infrastructure, energy, transport, labour, and environmental costs facilitates identifying exchangeable costs at the design stage. These categories are inspired by Huppes et al. (2008)'s fourth level of cost categories and Bradley et al. (2018)'s "total LCC model” (Paper IV).

- In order to use LCA and LCC as complementary, it is recommended to categorize the cost elements into lifecycle stages as presented in Table 12, which aggregates based on LCC and the stages the company can most easily 
influence. The lifecycle stages in Table 12 come from Paper III but were originally adapted from Rebitzer (2002). His work is extended upon to include repair/refurbish as an additional lifecycle phase covering the reverse logistics for the used product, the production of spare parts and the distribution of the repaired/refurbished product, in order to make it more relevant to the companies evaluating circular measures.

Table 12 List of activities included in each lifecycle stage for LCC and LCA Adapted from Kaddoura et al. (2019)

\begin{tabular}{|c|c|c|}
\hline Lifecycle phase & $\mathrm{LCC}_{\operatorname{man}}$ & LCA \\
\hline $\begin{array}{l}\text { Design \& } \\
\text { development }\end{array}$ & $\begin{array}{l}\text { - Research \& development } \\
\text { - Graphic design }\end{array}$ & \\
\hline $\begin{array}{l}\text { Marketing \& } \\
\text { sales }\end{array}$ & $\begin{array}{l}\text { - Marketing } \\
\text { - Order reception } \\
\text { - Transport } \\
\text { - Sales }\end{array}$ & \\
\hline Production & $\begin{array}{l}\text { - Administration } \\
\text { - Product reception } \\
\text { - Product i.e., price } \\
\text { - Transport (from first tier-supplier) } \\
\text { - Storage }\end{array}$ & $\begin{array}{l}\text { - Raw material extraction } \\
\text { and production } \\
\text { - Manufacturing activities } \\
\text { - Transport }\end{array}$ \\
\hline Distribution & $\begin{array}{l}\text { - Assembling } \\
\text { - Installation } \\
\text { - Transport (downstream) } \\
\text { - Administration }\end{array}$ & - Transport (downstream) \\
\hline Use $^{7}$ & - Maintenance & - Maintenance \\
\hline Repair/refurbish & $\begin{array}{l}\text { - Administration } \\
\text { - Inspection } \\
\text { - Product (i.e., price of spare part } \\
\text { - Repair/refurbish activities } \\
\text { - Transport }\end{array}$ & $\begin{array}{l}\text { - Raw material extraction } \\
\text { and production (spare part) } \\
\text { - Manufacturing activities } \\
\text { (spare part) } \\
\text { - Repair/refurbish activities } \\
\text { - Transport }\end{array}$ \\
\hline End-of-life & $\begin{array}{l}\text { - Transport (waste collection) } \\
\text { - Incineration }\end{array}$ & $\begin{array}{l}\text { - Transport (waste } \\
\text { collection) } \\
\text { - Incineration }\end{array}$ \\
\hline
\end{tabular}

- Categorizing LCC costs in lifecycle stages is useful when visualizing and evidencing the changing incentive structure. It can demonstrate, for example, the relative contribution of use costs to production (Papers II and V).

\footnotetext{
${ }^{7}$ Since the products in Paper III were passive, the operation had neither a cost nor an environmental burden, for example, energy or auxiliary materials were not consumed. However, it included some maintenance, which is why it is the only activity.
} 
- Moreover, when using LCC generally in support of circular measure implementation, it is suggested to further aggregate production costs into the costs and impacts of the parts, which are recirculated, and the ones which are replaced. This will also help clarify how much of the product is "in the loop", or rather remains in the economy, a challenge not currently addressed in the LCC methodologies for a circular economy by Jansen et al. (2020) and Bradley et al. (2018). An example can be found in Paper III where the terms "Production R", "Production D" and "Production S" are used.

The boundaries for each category or level of aggregation should be clearly stated because, as discussed in Paper V, individuals assign different meanings to terms.

\section{Cost estimation}

The majority of cost models will make use of historical data and expert judgements at some point, either to estimate costs or to understand the relationships between cost elements (Asiedu \& $\mathrm{Gu}, 1998$ ). In the PSS context, historical data might be of low quality or unavailable because it may be owned by the customer or other supply chain members who are not willing to share it (Paper I). In fact, a key challenge for companies is that there is a prevalence of product-focused information and costing structures that have not collected and are not geared to collecting information on services (Paper II).

Moreover, the collected service data may be irrelevant when providing a PSS (Paper I). This is because, in traditional product selling business models, the product is developed first. The service is developed after the product is designed, and, therefore, it is constrained by the latter's design. Additionally, service has historically been designed to be a source of income rather than a cost for the company. Ideally, developing a PSS will lead to integrating design of the product and service (Cavalieri \& Pezzotta, 2012) so that the following will be true:

\section{PSS costs < historical service costs + historical product costs (Paper I)}

Using expert judgements also should be approached with caution and ideally verified by people from other departments because individuals perform new practices from the standpoint of the other practices they perform (Paper V). Kreye et al. (2018) also found that behavioural aspects affected individuals' cost estimations and Rodríguez et al. (2019) pointed out that when humans build models based on experience, the models are limited by the cognitive capabilities of the individuals involved. However, in some cases, they can be the best approximation not only of known costs but also of hidden costs. Expert judgements and rules of thumb can provide crucial information, especially when using LCC to "understand and overcome challenges" where detailed and completely accurate financial information is not always necessarily needed.

In the multiple case study, sensitivity analysis was performed for the offerings, adding many layers of information to the initial analysis (Paper III). Generally, LCC methods recommend conducting sensitivity analysis and uncertainty analysis (Hunkeler et al., 2008), and the findings in this thesis are in line with those recommendations. 


\subsection{Interpretation and review}

Four methodological considerations for the interpretation stage were identified. The first concerns placing the LCC in the context of other information. LCC does not capture changes to demand and turnover of an offering that is covered by other financial analysis, which made be needed to complement the LCC. Changes to demand can be expected when the circular measure leads to a change in price due to cost savings on the companies' side or a change in willingness to pay on the customer side. LCC is limited to the product level and not a comprehensive financial comparison of business models (Paper IV). Another complementary analysis may be the estimation of change in the provider value (Matschewsky, Lindahl, et al., 2018). If there are many criteria of both qualitative and quantitative nature, structuring them together with LCC in a multi-criteria analysis can be helpful (Alamerew, Kambanou, Sakao, \& Brissaud, 2020).

The second consideration concerns visualization and data displays. Especially for the uses of "understanding and overcoming challenges" and "propelling LCM", it is allimportant that the results are presented in such a way that people can grasp the narrative. Although some methodologies like (Swarr \& Hunkeler, 2008) discuss the importance of visualisation, most do not even mention it or state that a budget should be allocated for this activity.

Thirdly, at this point, follow-up actions and recommendation should be decided upon. One not immediately apparent follow-up action is to translate the data gaps into IT systems requirements and subsequently recommendations. This seldom-thought-of use was found to be useful input to the IT department at Company X (Paper VI).

The final overarching methodological consideration is that, as per Paper V, LCC should be viewed as emergent. It is a practice to be established over time. Follow-up actions such as using the same people repetitively, creating a repository of LCCs, documenting lessons learnt, and obtaining feedback on intermediate LCC should be put in place. Settanni et al. (2014) also point out that in the PSS context, there has been a drive to use LCC strategically for continuous assessment that improves in accuracy over time, thus taking away the pressure of getting it right the first time.

\subsection{Dissemination}

This step is added to the list of methodological steps because it is considered central to a number of uses such as "propelling LCM" and "understanding and overcoming challenges". Also, it is one of the most important ways of establishing LCC as a practice (Paper V). To maximize dissemination the aim should not be a one-way communication but to also allow time for discussion and reflection. 


\subsection{Implications on future methodological LCC development}

Despite the proliferation of LCC methods, LCC is not widely adopted and often not practiced according to prescribed methods. A key contribution of this research is to provide one reason behind this situation by using practice theory. This has a number of implications on the development of LCC methodologies. An extensive list is included in Paper $\mathrm{V}$ and presented in Table 8. Some key issues and further reflections are presented and discussed here.

Firstly, when LCC is introduced, it has to contend with extant practices and, unless this contestation is overcome, it will not become established practice (Paper V). Therefore, future methodological development, rather than give companies more specific and detailed methods, should support them in, for example, step-wise implementation, developing capabilities and systems, integration into existing practices and establishing the logic so that they can consistently apply LCC and improve over time.

Secondly, as discussed in the theoretical background, Gluch et al. (2018) also suggest that tailoring might happen because the intended use is different from the use for which most LCC methodologies are developed, namely, to obtain detailed cost information. Gluch et al. (2018) discuss two such uses: to legitimize an alreadypreferred option and to facilitate a discussion about long-term issues such as renovation. Knauer and Möslang (2018) verified that companies have both cognitionrelated and result-oriented cost-management goals when using LCC. Facilitating discussions and improving cognition have similarities to the use presented in Chapter 5.4 of "understanding and overcoming challenges". Moreover, in this thesis, a variety of other uses are identified when answering the first research question. These resulted in use-specific methodological considerations. Therefore, future method development should take into consideration other intended uses such as the ones presented in Chapter 5. These uses are not exhaustive, and finding others can be a future research topic.

Thirdly, when LCC methods are developed to provide a detailed and accurate financial account, they should be very clear and limit flexibility on key methodological issues, for example, scoping, so that they actually fulfil that intended use. Less freedom should be given to the practitioner and key terms, for example, lifecycle should be clearly defined. Finally, as discussed in Chapter 6, it is recommended to approach LCC as a social process in order to understand why it is not used or not used to the level of sophistication in the methodology. The identified reasons can be addressed in future LCC method development to increase their uptake by practitioners. 


\section{ConClusions}

The point of departure is to explore how LCC can support companies, and more specifically, existing companies, in selecting and implementing circular measures for their offerings. Therefore, the first research question is formulated as follows:

RQ1: How can LCC be used to support companies in selecting and implementing circular measures for their offerings?

This research confirms that cost and revenue structures across the lifecycle change significantly when implementing circular measures for existing products, and that making the more circular offering financially viable is an on-going challenge for companies. LCC, with its easy-to-comprehend economic format and lifecycle perspective, is found to capture these changes and appeal to decision-makers. Moreover, an LCC can be accompanied by an LCA to understand the environmental perspective. However, this research goes beyond these two rather well-known uses to suggest other uses.

Firstly, from the LCC results, "the difference in material costs between the two alternatives" can be calculated. This can act as an indicator of comparative circularity performance. LCC can also help to generate rather than evaluate design ideas for a more circular offering based on the LCC of the current offering. This increases the chances of the design being cost-effective and the offerings financially viable. A significant use of LCC concerns helping individuals and companies become aware of and understand some of the changes and challenges when implementing circular measures, such as the new financial incentive structure or the economic uncertainty associated with new activities. This is a first step in overcoming them. Moreover, during the process of conducting LCC, practitioners can also use the opportunity to discuss such changes and challenges.

Finally, if LCM is conceptualized as emergent, meaning that it is not implemented according to a precise plan but emerges over time, then $L C C$ can propel $L C M$ due to its familiar and appealing monetary structure. It can help lifecycle thinking gain traction and create legitimacy for LCM. However, it can also lead to a narrow understanding of the term lifecycle as well as steer focus on resources rather than environmental impacts. This means that there are several uses, and LCC has the potential to support companies both as a recurrent process and when making specific decisions. Despite this plethora of potential uses, LCC cannot comprehensively support companies in selecting and implementing circular measures.

Many companies, though, do not use LCC, and if they do, then they develop their own methodologies or simplify prescribed ones. Therefore, the second research question is formulated as follows:

RQ2: Why do companies not use LCC? 
This research sheds light on one reason: when LCC is introduced, it is a new practice that contests and conforms with extant practices that an individual performs or are part of the company. It is the outcome of this contestation and conformity that defines if and how it is performed. Therefore, LCC should be treated as an emergent practice that needs to become routinized, integrated over time through repetition and continuous improvement. Researchers should approach LCC method development and companies use LCC with this in mind.

Finally, by using LCC at the companies, various methodological considerations associated with the identified uses and the specific context of selecting and implementing circular measures emerged. The third and final research question is formulated as follows.

RQ3: What are the core methodological considerations of LCC when used to support companies in the selection and implementation of circular measures for their offerings?

Various methodological considerations are presented in Chapter 7, and four key considerations are mentioned here. An overarching methodological consideration is that a multidisciplinary team with knowledge from across the lifecycle should make methodological decisions, such as choosing system boundaries because LCC can be in contestation with the practices an individual generally performs. Concerning scoping, because of the ambiguous definition of the term "lifecycle", companies should carefully evaluate where to set the LCC's boundaries, taking into consideration that it may affect other lifecycle practices, such as LCM.

When comparing alternatives before and after implementing a circular measure, the equivalence of the offerings needs to be carefully considered. The more circular offering might have a slightly different function, or the customer may perceive it to have a different value compared to business-as-usual. In this case, revenue and customer costs need to be calculated. Finding alternatives, which are completely functionally equivalent and of equal value to the customer, will result in precluding many viable alternatives.

Finally, data displays are found to be key to presenting conclusions and allowing recipients of the information to make their own inferences and to use the data in other practices they perform. Creative displays are dependent on the existence of multiple labels for cost elements and well-selected cost categories. Therefore, in order for LCC to fulfil its intended use, an effort has to be made for successful categorization and visualization. The LCC process is not over when the results are calculated.

Each type of use is found to have its own methodological considerations. This means that one of the reasons companies tailor LCC could be that LCC does not cater to the variety of uses. This is something that needs to be considered in future LCC methodological development.

In closing this section, it must be noted that case study research, as well as the pragmatism that states that reality is grounded in the environment and experiences of 
the individual, warn against generalising from the results. As such, the answers to the research questions cannot be seen as comprehensive. Other researchers may want to verify and expanded on them.

\subsection{Implications of the conclusions}

There are a number of implications of this research. The implications pertaining to LCC methodology development are discussed in Chapter 7.7; here, implications for companies, society, and adjacent research fields are discussed.

An implication for companies is that they can derive more value when using LCC than immediately apparent, and it can support them in a variety of specific ways when selecting and implementing circular measures. If a company decides to use LCC, it has to work towards repetitively using it and building up skills, capabilities and knowledge so that it becomes more effective. The methodological decisions should be sufficient to meet all intended uses.

Using LCC as a standalone or LCA and LCC in parallel can be very valuable to society because it allows for building up a body of knowledge around circular measures at the product level. For example, Lindahl et al. (2014) compared the traditional sale of products to their PSS counterparts to document the engineering activities and enablers that lead to joint environmental and economic benefits. Iraldo et al. (2017) used LCA and LCC to explore how extending the lifetime of energy-intensive products affected environment impacts and the users financially. Paper III used LCA and LCC to explore how extending the lifetime of passive and durable products affected environmental impacts and the companies financially. One of the first and foremost insights of this work is to highlight the challenge of "equivalence" between compared alternatives. Researchers using LCA and LCC to compare more circular alternatives to other predefined alternatives need to be very careful when assessing their functionality equivalence and the value received by the customer. If they are not equivalent, then revenue and potential customer costs will need to be calculated to understand the economic perspective. Also if there are more key stakeholders, then their costs and revenues will need to be calculated; otherwise, they will not participate in the supply chain (Schaubroeck et al., 2019).

Moreover, LCC has a product-level perspective. From a broader societal perspective, LCC does not capture changes to the economic system due to the introduction of circular measures, for example, secondary rebound effects from extra income. Other methods are needed for that.

As discussed in Section 2.4 and evidenced at the companies, the term "lifecyle" is very ambiguous. This ambiguity has been exacerbated in the context of a circular economy where things have multiple lifecycles or loops. If our goal as a society is to manage, evaluate and design for the lifecycle and use lifecycle tools, then an effort should be made to define it better or look further for new analogies. 
Regarding adjacent fields of research, one major contribution is about doing "more with less". Existing methods can be revisited to see if there are other potential uses and if more utility can be derived from them. This research also demonstrates not only that learning is a very important use of LCC but also that learning is very important for overcoming mind-set and cultural challenges with a circular economy. The implications of these are two-fold: first, that method and tools to support business model innovation and other such tools should facilitate learning and second, that tools to facilitate learnings are needed to overcome circular economy barriers. Here, it might be worth reflecting on a quote attributed to Winston S. Churchill: "I am always ready to learn although I do not always like being taught".

LCC is examined as a social process drawing of practice theory to understand why it was not used. "Conducting a method" is understood as a "practice", whereas "method" is a "general pattern of practice". This approach uncovers a reason for not using LCC that can be better addressed in future methodological development. If the normative goal is to move towards a more circular economy, then drawing on social theories to assess why tools that are developed are not used and then addressing those reasons may result in their quicker uptake and by extension a faster transition to a more circular economy. 


\section{REFERENCES}

Alamerew, Y. A., Kambanou, M. L., Sakao, T., \& Brissaud, D. (2020). A Multi-Criteria Evaluation Method of Product-Level Circularity Strategies. Sustainability, 12(12), 5129.

Albuquerque, T. L. M., Mattos, C. A., Scur, G., \& Kissimoto, K. (2019). Life cycle costing and externalities to analyze circular economy strategy: Comparison between aluminum packaging and tinplate. Journal of Cleaner Production, 234, 477-486.

Allwood, J. M., Ashby, M. F., Gutowski, T. G., \& Worrell, E. (2011). Material efficiency: A white paper. Resources, Conservation and Recycling, 55(3), 362-381.

Anderson, C. R., \& Zeithaml, C. P. (1984). Stage of the Product Life Cycle, Business Strategy, and Business Performance. Academy of Management Journal, 27(1), 5-24.

Annarelli, A., Battistella, C., \& Nonino, F. (2016). Product service system: A conceptual framework from a systematic review. Journal of Cleaner Production, 139, 1011-1032.

Antikainen, M., Uusitalo, T., \& Kivikytö-Reponen, P. (2018). Digitalisation as an Enabler of Circular Economy. Procedia CIRP, 73, 45-49.

Asiedu, Y., \& Gu, P. (1998). Product life cycle cost analysis: state of the art review. International Journal of Production Research, 36(4), 883-908.

Aurich, J. C., Fuchs, C., \& Wagenknecht, C. (2006). Life cycle oriented design of technical Product-Service Systems. Journal of Cleaner Production, 14(17), 1480-1494.

Babbitt, C. W., Gaustad, G., Fisher, A., Chen, W.-Q., \& Liu, G. (2018). Closing the loop on circular economy research: From theory to practice and back again. Resources, Conservation and Recycling, 135, 1-2.

Baumann, H., \& Tillman, A.-M. (2004). The hitchhiker's guide to LCA : an orientation in life cycle assessment methodology and application. Lund: Studentlitteratur.

Bey, N. (2018). Life Cycle Management. In M. Hauschild, R. K. Rosenbaum, \& S. Olsen (Eds.), Life Cycle Assessment: Theory and Practice (pp. 519-544): Springer International Publishing.

Bi, Z., De Kleine, R., \& Keoleian, G. A. (2017). Integrated Life Cycle Assessment and Life Cycle Cost Model for Comparing Plug-in versus Wireless Charging for an Electric Bus System. Journal of Industrial Ecology, 21(2), 344-355.

Bierer, A., Götze, U., Meynerts, L., \& Sygulla, R. (2015). Integrating life cycle costing and life cycle assessment using extended material flow cost accounting. Journal of Cleaner Production, 108, 1289-1301.

Blanchard, B. S., \& Fabrycky, W. J. (2006). Systems engineering and analysis (Vol. ). US: Pearson Prentice Hall.

Blessing, L., \& Chakrabarti, A. (2010). DRM, a Design Research Methodology. London: Springer.

Blomsma, F., \& Brennan, G. (2017). The Emergence of Circular Economy: A New Framing Around Prolonging Resource Productivity. Journal of Industrial Ecology, 21(3), 603-614. 
Blomsma, F., \& Tennant, M. (2020). Circular economy: Preserving materials or products? Introducing the Resource States framework. Resources, Conservation and Recycling, 156, 104698.

Bocken, N. M. P., de Pauw, I., Bakker, C., \& van der Grinten, B. (2016). Product design and business model strategies for a circular economy. Journal of Industrial and Production Engineering; 33(5), 308-320.

Bocken, N. M. P., Strupeit, L., Whalen, K., \& Nußholz, J. (2019). A Review and Evaluation of Circular Business Model Innovation Tools. Sustainability, 11(8), 2210.

Boehm, M., \& Thomas, O. (2013). Looking beyond the rim of one's teacup: a multidisciplinary literature review of Product-Service Systems in Information Systems, Business Management, and Engineering \& Design. Journal of Cleaner Production, 51, 245-260.

Bradley, R., Jawahir, I. S., Badurdeen, F., \& Rouch, K. (2018). A total life cycle cost model (TLCCM) for the circular economy and its application to post-recovery resource allocation. Resources, Conservation and Recycling, 135, 141-149.

Brandom, R. (2011). Perspectives on pragmatism : classical, recent, and contemporary. Cambridge, Massachusetts: Harvard University Press.

Bryman, A. (2016). Social research methods (5th ed.). US: Oxford university press.

Bush, P. D. (1993). The Methodology of Institutional Economics: A Pragmatic Instrumentalist Perspective. In M. R. Tool (Ed.), Institutional Economics: Theory, Method, Policy (pp. 59-118). Dordrecht: Springer Netherlands.

Böckin, D., Willskytt, S., André, H., Tillman, A.-M., \& Ljunggren Söderman, M. (2020). How product characteristics can guide measures for resource efficiency - A synthesis of assessment studies. Resources, Conservation and Recycling, 154, 104582.

Cavalieri, S., \& Pezzotta, G. (2012). Product-Service Systems Engineering: State of the art and research challenges. Computers in Industry, 63, 278-288.

Chaffee, E. E. (1985). Three Models of Strategy. The Academy of Management Review, 10(1), 89-98.

Conrad, F. G., \& Schober, M. F. (1999). Conversational interviewing and data quality. Paper presented at the Federal Committee on Statistical Methodology Conference.

Consulting, D. L. M. (2007). Life Cycle Costing (LCC) as a contribution to sustainable construction: a common methodology Retrieved from https:/ec.europa.eu/docsroom/documents/5054/attachments/1/translations/en/renditions /native

Cook, T. D., \& Campbell, D. T. (1979). Quasi-experimentation : design \& analysis issues for field settings. US: Houghton Mifflin.

Cooper, D. R., \& Gutowski, T. G. (2017). The Environmental Impacts of Reuse: A Review. Journal of Industrial Ecology, 21(1), 38-56.

Creswell, J. W., \& Clark, V. L. P. (2007). Designing and conducting mixed methods research. US: Sage Publications. 
D'Incognito, M., Costantino, N., \& Migliaccio, G. C. (2015). Actors and barriers to the adoption of LCC and LCA techniques in the built environment. Built Environment Project and Asset Management, 5(2), 202-216.

De Giacomo, M. R., Testa, F., Iraldo, F., \& Formentini, M. (2019). Does Green Public Procurement lead to Life Cycle Costing (LCC) adoption? Journal of Purchasing and Supply Management, 25(3), 100500.

den Hollander, M. C., Bakker, C. A., \& Hultink, E. J. (2017). Product Design in a Circular Economy: Development of a Typology of Key Concepts and Terms. Journal of Industrial Ecology, 21(3), 517-525.

Dewey, J. (1988). The Middle Works ofJohn Dewey (Vol. 4). Carbondale, IL: SIU Press.

Dhillon, B. S. (2009). Life Cycle Costing for Engineers. United Kingdom, Europe: CRC Press.

Di Maio, F., Rem, P. C., Baldé, K., \& Polder, M. (2017). Measuring resource efficiency and circular economy: A market value approach. Resources, Conservation and Recycling, $122,163-171$.

Diener, D. (2017). Scrap happens, but does it have to.? On the potential of increasing machine component reuse. Chalmers University of Technology, Sweden.

Directive 2008/98/EC. (2008). Waste and Repealing Certain Directives. Retrieved from European Parliament, Council of the European Union: https://eur-lex.europa.eu/legalcontent/EN/TXT/?uri=celex\%3A32008L0098

Eisenhardt, K. M. (1989). Building Theories from Case Study Research. The Academy of Management Review, 14(4), 532-550.

Elia, V., Gnoni, M. G., \& Tornese, F. (2017). Measuring circular economy strategies through index methods: A critical analysis. Journal of Cleaner Production, 142, 2741-2751.

Ellen MacArthur Foundation. (2013). Towards the Circular Economy Vol. 1: an economic and business rationale for an accelerated transition. Retrieved from https://www.ellenmacarthurfoundation.org/publications/towards-the-circular-economyvol-1-an-economic-and-business-rationale-for-an-accelerated-transition

Erkoyuncu, J. A., Durugbo, C., Shehab, E., Roy, R., Parker, R., Gath, A., \& Howell, D. (2013). Uncertainty driven service cost estimation for decision support at the bidding stage. International Journal of Production Research, 51(19), 5771-5788.

Erkoyuncu, J. A., Roy, R., Shehab, E., Durugbo, C., Khan, S., \& Datta, P. (2019). An effective uncertainty based framework for sustainable industrial product-service system transformation. Journal of Cleaner Production, 208, 160-177.

Feldman, M. S., \& Orlikowski, W. J. (2011). Theorizing Practice and Practicing Theory. Organization Science, 22(5), 1240-1253.

Finnveden, G., \& Moberg, А. (2005). Environmental systems analysis tools : an overview. Journal of Cleaner Production, 13(12), 1165-1173.

Flyvbjerg, B. (2006). Five Misunderstandings About Case-Study Research. Qualitative Inquiry, 12(2), 219-24.5. 
Fonseca, C., Franceys, R., Batchelor, C., McIntyre, P., Klutse, A., Komives, K., . . Pezon, C. (2011). Life-cycle costs approach: costing sustainable services. Retrieved from https://www.ircwash.org/sites/default/files/briefing_note_1a_-_life-

cycle_cost_approach.pdf

Frosch, R. A. (1992). Industrial ecology: a philosophical introduction. Proceedings of the national academy of sciences, 89(3), 800-803.

Geissdoerfer, M., Savaget, P., Bocken, N. M. P., \& Hultink, E. J. (2017). The Circular Economy - A new sustainability paradigm? Journal of Cleaner Production, 143, 757-768.

Ghisellini, P., Cialani, C., \& Ulgiati, S. (2016). A review on circular economy: the expected transition to a balanced interplay of environmental and economic systems. Journal of Cleaner Production, 114, 11-32.

Giorgi, S., Lavagna, M., \& Campioli, A. (2019). LCA and LCC as decision-making tools for a sustainable circular building process. IOP Conference Series: Earth and Environmental Science, 296, 012027.

Given, L. M. (2008). The Sage encyclopedia of qualitative research methods. US: Thousand Oaks : Sage Online, 2008.

Gluch, P., \& Baumann, H. (2004). The life cycle costing (LCC) approach: a conceptual discussion of its usefulness for environmental decision-making. Building and Environment, 39(5), 571-580.

Gluch, P., Gustafsson, M., Baumann, H., \& Lindahl, G. (2018). From tool-making to toolusing-and back: rationales for adoption and use of LCC. International Journal of Strategic Property Management, 22(3), 179-190.

Goodman, R. B. (1995). Pragmatism: A Contemporary Reader. UK: Routledge.

Govindan, K., \& Hasanagic, M. (2018). A systematic review on drivers, barriers, and practices towards circular economy: a supply chain perspective. International Journal of Production Research, 56(1-2), 278-311.

Guba, E. G., \& Lincoln, Y. S. (2005). Paradigmatic Controversies, Contradictions, and Emerging Confluences. In N. K. Denzin \& Y. S. Lincoln (Eds.), The Sage handbook of qualitative research (pp. 191-215). CA: Sage Publications.

Harris, S., Martin, M., \& Diener, D. (2021). Circularity for circularity's sake? Scoping review of assessment methods for environmental performance in the circular economy. Sustainable Production and Consumption, 26, 172-186.

Hart, C. (2001). Doing a Literature Search: A Comprehensive Guide for the Social Sciences. US: Sage Publications.

Hauschild, M. Z., Herrmann, C., \& Kara, S. (2017). An Integrated Framework for Life Cycle Engineering. Procedia CIRP, 61, 2-9.

Hertwich, E. G. (2005). Consumption and the Rebound Effect -An Industrial Ecology Perspective-. The Journal of Industrial Ecology, 9(1-2), 85-98.

Higham, A., Fortune, C., \& James, H. (2015). Life cycle costing: evaluating its use in UK practice. Structural Survey, 33(1), 73-87. 
Hochschorner, E., \& Noring, M. (2011). Practitioners' use of life cycle costing with environmental costs-a Swedish study. The InternationalJournal of Life Cycle Assessment, 16(9), 897.

Hoogmartens, R., Van Passel, S., Van Acker, K., \& Dubois, M. (2014). Bridging the gap between LCA, LCC and CBA as sustainability assessment tools. Environmental Impact Assessment Review, 48, 27-33.

Howieson, W. B., Burnes, B., \& Summers, J. C. (2019). Organisational leadership and/for sustainability: future directions from John Dewey and social movements. European Management Journal.

Hunkeler, D., Lichtenvort, K., \& Rebitzer, G. (2008). Environmental Life Cycle Costing. US: Society of Environmental Toxicology and Chemistry (SETAC).

Huppes, G., Ciroth, A., Lichtenvort, K., Rebitzer, G., Schmidt, W.-P., \& Seuring, S. (2008). Modeling for Life Cycle costing. In D. Hunkeler, K. Lichtenvort, \& G. Rebitzer (Eds.), Environmental life cycle costing. US: SETAC.

IEC. (2017). Dependability management - Part 3-3: Application guide - Life cycle costing. IEC 60300-3-3:2017-01. International Electrotechnical Commission.

Ingemarsdotter, E., Kambanou, M. L., Jamsin, E., Sakao, T., \& Balkenende, R. (2021). Challenges and solutions in condition-based maintenance implementation - A multiple case study. Journal of Cleaner Production, 296, 126420.

International Resource Panel. (2017). Assessing global resource use: A systems approach to resource efficiency and pollution reduction. Bringezu, S., Ramaswami, A., Schandl, H., O’Brien, M., Pelton, R., Acquatella, J., Ayuk, E., Chiu, A., Flanegin, R., Fry, J., Giljum, S., Hashimoto, S., Hellweg, S., Hosking, K., Hu, Y., Lenzen, M., Lieber, M., Lutter, S., Miatto, A., Singh Nagpure, A., Obersteiner, M., van Oers, L., Pfister, S., Pichler, P., Russell, A., Spini, L., Tanikawa, H., van der Voet, E., Weisz, H., West, J., Wiijkman, A., Zhu, B., Zivy, R. United Nations Environment Programme.

Iraldo, F., Facheris, C., \& Nucci, B. (2017). Is product durability better for environment and for economic efficiency? A comparative assessment applying LCA and LCC to two energy-intensive products. Journal of Cleaner Production, 140, 1353-1364.

ISO. (2000). Building and Constructed Assets - Service Life Planning: Part 1 - General Principles. ISO 15686-1:2000. International Organization for Standardization.

ISO. (2001). Petroleum and natural gas industries - Life cycle costing - Part 2: Guidance on application of methodology and calculation methods. ISO 15663-2:2001. International Organization for Standardization.

ISO. (2006). Environmental management - Life cycle assessment - Principles and framework. ISO 14040:2006. International Organization for Standardization.

Jansen, B. W., van Stijn, A., Gruis, V., \& van Bortel, G. (2020). A circular economy life cycle costing model (CE-LCC) for building components. Resources, Conservation and Recycling, 161, 104857.

Kaddoura, M., Kambanou, M. L., Tillman, A.-M., \& Sakao, T. (2019). Is Prolonging the Lifetime of Passive Durable Products a Low-Hanging Fruit of a Circular Economy? A Multiple Case Study. Sustainability, 11(18), 4819. 
Kambanou, M. L. (2020a). Additional uses for life cycle costing in life cycle management. Procedia CIRP, 90, 718-723.

Kambanou, M. L. (2020b). Life Cycle Costing: Understanding How It Is Practised and Its Relationship to Life Cycle Management-A Case Study. Sustainability, 12(8), 3252.

Kambanou, M. L., \& Lindahl, M. (2016). A Literature Review of Life Cycle Costing in the Product-Service System Context. Procedia CIRP, 47, 186-191.

Kambanou, M. L., \& Sakao, T. (2020). Using life cycle costing (LCC) to select circular measures: A discussion and practical approach. Resources, Conservation and Recycling, 155,104650 .

Kaufman, R. J. (1969). Life Cycle Costing: Decision Making Tool For Capital Equipment Acquisitions. Journal of Purchasing, 5(3), 16-31.

Kaza, S., Yao, L. C., Bhada-Tata, P., \& Van Woerden, F. (2018). What a Waste 2.0 : A Global Snapshot of Solid Waste Management to 2050. Washington, DC: World Bank.

Kerdlap, P., \& Cornago, S. (2021). Life Cycle Costing: Methodology and Applications in a Circular Economy. In L. Liu \& S. Ramakrishna (Eds.), An Introduction to Circular Economy (pp. 499-525). Singapore: Springer Singapore.

Kirchherr, J., Piscicelli, L., Bour, R., Kostense-Smit, E., Muller, J., Huibrechtse-Truijens, A., \& Hekkert, M. (2018). Barriers to the Circular Economy: Evidence From the European Union (EU). Ecological Economics, 150, 264-272.

Kirchherr, J., Reike, D., \& Hekkert, M. (2017). Conceptualizing the circular economy: An analysis of 114 definitions. Resources, Conservation and Recycling, 127, 221-232.

Kjaer, L. L., Pagoropoulos, A., Schmidt, J. H., \& McAloone, T. C. (2016). Challenges when evaluating Product/Service-Systems through Life Cycle Assessment. Journal of Cleaner Production, 120, 95-104.

Kjaer, L. L., Pigosso, D. C. A., Niero, M., Bech, N. M., \& McAloone, T. C. (2018). Product/Service-Systems for a Circular Economy: The Route to Decoupling Economic Growth from Resource Consumption? Journal of Industrial Ecology, 23(1), 22-35.

Klöpffer, W. (2008). Outlook: Role of Environmental Life Cycle Costing in Sustainability Assessment. In D. Hunkeler, K. Lichtenvort, \& G. Rebitzer (Eds.), Environmental life cycle costing. US: SETAC.

Knauer, T., \& Möslang, K. (2018). The adoption and benefits of life cycle costing. Journal of Accounting \& Organizational Change, 14(2), 188-215.

Korhonen, J., Honkasalo, A., \& Seppälä, J. (2018). Circular Economy: The Concept and its Limitations. Ecological Economics, 143, 37-46.

Korpi, E., \& Ala-Risku, T. (2008). Life cycle costing: a review of published case studies. Managerial Auditing Journal, 23(3), 240-261.

Kreye, M. E., Goh, Y. M., \& Newnes, L. B. (2018). Uncertainty perception in bidding for Product-Service Systems under competition. Journal of Purchasing and Supply Management, 24(1), 31-40. 
Kristensen, H. S., \& Mosgaard, M. A. (2020). A review of micro level indicators for a circular economy - moving away from the three dimensions of sustainability? Journal of Cleaner Production, 243, 118531.

Krueger, R. A., \& Casey, M. A. (2014). Focus groups: A practical guide for applied research. US: Sage publications.

Kuhn, T. S. (1970). The structure of scientific revolutions (2nd edition ed.). Chicago: University of Chicago Press.

Laasch, O., \& Conaway, R. (2016). Responsible Business. London: Routledge.

Lewandowski, M. (2016). Designing the Business Models for Circular Economy-Towards the Conceptual Framework. Sustainability, 8(1), 43.

Lichtenvort, K., Rebitzer, G., Huppes, G., Ciroth, A., Seuring, S., Schmidt, W.-P., . . . Hunkeler, D. (2008). Introduction. In D. Hunkeler, K. Lichtenvort, \& G. Rebitzer (Eds.), Environmental life cycle costing. US: SETAC.

Lieder, M., \& Rashid, A. (2016). Towards circular economy implementation: a comprehensive review in context of manufacturing industry. Journal of Cleaner Production, 115, 36-51.

Lindahl, M. (2018). 11 Key issues when designing solutions for a Circular Economy. In M. Charter (Ed.), Designing for the Circular Economy. London: Routledge.

Lindahl, M., Sundin, E., \& Sakao, T. (2014). Environmental and economic benefits of Integrated Product Service Offerings quantified with real business cases. Journal of Cleaner Production, 64, 288-296.

Linder, M., Sarasini, S., \& van Loon, P. (2017). A Metric for Quantifying Product-Level Circularity. Journal of Industrial Ecology, 21(3), 545-558.

Marshall, A., Ojiako, U., Wang, V., Lin, F., \& Chipulu, M. (2019). Forecasting unknownunknowns by boosting the risk radar within the risk intelligent organisation. International Journal of Forecasting, 35(2), 644-658.

Martinez, V., Bastl, M., Kingston, J., \& Evans, S. (2010). Challenges in transforming manufacturing organisations into product - service providers. Journal of Manufacturing Technology Management, 21(4), 449-469.

Matschewsky, J., Kambanou, M. L., \& Sakao, T. (2018). Designing and providing integrated product-service systems - challenges, opportunities and solutions resulting from prescriptive approaches in two industrial companies. International Journal of Production Research, 56(6), 2150-2168.

Matschewsky, J., Lindahl, M., \& Sakao, T. (2018). Capturing and enhancing provider value in product-service systems throughout the lifecycle: A systematic approach. CIRPJournal of Manufacturing Science and Technology, 29, 191-204.

McDowall, W., Geng, Y., Huang, B. J., Bartekova, E., Bleischwitz, R., Turkeli, S., . . . Domenech, T. (2017). Circular Economy Policies in China and Europe. Journal of Industrial Ecology, 21(3), 651-660.

Meier, H., Roy, R., \& Seliger, G. (2010). Industrial Product-Service Systems-IPS 2. CIRP Annals, 59(2), 607-627. 
Miles, M. B., \& Huberman, A. M. (1994). Qualitative data analysis: An expanded sourcebook. US: Sage Publications.

Mont, O. (2002). Clarifying the concept of product-service system. Journal of Cleaner Production, 10(3), 237-245.

Mont, O., Plepys, A., Whalen, K., \& Nußholz, J. L. (2017). Business model innovation for a circular economy: drivers and barriers for the Swedish industry-the voice of REES companies. Retrieved from http://lup.lub.lu.se/search/ws/files/33914256/MISTRA_REES_Drivers_and_Barriers_Lu nd.pdf

Moreau, V., \& Weidema, B. P. (2015). The computational structure of environmental life cycle costing. The International Journal of Life Cycle Assessment, 20(10), 1359-1363.

Morgan, G. (2006). Images of organization. US: Sage Publications.

Murray, A., Skene, K., \& Haynes, K. (2017). The Circular Economy: An Interdisciplinary Exploration of the Concept and Application in a Global Context. Journal of Business Ethics, 140(3), 369-380.

Neugebauer, S., Forin, S., \& Finkbeiner, M. (2016). From Life Cycle Costing to Economic Life Cycle Assessment-Introducing an Economic Impact Pathway. Sustainability, 8(5), 428.

Nicolini, D. (2009). Zooming In and Out: Studying Practices by Switching Theoretical Lenses and Trailing Connections. Organization Studies, 30(12), 1391-1418.

Nicolini, D. (2013). Practice Theory, Work, and Organization : An Introduction. Oxford, UK: Oxford University Press.

Nilsson-Lindén, H., Diedrich, A., \& Baumann, H. (2020). Life Cycle Work: A Process Study of the Emergence and Performance of Life Cycle Practice. Organization \& Environment, 34(1), 99-122.

Nonaka, I. (1994). A Dynamic Theory of Organizational Knowledge Creation. Organization Science, 5(1), 14-37.

Nonaka, I., \& Takeuchi, H. (1995). The knowledge-creating company: How Japanese companies create the dynamics of innovation. Oxford, UK: Oxford university press.

Nußholz, J. L. K., Rasmussen, F. N., Whalen, K., \& Plepys, A. (2020). Material reuse in buildings: Implications of a circular business model for sustainable value creation. Journal of Cleaner Production, 245, 118546.

Opoku, A. (2013). The application of whole life costing in the UK construction industry: Benefits and Barriers. International Journal of Architecture, Engineering and Construction, 2(1), 35-42.

Pagoropoulos, A. (2017). Product/Service-Systems in the Maritime Industry - From Economic Evaluation Throughout the Life Cycle to Implementation. Technical University of Denmark, Denmark.

Palo, T., Åkesson, M., \& Löfberg, N. (2019). Servitization as business model contestation: A practice approach. Journal of Business Research, 104, 486-496. 
Parrique, T., Barth, J., Briens, F., Kerschner, C., Kraus-Polk, A., Kuokkanen, A., \& Spangenberg, J. (2019). Decoupling debunked: Evidence and arguments against green growth as a sole strategy for sustainability. European Environment Bureau.

Patton, M. Q. (2002). Qualitative Research \& Evaluation Methods. US: Thousand Oaks: SAGE.

Pearce, L. D. (2016). Thinking Outside the Q Boxes Further Motivating a Mixed Research Perspective. Oxford, UK: Oxford University Press.

Pieroni, M. P. P., McAloone, T. C., \& Pigosso, D. C. A. (2019). Business model innovation for circular economy and sustainability: A review of approaches. Journal of Cleaner Production, 215, 198-216.

Potting, J., Hekkert, M., Worrell, E., \& Hanemaaijer, A. (2017). Cicular Economy: Measuring innovation in the product chain. PBL Netherlands Environmental Assessment Agency.

Putnam, H. (1995). Pragmatism: An Open Question (Vol. 95). US: Wiley - Blackwell.

Raddats, C., Kowalkowski, C., Benedettini, O., Burton, J., \& Gebauer, H. (2019). Servitization: A contemporary thematic review of four major research streams. Industrial Marketing Management, 83, 207-223.

Rebitzer, G. (2002). Integrating Life Cycle Costing and Life Cycle Assessment for Managing Costs and Environmental Impacts in Supply Chains. Paper presented at the Cost Management in Supply Chains, Heidelberg.

Rebitzer, G., \& Hunkeler, D. (2003). Life cycle costing in LCM: ambitions, opportunities, and limitations. The International Journal of Life Cycle Assessment, 8(5), 253-256.

Reckwitz, A. (2002). Toward a Theory of Social Practices:A Development in Culturalist Theorizing. European Journal of Social Theory, 5(2), 243-263.

Reim, W., Parida, V., \& Örtqvist, D. (2015). Product-Service Systems (PSS) business models and tactics - a systematic literature review. Journal of Cleaner Production, 97, 6175 .

Remmen, A., Jensen, A. A., \& Frydendal, J. (2007). Life cycle management: a business guide to sustainability. Paris: UNEP/SETAC.

Rizos, V., Behrens, A., van der Gaast, W., Hofman, E., Ioannou, A., Kafyeke, T., . . . Topi, C. (2016). Implementation of Circular Economy Business Models by Small and Medium-Sized Enterprises (SMEs): Barriers and Enablers. Sustainability, 8(11), 1212.

Roda, I., Macchi, M., \& Albanese, S. (2020). Building a Total Cost of Ownership model to support manufacturing asset lifecycle management. Production Planning \& Control, 31(1), 19-37.

Rodríguez, A. E., Pezzotta, G., Pinto, R., \& Romero, D. (2019). A comprehensive description of the Product-Service Systems' cost estimation process: An integrative review. International Journal of Production Economics, 221, 107481.

Saidani, M., Yannou, B., Leroy, Y., \& Cluzel, F. (2017). How to Assess Product Performance in the Circular Economy? Proposed Requirements for the Design of a Circularity Measurement Framework. Recycling, 2(1), 6. 
Saidani, M., Yannou, B., Leroy, Y., Cluzel, F., \& Kendall, A. (2019). A taxonomy of circular economy indicators. Journal of Cleaner Production, 207, 542-559.

Sakao, T., \& Brambila-Macias, S. A. (2018). Do we share an understanding of transdisciplinarity in environmental sustainability research? Journal of Cleaner Production, 170, 1399-1403.

Sakao, T., \& Lindahl, M. (2015). A method to improve integrated product service offerings based on life cycle costing. CIRP Annals - Manufacturing Technology, 64(1), 33-36.

Sassanelli, C., Rosa, P., Rocca, R., \& Terzi, S. (2019). Circular economy performance assessment methods: A systematic literature review. Journal of Cleaner Production, 229, 440-453.

Schatzki, T. R. (1996). Social Practices: A Wittgensteinian Approach to Human Activity and the Social. Cambridge: Cambridge University Press.

Schaubroeck, T., Petucco, C., \& Benetto, E. (2019). Evaluate impact also per stakeholder in sustainability assessment, especially for financial analysis of circular economy initiatives. Resources, Conservation and Recycling, 150, 104411.

Scheepens, A. E., Vogtländer, J. G., \& Brezet, J. C. (2016). Two life cycle assessment (LCA) based methods to analyse and design complex (regional) circular economy systems. Case: making water tourism more sustainable. Journal of Cleaner Production, 114, 257 268.

Schmidt, K. (2013). Social Practices: a new focus area in LCM. Proceedings of the 6th International Conference on Life Cycle Management, 51-54.

Schwandt, T. A. (2014). The Sage dictionary of qualitative inquiry. US: Sage publications.

Seidel-Sterzik, H., McLaren, S., \& Garnevska, E. (2018). A Capability Maturity Model for Life Cycle Management at the Industry Sector Level. Sustainability, 10(7), 2496.

Settanni, E. (2008). The need for a computational structure of LCC. The International Journal of Life Cycle Assessment, 13(7), 526.

Settanni, E., Newnes, L. B., Thenent, N. E., Parry, G., \& Goh, Y. M. (2014). A throughlife costing methodology for use in product-service-systems. International Journal of Production Economics, 153, 161-177.

Sherif, Y. S., \& Kolarik, W. J. (1981). Life cycle costing: Concept and practice. Omega, 9(3), 287-296.

Stahel, W. (2010). The performance economy. UK: Palgrave Macmillan.

Swarr, T., \& Hunkeler, D. (2008). Life Cycle Costing in Life Cycle Management. In D. Hunkeler, K. Lichtenvort, \& G. Rebitzer (Eds.), Environmental life cycle costing. US: SETAC.

Tashakkori, A., \& Teddlie, C. (1998). Mixed methodology: Combining qualitative and quantitative approaches. US: Sage Publications.

Terzi, S., Bouras, A., Dutta, D., Garetti, M., \& Kiritsis, D. (2010). Product lifecycle management-from its history to its new role. International Journal of Product Lifecycle Management, 4(4), 360-389. 
Tukker, A. (2004). Eight Types of Product-Service System: Eight Ways to Sustainability? Experiences from Suspronet. Business Strategy and the Environment, 13, 246 - 260.

Tukker, A. (2015). Product services for a resource-efficient and circular economy - a review. Journal of Cleaner Production, 97, 76-91.

UN General Assembly. (2015). A/RES/70/1 - Transforming our world : the 2030 Agenda for Sustainable Development

UNEP. (2011). Decoupling natural resource use and environmental impacts from economic growth. A Report of the Working Group on Decoupling to the International Resource Panel. Fischer-Kowalski, M., Swilling, M., von Weizsäcker, E.U., Ren, Y., Moriguchi, Y., Crane, W., Krausmann, F., Eisenmenger, N., Giljum, S., Hennicke, P., Romero Lankao, P., Siriban Manalang, A., Sewerin, S.

Velamuri, V. K., Neyer, A.-K., \& Möslein, K. M. (2011). Hybrid value creation: a systematic review of an evolving research area. Journal für Betriebswirtschaft, 61(1), 3-35.

Walker, S., Coleman, N., Hodgson, P., Collins, N., \& Brimacombe, L. (2018). Evaluating the Environmental Dimension of Material Efficiency Strategies Relating to the Circular Economy. Sustainability, 10(3), 666.

Werning, J. P., \& Spinler, S. (2020). Transition to circular economy on firm level: Barrier identification and prioritization along the value chain. Journal of Cleaner Production, 245, 118609 .

Westkämper, Alting, \& Arndt. (2000). Life Cycle Management and Assessment: Approaches and Visions Towards Sustainable Manufacturing. CIRP Annals, 49(2), 501526.

Wicks, A. C., \& Freeman, R. E. (1998). Organization Studies and the New Pragmatism: Positivism, Anti-positivism, and the Search for Ethics. Organization Science, 9(2), 123-140.

Willskytt, S., \& Brambila-Macias, S. A. (2020). Design Guidelines Developed from Environmental Assessments: A Design Tool for Resource-Efficient Products. Sustainability, 12(12), 4953.

Willskytt, S., \& Tillman, A.-M. (2019). Resource efficiency of consumables - Life cycle assessment of incontinence products. Resources, Conservation and Recycling, 144, 13-23.

Woodward, D. G. (1997). Life cycle costing-Theory, information acquisition and application. International Journal of Project Management, 15(6), 335-344.

World Commission on Environment and Development. (1987). Our common future (Brundtland Report). Oxfor University Press.

Yin, R. K. (2014). Case study research : design and methods (5th edition ed.). London: SAGE Publications.

Zhang, W., Guo, J., Gu, F., \& Gu, X. (2018). Coupling life cycle assessment and life cycle costing as an evaluation tool for developing product service system of high energyconsuming equipment. Journal of Cleaner Production, 183, 1043-1053.

Zink, T., \& Geyer, R. (2017). Circular Economy Rebound. Journal of Industrial Ecology, 21(3), 593-602. 


\section{Papers}

The papers associated with this thesis have been removed for copyright reasons. For more details about these see:

http://urn.kb.se/resolve?urn=urn:nbn:se:liu:diva-175399 


\section{FACULTY OF SCIENCE AND ENGINEERING}

Linköping Studies in Science and Technology, Dissertation No. 2152, 2021

Department of Management and Engineering

Linköping University

SE-581 83 Linköping, Sweden

www.liu.se

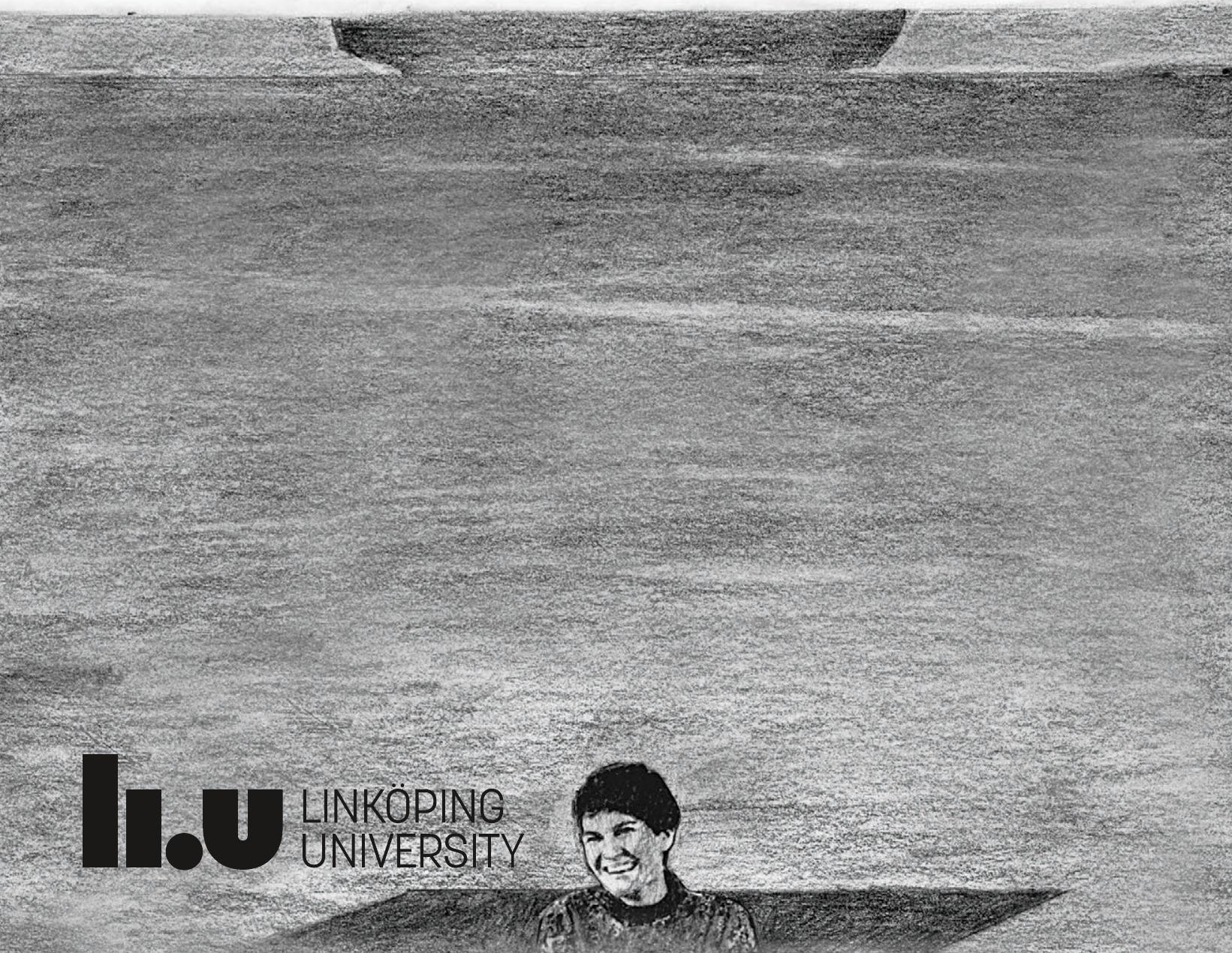

